\title{
Limiting viral infections with immunomodulating agents
}

Citation for published version (APA):

Gaajetaan, GR-GJL. (2012). Limiting viral infections with immunomodulating agents. [Doctoral Thesis, Maastricht University]. Maastricht University. https://doi.org/10.26481/dis.20121129gg

Document status and date:

Published: 01/01/2012

DOI:

10.26481/dis.20121129gg

Document Version:

Publisher's PDF, also known as Version of record

\section{Please check the document version of this publication:}

- A submitted manuscript is the version of the article upon submission and before peer-review. There can be important differences between the submitted version and the official published version of record.

People interested in the research are advised to contact the author for the final version of the publication, or visit the DOI to the publisher's website.

- The final author version and the galley proof are versions of the publication after peer review.

- The final published version features the final layout of the paper including the volume, issue and page numbers.

Link to publication

\footnotetext{
General rights rights.

- You may freely distribute the URL identifying the publication in the public portal. please follow below link for the End User Agreement:

www.umlib.nl/taverne-license

Take down policy

If you believe that this document breaches copyright please contact us at:

repository@maastrichtuniversity.nl

providing details and we will investigate your claim.
}

Copyright and moral rights for the publications made accessible in the public portal are retained by the authors and/or other copyright owners and it is a condition of accessing publications that users recognise and abide by the legal requirements associated with these

- Users may download and print one copy of any publication from the public portal for the purpose of private study or research.

- You may not further distribute the material or use it for any profit-making activity or commercial gain

If the publication is distributed under the terms of Article $25 \mathrm{fa}$ of the Dutch Copyright Act, indicated by the "Taverne" license above, 


\section{Limiting viral infections with immunomodulating agents}

Giel Gaajetaan 
ISBN

(c) Giel Gaajetaan, M aastricht 2012

All rights reserved. No part of this thesis may be reproduced, stored in a retrieval system or transmitted in any form or by any means, electronic or mechanical, including photocopy, without prior written permission of the publisher and copyright owner, or where appropriate, the publisher of the articles.

Cover design: Mayk Lucchesi, Océ Business Services

Printed by: Océ Business Services, Maastricht

The research in this thesis was funded by the Dutch Top Institute Pharma (grant D1.101-0).

Financial support by Danone Research for the printing of this thesis is gratefully acknowledged. 


\title{
Limiting viral infections with immunomodulating agents
}

\author{
PROEFSCHRIFT \\ Ter verkrijging van de graad van doctor \\ aan de Universiteit Maastricht, \\ op gezag van de Rector Magnificus, \\ Prof. dr. L.L.G. Soete, \\ volgens het besluit van het College van Decanen, \\ in het openbaar te verdedigen \\ op donderdag 29 november 2012 om 12.00 uur
}

door

Giel Rodion-Guillaume Johannes Lambertus Gaajetaan geboren te M aastricht op 15 april 1984 


\section{Promotor}

Prof. dr. C.A. Bruggeman

\section{Copromotor}

Dr. F.R.M. Stassen

\section{Beoordelingscommissie}

Prof. dr. E.F.M. Wouters (voorzitter)

Prof. dr. G.M.J. Bos

Dr. G.H. Koek

Prof. dr. J. Garssen (Universiteit Utrecht en Danone Research Wageningen) 
Aon pap \& mam 



\section{Contents}

List of abbreviations

Chapter 1 Aim of the study \& outline of the thesis

Chapter 2 The type I interferon response during viral infections:

a SWOT "analysis"

Chapter $3 \quad \mathrm{CpG}$ and poly(l:C) stimulation of dendritic cells and fibroblasts limits herpes simplex virus type 1 infection in an IFN $\beta$-dependent and - independent way

Chapter 4 Lactobacilli limit herpes simplex virus type I infection through stimulation of a dendritic cell-dependent antiviral mechanism

Chapter 5 The effects of a specific mixture of oligosaccharides on a systemic infection with cytomegalovirus in mice

Chapter 6 Interferon $\beta$ induces a long-lasting antiviral state in human respiratory epithelial cells

Samenvatting

Dankwoord 



\section{List of abbreviations}

$\begin{array}{ll}\text { AE } & \text { acute exacerbation } \\ \text { AKB } & \text { Ali Kerim Bey } \\ \text { APC } & \text { antigen-presenting cell } \\ \text { APOBEC } & \text { apolipoprotein B-mRNA-editing enzyme-catalytic polypeptide- } \\ & \text { like 3G } \\ \text { BM } & \text { bone marrow } \\ \text { BM-DC } & \text { BM-derived dendritic cell } \\ \text { BST-2 } & \text { bone marrow stromal antigen-2 } \\ \text { CDC } & \text { conventional dendritic cell } \\ \text { CLR } & \text { C-type lectin receptor } \\ \text { COPD } & \text { chronic obstructive pulmonary disease } \\ \text { CPE } & \text { cytopathogenic effect } \\ \text { CPG ODN } & \text { CpG oligodeoxynucleotides } \\ \text { CVC } & \text { Charles Vos cour } \\ \text { DAI } & \text { DNA-dependent activator of IFN-regulatory factors } \\ \text { DC } & \text { dendritic cell } \\ \text { dSRNA } & \text { double stranded RNA } \\ \text { DTH } & \text { delayed-type hypersensitivity } \\ \text { FL } & \text { Flt-3L } \\ \text { GM } & \text { GM-CSF } \\ \text { HCV } & \text { hepatitis C virus } \\ \text { HIV } & \text { human immunodeficiency virus } \\ \text { Hj } & \text { Hoi jong } \\ \text { HPV } & \text { human papilloma virus } \\ \text { HSV } & \text { herpes simplex virus } \\ \text { IFN } & \text { interferon } \\ \text { IFNAR } & \text { interferon } \alpha / \beta \text { receptor } \\ \text { IRF } & \text { interferon response factor } \\ \text { ISG } & \text { interferon-stimulated gene } \\ \text { ISG15 } & \text { IFN-stimulated protein of 15kDa } \\ \text { ICFOS } & \text { long-chain fructooligosaccharides } \\ \text { LPS } & \text { lipopolysaccharide } \\ & \\ & \end{array}$




$\begin{array}{ll}\text { M CM V } & \text { mouse cytomegalovirus } \\ \text { MDA5 } & \text { melanoma differentiation-associated gene 5 } \\ \text { miRNA } & \text { microRNA } \\ \text { M LN } & \text { mesenteric lymph node } \\ \text { MS } & \text { multiple sclerosis } \\ \text { M X1 } & \text { myxovirus resistance 1 } \\ \text { NF-kB } & \text { nuclear factor kB } \\ \text { NK } & \text { natural killer } \\ \text { NLR } & \text { NOD-like receptor } \\ \text { NS1 } & \text { non-structural 1 } \\ \text { OAS1 } & \text { oligoadenylate synthetase 1 } \\ \text { PAMP } & \text { pathogen-associated molecular patterns } \\ \text { PAOS } & \text { pectin-derived acidic oligosaccharides } \\ \text { PBEC } & \text { primary bronchial epithelial cell } \\ \text { pDC } & \text { plasmacytoid dendritic cell } \\ \text { Peg-IFN } & \text { pegylated IFN } \\ \text { PKR } & \text { protein kinase R } \\ \text { Poly(I:C) } & \text { polyinosinic:polycytidylic acid } \\ \text { PRR } & \text { pattern recognition receptor } \\ \text { RIG-I } & \text { retinoic acid inducible gene I } \\ \text { RNAse L } & \text { ribonuclease L } \\ \text { RV } & \text { rhinovirus } \\ \text { SARS CoV } & \text { severe acute respiratory syndrome corona virus } \\ \text { SCFA } & \text { short-chain fatty acids } \\ \text { SCGOS } & \text { short-chain galactooligosaccharides } \\ \text { SLE, } & \text { systemic lupus erythematosus } \\ \text { SSRNA } & \text { single stranded RNA } \\ \text { SWOT } & \text { strengths-weaknesses-opportunities-threats } \\ \text { TLR } & \text { Toll-like receptor } \\ \text { TNF } \alpha & \text { tumour necrosis factor } \alpha \\ \text { TRIM5 } \alpha & \text { tripartite motif 5 } \alpha \\ \text { UNG } & \text { uracil-N-glycosylase } \\ \text { URT } & \text { upper respiratory tract } \\ & \end{array}$




\section{1}

Aim of the study \& outline of the thesis 


\section{Aim of the study}

Viruses are obligate intracellular parasites which have claimed millions of lives throughout history. Because viruses were for a long-time not recognized as the causative agent of certain diseases like smallpox, no knowledge existed about their infectious nature. The poor hygiene in the past resulted in an easy spread throughout the population and therefore infectious disease caused by viruses, bacteria and other microbes, were the major cause of death.

Nowadays, viruses are still a major threat to worldwide health. Overcrowded conditions and increasing travelling around the globe facilitate the spread of many viruses and the emergence of new virus strains like H1N1 swine flu in 2009. Many new viruses or virus strains such as severe acute respiratory syndrome (SARS) virus in 2003 and H5N1 bird flu in 1997 respectively, originate in Southeast Asia, where many people and animals live in close contact. The identification of human immune-deficiency virus (HIV) in 1983 and its global prevalence and high mortality rates today, is the most striking example of the problems with viruses which we are still facing. In contrast, several viruses are harmless (viral infections of the upper respiratory tract) or cause asymptomatic diseases (herpesviruses) in the healthy population. However, in immunocompromised patients, infections with these usually harmless viruses can result in severe symptoms and death.

Since the development of antiviral drugs and vaccination, a large variety of viral infections can now be controlled. Nevertheless, due to high mutation rates, viruses such as influenza virus and HIV can still escape from antiviral medication and/or vaccination and resistant virus strains are increasingly recognized. Moreover, the availability of vaccines to prevent viral infections is still limited. In addition, at later age the efficacy of the immune system declines substantially, resulting in increased morbidity due to opportunistic viral infections in our aging population.

Boosting the adaptive immune response by vaccination has proven to be an efficient method to prevent certain viral infections. Therefore, additional stimuli for the immune system can be an attractive opportunity to further counteract viral disease and dissemination. 
The aim of this study was to test the antiviral potency of various immunomodulating agents in specific in vitro or in vivo model systems and investigate the molecular mechanisms involved in the stimulation of the innate immune response.

\section{Outline of the thesis}

Although vaccination and antiviral drugs have been successful in the prevention or limitation of many viral infections, additional medication is required to further reduce viral disease. As innate immunity has been shown to be essential in the induction of adequate immune responses towards viruses, therapies are now being investigated which modulate these innate antiviral immune responses. In this thesis, the immunomodulating characteristics - and in particular the antiviral properties - of various agents were investigated in different virus-model systems. Moreover, we tried to analyse the molecular mechanisms involved and focussed particularly how these agents can modulate the type I interferon (IFN) response, which is one of the most important antiviral mechanisms in the human system.

Because of the importance, but also the complexity of the type I IFN response, a detailed overview of current knowledge of the type I IFN response is made for this purpose. Moreover, we performed a "Strength-WeaknessesOpportunities-Threats" (SWOT) analysis of the type I IFN response during viral infections. The type I IFN response of the immune system is essential for the control of viral infections but can also be evaded by many viruses, which may result in (severe) disease. This requires additional or more efficient stimulation of immunity to prevent viral spread and disease. For this purpose, we describe various immunomodulating agents which are currently being investigated for their antiviral properties and discuss their potential application in the clinic. Finally, we evaluate the current problems with these agents (chapter 2).

Normally, microbes are predominantly detected by receptors present on immune cells. One group of receptors, the toll-like receptors (TLRs), is essential in the recognition of viruses by dendritic cells (DCs). After sensing viral components by TLRs, DCs can produce large amounts of type I IFN to inhibit the viral infection. Recently, synthetic ligands were developed which 
specifically stimulate these receptors to activate the immune response. As such, we tested and compared various TLR-ligands for their potency to limit viral infection by stimulation of the TLRs on DCs. In addition, we investigated which type I IFNs in the TLR-induced immune responses were responsible for the protection against viral infection (chapter 3).

Probiotics are live bacteria which also have immunomodulating properties and their application can result in a health benefit to the host. Nevertheless, their application as a prophylactic antiviral agent requires further investigation. As various probiotic strains can be recognized by TLRs, we tested and compared the antiviral potency and mechanisms of three different probiotic strains in the same viral infection model for TLR-ligands (chapter 4).

It has also been shown that oligosaccharides are immunomodulatory and thus potentially antimicrobial. Earlier data already demonstrated that a specific mixture of oligosaccharides can enhance vaccination responses in mice, suggesting a role for this prebiotic mixture in antiviral defence. To test this, we investigated whether dietary supplementation with a prebiotic mixture of specific oligosaccharides was able to limit a systemic viral infection. In a wellestablished in vivo model, mice were fed a normal diet or a diet with the prebiotic mixture of oligosaccharides. Afterwards, the mice were infected with mouse cytomegalovirus (MCMV) and we determined the antiviral potency of the prebiotic mixture and the effect on immunologic parameters (chapter 5). Finally, type I IFNs (IFN $\alpha / \beta$ ) are indispensable for the antiviral response and might therefore be attractive candidates as therapeutics to limit viral infection. For example, local administration of type I IFNs might be suitable to limit or prevent virally-associated exacerbations in chronic obstructive pulmonary disease (COPD) and asthmatic patients. Although previous studies have shown beneficial effects in virally-infected patients, the prolonged and repetitive use of type I IFNs is often associated with severe side effects. Therefore, we investigated the duration of protection of various concentrations IFN $\beta$ against a subsequent rhinovirus (RV) infection of respiratory epithelial cells. The molecular mechanisms involved in the IFN $\beta$-induced protection were also investigated (chapter 6). 
In the final chapter (chapter 7), we compare and summarize the results and conclusions of our studies and discuss possible clinical applications of immunomodulating agents to limit and/or control viral infections. 



\section{Chapter}

\section{The type I interferon response during viral infections: a "SWOT" Analysis}

Giel R Gaajetaan, Cathrien A Bruggeman, Frank R Stassen

Adapted from Reviews in Medical Virology 2012 22(2):122-37 


\section{Abstract}

The type I interferon (IFN) response is a strong and crucial moderator for the control of viral infections. The strength of this system is illustrated by the fact that, despite some temporary discomfort like a common cold or diarrhoea, most viral infections will not cause major harm to the healthy immunocompetent host. To achieve this, the immune system is equipped with a wide array of pattern recognition receptors (PRRs) and the subsequent coordinated type I IFN response orchestrated by plasmacytoid dendritic cells ( $p D C s$ ) and conventional dendritic cells (cDCs). The production of type I IFN subtypes by dendritic cells (DCs), but also other cells is crucial for the execution of many antiviral processes. Despite this coordinated response, morbidity and mortality is still common in viral disease due to the ability of viruses to exploit the weaknesses of the immune system. Viruses successfully evade immunity and infection can result in aberrant immune responses. However, these weaknesses also open opportunities for improvement via clinical interventions as can be seen in current vaccination and antiviral treatment programs. The application of IFNs, Toll-like receptor (TLR) ligands, DCs and antiviral proteins is now being investigated to further limit viral infections. Unfortunately, a common threat during stimulation of immunity is the possible initiation or aggravation of autoimmunity. Also the translation from animal models to the human situation remains difficult. With a Strengths-Weaknesses-

Opportunities-Threats ("SWOT") analysis we discuss the interaction between host and virus as well as (future) therapeutic options, related to the type I IFN system. 


\section{Introduction}

For centuries, infectious diseases have been the most common cause of morbidity and mortality worldwide. Due to achievements like vaccination and antimicrobial drugs, many infectious diseases can now be prevented or controlled. Most striking in this respect is the development of a vaccine against smallpox, a lethal virus which globally claimed millions of lives. Although the vaccination procedure was already developed in the 18th century, it lasted until the end of the $20^{\text {th }}$ century before the world was declared smallpox-free. Based on this success, there was great confidence that viral infections could be conquered definitely, either by vaccination or by antiviral drug treatment. Inspired by these successes the US Surgeon General William Stewart stated in 1967 that "The time has come to close the book on infectious diseases". Unfortunately, the future has shown otherwise.

In 1983, the HIV was discovered as the AIDS causing agent. Despite massive efforts, HIV is still a major problem worldwide ${ }^{1,2}$. In addition, the rise of new (variants of) viruses like influenza A strains ${ }^{3,4}$ and severe acute respiratory syndrome corona virus (SARS CoV) and their potential pandemic threat is a general and realistic concern ${ }^{5}$. Furthermore, seasonal respiratory viral infections and various other viruses can cause major inconvenience in healthy people and can be life-threatening in the immunocompromised ${ }^{5,6}$. Thus, despite vaccines and antiviral drugs, viral disease is still common and requires development of additional therapeutics.

In this review we apply a Strengths-Weaknesses-Opportunities-Threats (SWOT) analysis to discuss virus-immune interactions and speculate on (im)possibilities how to use these interactions in view of new treatment options.

\section{Strengths}

Once the virus has been able to cross first barriers like the skin or mucosa, the strength of the host's natural defence system will determine the outcome of the infection. In the succeeding text, we will briefly discuss some of the initial key steps involved in the antiviral response (see also Figure 1). 


\section{Recognition: pattern recognition receptors}

Before an appropriate immune response can be generated, the virus needs to be recognized. For this, immune cells are equipped with different groups of receptors, which are able to sense microbial intruders including viruses. These pattern recognition receptors (PRRs) recognize pathogen-associated molecular patterns (PAMPs), which are fundamentally different from host structures. One of the first discovered and best characterized PRRs are the Toll-like receptors (TLRs) ${ }^{7-10}$, which are mostly present on antigen-presenting cells (APCS) like macrophages and dendritic cells (DCs) ${ }^{8,9}$ but also on non-immune cells like fibroblasts and epithelial cells ${ }^{10}$. These transmembrane receptors are located on the cell surface or at the endosome ${ }^{7,9-11}$. The cell surface-located TLRs recognize mainly lipids and proteins from bacteria and yeasts ${ }^{10}$. Viruses, on the other hand, are intracellular parasites, which may explain the endosomal localisation of the viral nucleic acid-recognizing TLR3, TLR7, TLR8 and TLR9 (figure 1) ${ }^{11-19}$. Also, this endosomal location of the TLRs probably serves to ensure tolerance for 'self' molecules and to promote ligand accessibility 10,14 . Interestingly, in addition to the well-known lipopolysaccharides (LPS) from gram-negative bacteria, cell surface TLRs have also been associated with viral recognition. TLR4 has been shown to recognize the fusion protein of RSV ${ }^{10,20}$. Likewise, next to the recognition of Grampositive bacteria, TLR2 is involved in detection of various DNA viruses like HSV1 and 2, measles virus, vaccinia virus and CMV ${ }^{21-23}$. Interestingly, this TLR2dependent detection seems to be regulated especially by monocytes ${ }^{21,22,24}$. In addition to the well-described TLRs, other PRRs also play an important role in viral recognition. The cytoplasmic PRRs, such as retinoic acid-inducible gene I (RIG-I), melanoma differentiation-associated gene 5 (MDA5) and DNAdependent activator of IFN-regulatory factors (DAI), recognize viral nucleic acids ${ }^{25,26}$ and are, in contrast to TLRs, expressed in all cells. RNA viruses are differentially recognized by RIG-I and MDA5, but activate similar pathways (Figure 1$)^{26-28}$. While RIG-I can respond to both positive and negative strand RNA viruses, MDA5 senses mainly picornaviruses like rhinovirus and poliovirus 29, 30. Earlier data suggested that MDA5 preferentially binds long dsRNA (picornaviruses), while shorter fragments of dsRNA and other specific nucleotide sequences are sensed by RIG-I ${ }^{30,31}$. However, some viruses can be 
detected by both receptors ${ }^{29}$. Also, the recently discovered receptor DAI is important for intracellular detection of viral DNA ${ }^{32,33}$.

C-type lectin receptors (CLRs) and NOD-like receptors (NLRs) also belong to the large family of PRRs. CLRs are present on DCs and recognize carbohydrate structures present on pathogens ${ }^{34,35}$ and are especially important for induction of antigen presentation to $T$ cells, but also in modulating TLR responses ${ }^{36}$. NLRs, a group of cytoplasmic proteins formerly thought to detect only bacterial PAMPs, also sense RNA ${ }^{37-39}$ and DNA viruses ${ }^{33,40,41}$. This induces the production of the proinflammatory cytokines $\mathrm{IL}-1 \beta$ and IL-18 via the inflammasome, a complex composed of NLRs, and leads to the recruitment of immune cells to the site of infection ${ }^{42,43}$.

Taken together, the innate immune system is equipped with a large variety of PRRs and this extended array is essential to sense the various microbial components and to prevent or limit viral spread as much as possible ${ }^{7,44,45}$.

\section{Implementation of antiviral immunity: conventional and plasmacytoid dendritic cells}

After recognition of a virus, a cell- dependent signalling cascade will be initiated. Infection of non-immune cells usually results in detection of viral DNA/RNA or their intermediates by the cytoplasmic PRRs. and the production of IFN $\beta$, which is required to limit the infection. This antiviral cytokine also primes cells to produce other type I IFNs, which comprise all IFN $\alpha$ subtypes, IFN $\beta$ and various other IFN types, essential to initiate production of antiviral proteins $^{46}$.

DCs are better equipped than non-immune cells for the initiation of an antiviral response. Conventional dendritic cells (CDCs) recognize viral invaders with both extracellular (TLR 4 and CLRs) and intracellular PRR (TLR3, 8, RIG-I, MDA5), which are highly expressed on CDCs (figure 1 ) ${ }^{11,12,47,48}$. As in infection of nonimmune cells, viral nucleic acids need to be detected before IFN $\beta$ and other type I IFNs can be produced.

For the successful eradication or control of the virus, the intervention of plasmacytoid dendritic cells ( $\mathrm{pDCs}$ ) is indispensable. The pDC is one of the few cells which express both TLR7 and TLR9 (figure 1), allowing detection of an extended repertoire of viruses. To initiate the antiviral response, viruses or virus-infected cells are first internalized by endocytosis or phagocytosis, 
respectively, and subsequently recruited to the endolysosomes of the pDC ${ }^{49}$. The acidic environment disassembles the virus, and viral nucleic acids are subsequently recognized by TLR7 or TLR9 ${ }^{50,51}$. Ultimately, massive amounts of type I IFN are produced. In contrast to CDCs and non-immune cells, in pDCs the TLRs contribute significantly more to viral recognition than the cytoplasmic PRRs RIG-I and MDA5 ${ }^{26,52,53}$. Consequently, pDCs are less dependent on steps in the viral life cycle for recognition, which significantly accelerates the response to an infection in these DCs.

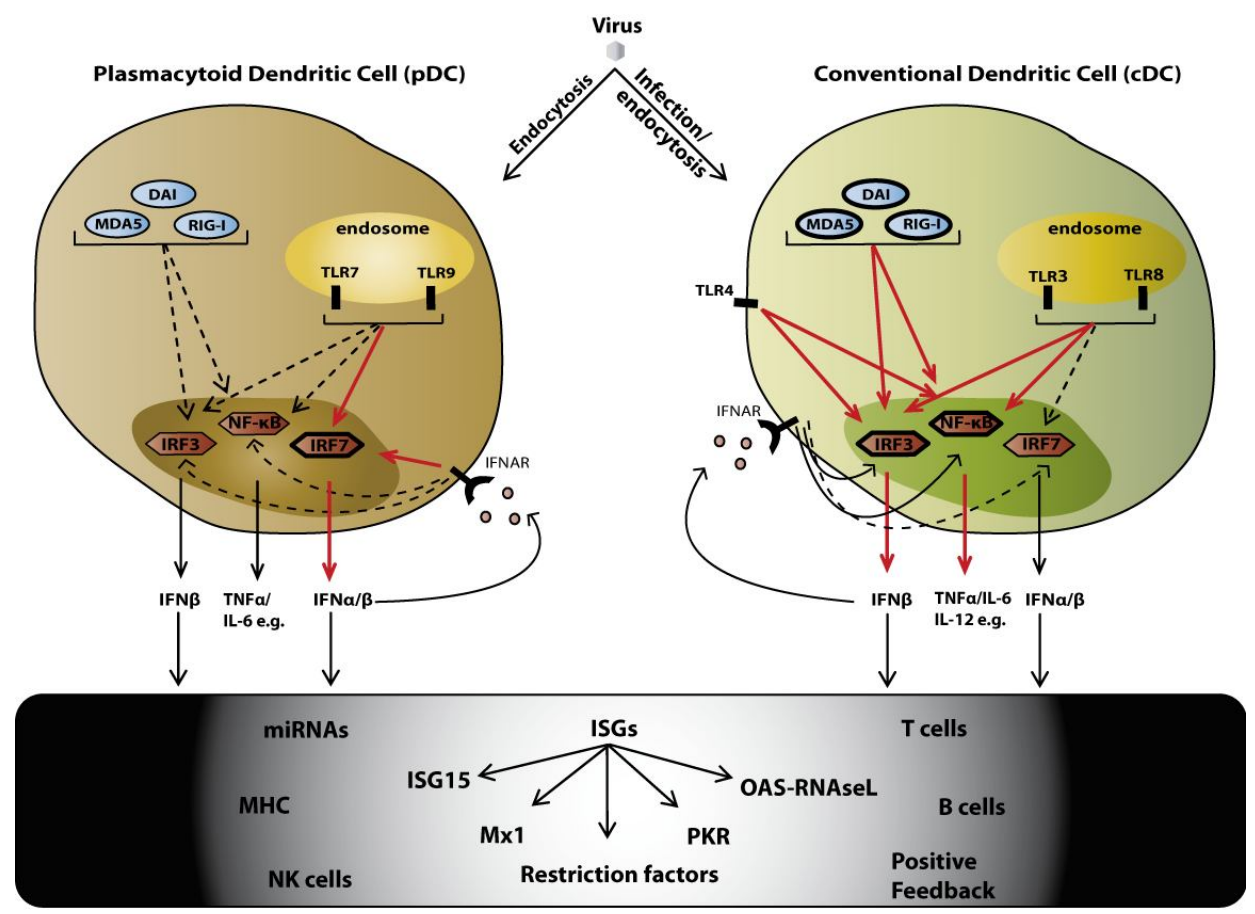

Figure 1. Schematic overview of different signal transduction pathways that are activated in plasmacytoid dendritic cells ( $\mathrm{pDCs}$ ) and conventional dendritic cells (cDCs) following viral encounters. In general, pDCs endocytose the virus and subsequently TLR7 and/or TLR9 is stimulated. Interferon response factor 7 is activated and induces transcription of IFN $\alpha / \beta$. Besides execution of many antiviral functions, autocrine signalling via the interferon $\alpha / \beta$ receptor (IFNAR) also induces more type I IFN production. In contrast, infection of or endocytosis by CDCs results in activation of the cytoplasmic pattern recognition receptors, TLR3, and TLR8. Accordingly, IRF3 and nuclear factor $\mathrm{kB}$ facilitate transcription of IFN $\beta$ and proinflammatory cytokines. Via IFNAR, IRF7 is activated and induces production of type IFN $\alpha / \beta$. Red indicates major routes, dotted arrows indicate minor routes. 
The difference in response time between $\mathrm{pDC}$ and $\mathrm{CDC}$ is also due to marked differences in intracellular signalling cascades which are activated following PRR stimulation. In CDCs, viral components stimulate the TLRs (apart from the cytoplasmic PRRs) resulting in phosphorylation of interferon-regulatory factor 3 (IRF3). IRF3 is essential for the production of proinflammatory cytokines and IFN $\beta$ (the first wave IFN) and is constitutively expressed, not only in CDCs but in most cell types ${ }^{10,54}$. Next, due to autocrine or paracrine signalling through the interferon- $\alpha / \beta$ receptor (IFNAR), IRF7 is activated, leading to the production of all type I IFNs including the various IFNa subtypes (the second wave IFN) ${ }^{55,56}$. Alternatively, in pDCS IRF7 is constitutively expressed and activated immediately after stimulation of TLR7 or TLR9 and thus no prior phosphorylation of IRF3 or autocrine/ paracrine signalling is required (Figure 1) 48, 52, 57-60. Accordingly, a robust antiviral response is initiated which, in contrast to the response seen in CDCs, is rapid and characterized by the production of high amounts of type I IFNs ${ }^{61,62}$.

Consequently, the $\mathrm{pDC}$ is clearly the major antiviral cell type due to its rapid and abundant IFN $\alpha$ production. Yet, the CDC is indispensable for clearance of a viral infection. This can be illustrated by the function of TLR8 expressed by CDCs. This receptor is similar to TLR7 in pDCs and also recognizes viral ssRNA. Interestingly, stimulation of TLR8 on CDCs and TLR7 on pDCs results in entirely different responses ${ }^{63}$. While the $\mathrm{PDC}$ produces mainly IFN $\alpha$, the $\mathrm{CDC}$ induces a pro-inflammatory profile in which nuclear factor-кB (NF-kB) is activated for the production of TNF- $\alpha$ and IL- $6{ }^{64}$. M ore importantly, IL-12 is produced (figure 1 ). This cytokine augments the cytolytic activity of natural killer (NK) cells and also induces the production of the immunoregulatory cytokine IFN $\gamma$ by $T$ and NK cells ${ }^{65}$. Thus, although both DC subsets use different antiviral pathways, they are certainly not mutually exclusive in their response to viral infection. Due to their different cytokine patterns, pDCs and CDCs respond collaboratively to viral infection and connect innate and adaptive immunity ${ }^{66}$. Communication and cooperation between these two DC subsets are vital to induce appropriate immune responses towards invading pathogens.

\section{Effector: type I interferon}

The type I IFNs are key effector molecules of the innate immune system and are essential for the antiviral response towards a plethora of viruses. In 
humans, the type I IFN family comprises 13 IFN $\alpha$ subtypes, IFN, IFNא, IFN $\varepsilon$, IFNo, IFN $\tau$ and IFN $\delta$ and all these molecules engage the ubiquitously expressed IFNAR. Binding to IFNAR then stimulates more than 300 ISGs ${ }^{67,68}$, which subsequently induce an antiviral state. The antiviral state is a collective term for limitation of viral replication, viral resistance of neighbouring cells and apoptosis of virally infected cells.

Although IFNAR signalling induces the transcription of more than 300 ISGs, surprisingly few of these genes encode proteins with direct antiviral effects ${ }^{69}$. Those proteins target viruses in many different ways (figure 1). For example, the protein ISG15 (IFN-stimulated protein of M r 15,000) has been reported to prevent virus-mediated degradation of IRF3 ${ }^{70}$, to enhance NF- $\mathrm{KB}$ signalling ${ }^{71}$ and modulate the immune response ${ }^{72}$. M yxovirus resistance $1(\mathrm{M} \times 1)$ proteins target viral nucleocapsid-like structures ${ }^{73}$ and mediate vesicle trafficking in the ER to effectively trap essential viral components and subsequently degrade them ${ }^{74,75}$. The enzyme $2^{\prime}, 5^{\prime}$-oligoadenylate synthetase 1 (OAS1) accumulates after signalling through the IFNAR by type I IFN. When exposed to dsRNA, this enzyme gains activity which eventually leads to the activation of ribonuclease $L$ (RNAseL), concomitantly enabling cleavage of cellular and viral RNAs ${ }^{69,} 76$. Protein kinase $R(P K R)$ is also initially inactive. Type I IFN induces accumulation of PKR and dsRNA activates PKR to inhibit translation ${ }^{77}$. For a more detailed overview of the ISG function, we would like to refer to the excellent review recently published by Sadler et al ${ }^{69}$.

IFNs also induce antiviral proteins termed restriction factors. A good example is the bone marrow stromal antigen-2 (BST-2) protein, which restricts the release of fully formed progeny virions from infected cells. This tetherin protein showed activity against various viruses, including HIV ${ }^{78-80}$. Another restriction factor is apolipoprotein B-mRNA-editing enzyme-catalytic polypeptide-like 3G (APOBEC3G), which leads to degradation of HIV DNA ${ }^{81,82}$. The restriction factor tripartite motif $5 \alpha$ (TRIM $5 \alpha$ ) seems to counteract capsid formation by HIV (reviewed by Sastri et al) ${ }^{83}$.

In addition, many proteins stimulated by type I IFN are involved in IFN signalling (IRF7, RIG-I, MDA5, TLRs), thereby amplifying the IFN response (positive feedback). IFNs also induce or modulate adaptive immune responses by upregulating MHC class I and II, to facilitate T and B cell stimulation ${ }^{84,85}$. Finally, IFNs promote leukocyte accumulation at sites of infection by 24 
promoting vascular adhesion molecule expression and induction of chemokines, which are essential in leukocyte recruitment ${ }^{86}$.

Recently, a new type I IFN-dependent antiviral pathway has been suggested. Pedersen et al. demonstrated that IFN $\beta$ rapidly induced the expression of several microRNAs (miRNAs) both in a hepatocarcinoma cell line (Huh cells) and primary hepatocytes ${ }^{87}$. These small non-coding RNA molecules are posttranscriptional regulators which inhibit gene expression by translational repression, mRNA cleavage and deadenylation ${ }^{87,88}$. Intriguingly, eight of these IFNß-induced miRNAs showed sequence-predicted targets within the HCV genomic RNA. Moreover, application of synthetic miRNA-mimics resulted in antiviral effects similar to those induced by IFN $\beta$, while anti-miRNA markedly reduced the IFN $\beta$-mediated antiviral effect ${ }^{87}$. In addition, it has recently been shown that hepatic miRNA expression might be a useful tool for predicting the therapeutic outcome of a pegylated IFN/ribavirin combination therapy, further emphasizing the potential role of miRNAs in IFN-mediated antiviral effects ${ }^{89}$.

In conclusion, the presence of a wide variety of PRRs enables the detection of multiple viral ligands present during infection. Activation of the PRR-DC-type I IFN axis (and especially the TLR7/9-pDC-IFN $\alpha$ axis) induces a rapid response to the virus. The many ISGs and the diversity of the type I IFNs which can be stimulated or produced, respectively, enables a coordinated response to the various viral infections, leading to control or elimination of the viral intruder.

\section{Weaknesses}

In the previous section we described how well-equipped the immune system is to protect the host against viral infections. Nevertheless, viruses can evade or influence the immune response by targeting certain weaknesses of the immune system resulting in (severe) disease.

\section{M odulation of the type I interferon response by viruses}

Due to the strong antiviral and immunoregulatory role of type I IFN, viruses developed a large variety of anti-type I IFN mechanisms. Consequently, nearly all steps of the type I IFN pathway can be blocked or manipulated by different 
viruses for their own benefit (table 1) ${ }^{90,91}$. For example, PRR signalling can be suppressed by inhibition of downstream signalling or by sequestration of typical viral nucleic acids like dsRNA ${ }^{90}$. In this way, viral recognition is inhibited. Alternatively, viruses interfere with the production of type I IFN by targeting the transcription factors IRF3 and IRF7. The proteins involved in IRF activation are inactivated or IRF mimics are synthesized, which compete with the host IRFs ${ }^{90,92,93}$. Also, binding of IFN to IFNAR can be prevented by a virally-encoded type I IFN receptor, as observed during vaccinia virus infection 94, 95. Finally, the antiviral or immunoregulatory effects of type I IFN are inhibited by targeting various ISGs and thereby facilitating viral replication and preventing immune recognition ${ }^{96-99}$.

Table 1.Viral inhibition of the type I IFN pathway

\begin{tabular}{llll}
\hline General target & Specific Target & Virus examples & Refs. \\
\hline PRR signalling & almost all proteins & Ebola, influenza, HCV & 90,91 \\
Transcription & IRF3, IRF7 & Paramyxoviruses, Rabies & $90,92,93$ \\
Cytokine receptors & IFNAR & Vaccinia & 94,95 \\
ISGs & ISG15, mx1, OAS1, PKR e.g. & SARS, influenza, HCV & $96-99$ \\
\hline
\end{tabular}

PRR, pattern recognition receptor; ISGs, interferon-stimulated genes; IRF, interferon response factor; IFNAR, interferon $\alpha / \beta$ receptor; SARS, severe acute respiratory syndrome.

Alternatively, virus-related morbidity and mortality are not only due to virusinduced immune evasion, which facilitates extensive viral replication, buy may also results from an concomitant inappropriate, exaggerated response of the immune system with devastating consequences for the host. A typical example of a combination of efficient inhibition of the type I IFN response together with an exaggerated immune response is provided by the highly pathogenic avian H5N1 influenza strain. The non-structural 1 (NS1) protein of H5N1 is an effective antagonist of the type I IFN pathway ${ }^{100-102}$. This results not only in high viral replication, but also in an inflammatory response characterized by high levels of cytokines like TNF ${ }^{103}$. This 'hypercytokinemia' or 'cytokine storm' results in excessive infiltration of inflammatory cells into the lungs ${ }^{103-}$ ${ }^{106}$. Also, higher plasma levels of inflammatory mediators were detected in deceased H5N1 patients compared to survivors ${ }^{107}$. The deregulation of type I 
IFN by H5N1 is also observed in the highly virulent 1918 H1N1 influenza strain and the Ebola and Marburg viruses ${ }^{108-112}$, in which both viral and immune pathology result in severe disease ${ }^{6}$. Thus, the increased resistance to the antiviral effects of IFN enhances viral replication and evokes an aberrant proinflammatory response characterized by high levels of cytokines and chemokines, which induces the pulmonary injury observed in H5N1 patients. Likewise, the devastating effects of an HIV infection may also results from such a combination. HIV infection results in progressive immune deficiency, impaired adaptive responses, low CD4 T cell counts and increases susceptibility to opportunistic infections. One of the earliest findings during the AIDS epidemic was a deficient IFNa production in HIV-infected patients. Next to a lower number of IFN-producing cells, also each cell produced less IFNa in response to HIV ${ }^{113,114}$. The decrease in IFNa can be due to the Vpr protein of HIV, which strongly inhibits type I IFN production by pDCs ${ }^{115}$. In addition, the effects of IFN $\alpha$ are antagonised by the HIV protein Vpu, which induces degradation of the restriction factor BST2 ${ }^{79,116}$. However, during the chronic phase of HIV infection, it is hypothesized that IFN $\alpha$ contributes to the decline of the immune system by inducing apoptosis of CD4 T cells. Due to the noninfectious interaction between the HIV-bound gp120 protein and the CD4 receptor on pDCs, IFN $\alpha$ is produced and this results in killing (possibly by pDCs) of uninfected CD4 T cells ${ }^{117}$. Thus, although apoptosis of infected cells is usually a protective mechanism to prevent viral spread ${ }^{118,119}$, here it results in a distinct advantage for the virus due to the decreased immune control by CD4 $T$ cells.

Thus, despite the strength of the type I IFN system, viruses have evolved mechanisms to evade or manipulate the system to guarantee their survival. Among others this is predominantly accomplished through interfering with PRR signalling, inhibition of IRF3 and IRF7 activation and targeting ISGs.

\section{Opportunities}

The search for therapies has led to the development of vaccines and antiviral drugs which resulted in an impressive reduction in virus-related morbidity and mortality. Unfortunately, both vaccination and antiviral drugs are not sufficient 
to prevent or control all viral infections which make it imperative to develop novel therapies. As a result, immune-based therapies are currently under development as new treatment methods. This may provide new opportunities for the treatment of acute or chronic viral infections (figure 2).

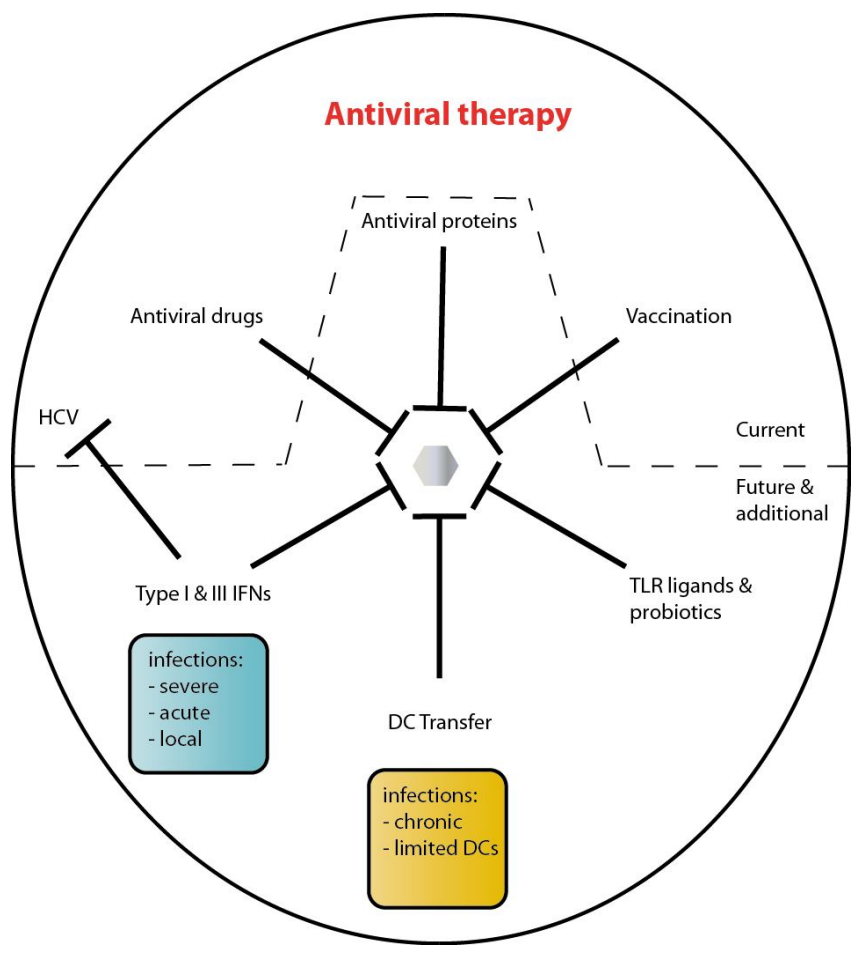

Figure 2. Antiviral therapy options. Current therapy involves antiviral drugs, vaccination and IFNa therapy for treatment of HCV patients. In addition to these therapies, treatment with type I and III IFNs can counteract acute and local infections, TLR ligands and probiotics have shown to be beneficial in various viral infections and DC transfer could be attractive where dysfunctional or limited numbers of DCs contribute to the pathogenesis.

\section{Interferon therapy revisited}

A plausible approach to treat virally infected patients is the administration of type I IFN. Indeed, pegylated IFNa in combination with the antiviral drug ribavirin is commonly used in treating patients with a chronic HCV infection. Although this therapy is effective in nearly $50 \%$ of the cases, the administration of pegylated IFNa is associated with severe side effects ${ }^{120-122}$. Normally, during viral infections type I IFN gives the 'sick-signal' which results in fever. Patients treated with type I IFN have to endure these feverish periods for prolonged periods of time. In addition, hematologic and psychological problems have been frequently reported during treatment periods. Also with respect to HIV, positive effects of IFN-treatment have been reported both in vitro ${ }^{123,124}$ as in clinical trials ${ }^{125-129}$. On the other hand, (excessive) IFNa can contribute to the 
immunopathogenesis (reviewed by Herbeuval et al) ${ }^{117}$. Thus, it remains controversial whether IFN $\alpha$ is beneficial or detrimental in HIV, because both under-and overproduction of IFN $\alpha$ can induce severe effects in the host.

Nonetheless, because of their strong antiviral effects, type I IFNs remain attractive drugs for antiviral therapy. In particular during acute (respiratory) infections, IFNs may be an interesting therapy. This requires no systemic and chronic application of IFNs as observed in HCV patients which may therefore significantly reduce the observed side effects. Local application, e.g. by a nasal spray, has been shown to be effective in the prevention of seasonal respiratory infections without causing severe side effects ${ }^{86,130}$. This administration route might be particularly attractive for the prevention of virus-induced exacerbations in chronic obstructive pulmonary disease (COPD) and asthmatic patients in which impaired IFN production may be an important mechanism contributing to virus-induced exacerbations ${ }^{131,132}$. IFN $\alpha$ also showed promising effects in severe acute respiratory syndrome (SARS) ${ }^{133-135}$ and can be very important to induce an adequate immune response and possibly suppress excessive inflammatory responses observed in SARS ${ }^{136-139}$. Interestingly, also other members of the IFN family can be used to prevent or treat viral respiratory infections. The recently discovered type III IFNs (or IFN $\lambda 1$ and

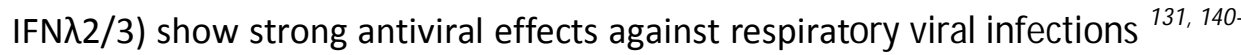
${ }^{142}$, especially when given prophylactically ${ }^{143}$.

\section{Toll-like receptor ligands}

Since stimulation of TLRs by antigenic microbial epitopes is sufficient to induce a full-blown immune response, TLRs seem a likely target for antimicrobial therapy. Indeed, synthetic variants of the microbial structures have been shown to induce natural responses without the need for infection and this quality has been used extensively to improve the efficacy of vaccines. For example, vaccines composed of a mixture of TLR ligand and antigens have been shown to be more effective than antigens alone ${ }^{144-148}$. Moreover, TLR ligands covalently linked to peptides are even superior in their ability to induce specific CD8+T-cells ${ }^{149}$.

When a direct antiviral response is required, the use of synthetic TLR3, TLR7, TLR8 or TLR9 ligands can be considered. Both in vitro and in vivo studies have 
shown that prophylactic treatment with the dsRNA mimic polyinosinic:polycytidylic acid (poly(l:C)) and CpG oligodeoxynucleotides (CpG ODNs) specific for TLR3 and TLR9, respectively, is protective during viral infection ${ }^{150-153}$. Depending on virus and cell type, different types of CpG ODNs can be applied to initiate an appropriate response ${ }^{154-156}$. Also, TLR7 and TLR8 may be therapeutic targets. For stimulation of these TLRs, imidazoquinolones (e.g resiquimod and imiquimod) are the best known ligands and these small molecular weight compounds have indeed been shown to possess antiviral properties ${ }^{15,16,157-160}$ although their immunostimulatory and antiviral effect may be limited compared to poly $(\mathrm{I}: \mathrm{C})$ and $\mathrm{CPG}$ ODNs ${ }^{161}$. Interestingly, the use of imiquimod as a cream to treat human papillomavirus (HPV)-induced genital warts has already been approved ${ }^{16,146,162}$. TLR ligands can also reduce HCV viremia ${ }^{163-165}$ and even HIV could be targeted ${ }^{166}$. Besides stimulation of type I IFN production, TLR ligands also initiate immunoregulatory mechanisms ${ }^{167}$. This is particularly important for the generation of the adaptive immune response and immunological memory. Nonetheless, at this time, few TLR ligands have been approved for clinical application in treating viral disease ${ }^{13}$, 144 .

\section{Dendritic cell transfer}

During various viral infections, pDCs (and CDCs) are less functional or are present in lower numbers ${ }^{168-170}$. This is for example observed in HCV- infected 171,172 and HIV-infected patients, where the number of pDCs (partially) predicts the clinical outcome ${ }^{173-175}$. Therefore, adoptive transfer of pDCs (and cDCs) can be used to reach the required level of pDCs and the subsequent initiation of the type I IFN response.. M oreover, this will increase the efficacy of TLR ligands as they require their appropriate receptors which are predominantly present on DCs. As shown by Wang et al, adoptive transfer of pDCs was used to successfully activate the antiviral response and limit RSV replication ${ }^{176}$. Thus, the administration of (stimulated) pDCs (in concert with CDCs) to restore DC function and/or numbers can activate the innate immune system to reach the required level of immune activation to control the viral infection, but this is probably dependent on the individual, the type of viral infection (chronic) and the stage of infection. 


\section{Probiotics}

Probiotics are live bacteria with possible health promoting effects for the host 177. Among these probiotics, especially lactobacilli and bifido bacteria have been claimed to be beneficial for human health ${ }^{177,}{ }^{178}$. These bacteria prevent colonization or infection of the gut by potentially pathogenic bacteria. More importantly, immune-modulating properties have been reported which makes them attractive for treatment or prevention of infectious diseases ${ }^{177,}{ }^{179}$. For example, probiotic strains have been shown to interact with DCs resulting in the production of IFN $\beta^{177,180,181}$, which requires recognition of probiotic components by TLRs and other PRRs on the DCs or other cells ${ }^{182}$. Therefore, probiotic strains might act like TLR-ligands and result in type I IFN production despite their non-pathogenic nature.

Inspired by the observed activation of the type I IFN response by certain probiotics, it has been speculated that specific probiotic strains could be beneficial to counteract viral infections. Accordingly, probiotics have been used successfully to limit symptoms of gastrointestinal viral infections ${ }^{178,}{ }^{183}$. Interestingly, recent data demonstrated that probiotics may also be useful in the prevention of viral infections of respiratory tract. Although not all studies showed beneficial effects ${ }^{184,}{ }^{185}$, others have demonstrated protection against the common cold and influenza ${ }^{186-188}$. Yet, more studies are required to elucidate the potency of probiotics to act as prophylactic agents against viral infections.

\section{Other options}

As observed in many viral infections, the (concomitant) proinflammatory response can contribute significantly to the disease. Therefore, antiinflammatory drugs ${ }^{189}$ are attractive to suppress symptoms during viral disease. Also the use of antiviral drugs for specific inhibition of viral replication remains attractive as therapy, especially in combination with other treatments (like IFN $\alpha$ treatment and ribavirin in HCV patients). Furthermore, although TLR ligands and IFNs can induce production of restriction factors, these might also be applied directly to limit viral replication. On the other hand, IFN-inhibitor proteins of viruses can be targeted to restore immune functions ${ }^{190}$ and make additional restriction factors or immunotherapy more effective. 
Taken together, although viruses are well able to subvert or manipulate the type I IFN response, the IFN system can also be used or stimulated to strengthen the response towards viral infections. IFNs themselves are already used in HCV treatment and promising effects have been shown in respiratory viral infections. Moreover, the therapeutic use of TLR ligands is currently under intense investigation as they have shown to have great potency to stimulate those immune cells critically involved in the antiviral immune response. This stimulates the production of antiviral proteins or inhibitors of viral evasion proteins, which can also be used independently of TLR stimulation or IFN application. The transfer of (stimulated) pDCs for gradual production of type I IFN and other cytokines (in combination with cDCs for induction of adaptive immunity) might be an option to limit symptoms or even control virus replication. Finally, probiotic bacteria can be applied as live nutritional or nasal component to limit viral gastrointestinal or respiratory infections, respectively.

\section{Threats}

In the previous section, we revealed among others the opportunities related to $T L R$ ligands as potential antiviral drugs. Yet, although promising results with $T L R$ ligands have been reported during the last decade, there are also several threats.

\section{Autoimmunity}

Endosomal TLRs usually only respond to DNA/RNA derived from pathogens while immune responses to host genetic material are prevented in different ways. First, DNA (and RNA) from apoptotic or necrotic host cells is removed by DNAses (and RNAses, respectively). Second, the nucleic acids from microbes are fundamentally different from host nucleic acids. Viral and bacterial DNA contain unmethylated CpG motifs, while in host DNA heavy methylation and fewer CpG motifs are common ${ }^{191}$. Furthermore, the TLRs which bind (microbial) nucleic acids are endosomally located ${ }^{7,14}$. Due to this intracellular localisation, self-nucleic acids cannot stimulate these TLRs. Finally, regulatory receptors are present on pDCs which limit type I IFN responses ${ }^{192}$. 
Sometimes, however, these barriers are not sufficient and aberrant immune responses arise ultimately resulting in autoimmune diseases like systemic lupus erythematosus (SLE) ${ }^{193-195}$, an autoimmune disorder which especially affects the skin. In SLE, it is assumed that apoptotic or necrotic material containing nucleic acids are phagocytosed by pDCs and cDCs. The pDCs respond with production of type I IFN and other cytokines resulting in activation of the CDCs, which then stimulate autoreactive $T$ and $B$ cells. After differentiation of $B$ cells into plasma cells, autoantibodies are produced and complex with the nucleic acids from necrotic cells. Subsequent binding to the Fc receptor for IgG (FcyRIla) on pDCs ${ }^{196}$ and CDCs results in further type I IFN production and $B$ cell stimulation ${ }^{197}$. This vicious cycle can be evoked or aggravated by the administration of TLR ligands. The reason why these pDCs respond to the host-derived nucleic acids is still unclear.

Thus, concerns about instigating or enhancing autoimmune diseases are an important reason why TLR ligands are not extensively administered in the clinic. Despite promising results in the last decade with these ligands in antiviral therapy, precautionary measures to prevent induced autoimmune responses are definitely necessary.

\section{Species differences}

Much of what we know comes from animal experiments, but translating experimental results from laboratory animals to humans is often problematic. This is also the case with the translation of our knowledge from the immune response of well-studied mouse models to humans. For example, the response to certain viruses can be entirely different in both hosts, due to adaption of the virus to its host ${ }^{198}$. Moreover, important differences in antiviral mechanisms between mice and humans have been observed.

First, there are differences in the TLR-induced response. Studies indicate that murine pDCs are able to produce IL-12p70 in addition to IFN $\alpha$ post-TLR9 stimulation, whereas human pDCs do not ${ }^{60,62,63}$. Secondly, the location of TLR9 is different in mice than in humans. In humans, TLR9 is exclusively expressed in pDCs and B cells ${ }^{199}$ while mice express TLR9 on CDCs, B-cells, macrophages and monocytes ${ }^{200}$. Thus, a TLR9 ligand can induce entirely different responses in both species. Another major difference is the function of TLR8. TLR8 stimulation induces IL-12 production in humans ${ }^{201}$, but this 
receptor appears to be non-functional in mice, although this is still matter of debate ${ }^{202}$. Finally, the cytokine flt-3 ligand is used to differentiate murine hematopoietic stem cells into DCs with a relatively high percentage of pDCs ${ }^{203}$, 204. This does not reflect the human situation in which most experiments are performed with PBMCs, containing a very low number of pDCs ${ }^{205}$ that are probably at a different stage of maturation.

Hence, as stimulation of the type I IFN response can improve immunity toward viral infection, it can also evoke or aggravate aberrant immune responses (autoimmunity), thereby limiting clinical application of TLR ligands and IFNs. Furthermore, although animal experiments have been extremely helpful in deciphering antiviral responses, these are not an exact representation of the human type I IFN response, further hindering clinical application.

\section{Conclusion}

In this review, we provided a condensed overview of the molecular pathways involved in the most potent antiviral part of the innate immune system, the type I IFN response. M oreover, we reviewed the cells and receptors which are intimately involved in this type I IFN system. Also, we evaluated the (im)possibilities of new ways to modulate the type I IFN response, e.g. by TLR ligands, adoptive DC transfer or probiotics, as promising future antiviral therapies. Nonetheless, although strong antiviral effects of IFNs, TLR ligands, DCs, probiotics and restriction factors have been shown by many studies, the clinical application of these immune-based therapies is unfortunately still limited, which might be related to concern for eventual undesired side effects like autoimmune diseases. Therefore, to be clinically successful, perhaps a more personalised approach is required. The application of these immunebased therapies can then be considered based on the individual, virus, stage of infection and symptoms, thereby fine-tuning the type I IFN response and preventing side effects as much as possible. 


\section{References}

1. Barre-Sinoussi, F. 2010. HIV: a discovery opening the road to novel scientific knowledge and global health improvement. Virology 397: 255-259.

2. Kilmarx, P. H. 2009. Global epidemiology of HIV. Curr Opin HIV AIDS 4: 240-246.

3. Smith, G. J., D. Vijaykrishna, J. Bahl, et al. 2009. Origins and evolutionary genomics of the 2009 swine-origin H1N1 influenza A epidemic. Nature 459: 1122-1125.

4. Neumann, G., T. Noda, and Y. Kawaoka. 2009. Emergence and pandemic potential of swine-origin H1N1 influenza virus. Nature 459: 931-939.

5. Osterhaus, A. D. 2008. New respiratory viruses of humans. Pediatr Infect Dis J 27: S7174.

6. Tregoning, J. S., and J. Schwarze. 2010. Respiratory viral infections in infants: causes, clinical symptoms, virology, and immunology. Clin Microbiol Rev 23: 74-98.

7. Blasius, A. L, and B. Beutler. 2010. Intracellular toll-like receptors. Immunity 32: 305315.

8. Aderem, A., and R. J. Ulevitch. 2000. Toll-like receptors in the induction of the innate immune response. Nature 406: 782-787.

9. Akira, S., K. Takeda, and T. Kaisho. 2001. Toll-like receptors: critical proteins linking innate and acquired immunity. Nat Immunol 2: 675-680.

10. Kawai, T., and S. Akira. 2010. The role of pattern-recognition receptors in innate immunity: update on Toll-like receptors. Nat Immunol 11: 373-384.

11. Ito, T., Y. H. Wang, and Y. J. Liu. 2005. Plasmacytoid dendritic cell precursors/type I interferon-producing cells sense viral infection by Toll-like receptor (TLR) 7 and TLR9. Springer Semin Immunopathol 26: 221-229.

12. Trinchieri, G., and A. Sher. 2007. Cooperation of Toll-like receptor signals in innate immune defence. Nat Rev Immunol 7: 179-190.

13. Cao, W., and Y. J. Liu. 2007. Innate immune functions of plasmacytoid dendritic cells. Curr Opin Immunol 19: 24-30.

14. Barton, G. M., J. C. Kagan, and R. Medzhitov. 2006. Intracellular localization of Toll-like receptor 9 prevents recognition of self DNA but facilitates access to viral DNA. Nat Immunol 7: 49-56.

15. Lund, J. M., L. Alexopoulou, A. Sato, et al. 2004. Recognition of single-stranded RNA viruses by Toll-like receptor 7. Proc Natl Acad Sci U SA 101: 5598-5603.

16. Diebold, S. S., T. Kaisho, H. Hemmi, et al. 2004. Innate antiviral responses by means of TLR7-mediated recognition of single-stranded RNA. Science 303: 1529-1531.

17. Krug, A., A. R. French, W. Barchet, et al. 2004. TLR9-dependent recognition of MCM V by IPC and DC generates coordinated cytokine responses that activate antiviral NK cell function. Immunity 21: 107-119.

18. Lund, J., A. Sato, S. Akira, et al. 2003. Toll-like receptor 9-mediated recognition of Herpes simplex virus-2 by plasmacytoid dendritic cells. J Exp Med 198: 513-520. 
19. Weber, F., V. Wagner, S. B. Rasmussen, et al. 2006. Double-stranded RNA is produced by positive-strand RNA viruses and DNA viruses but not in detectable amounts by negative-strand RNA viruses. J Virol 80: 5059-5064.

20. Kurt-Jones, E. A., L. Popova, L. Kwinn, et al. 2000. Pattern recognition receptors TLR4 and CD14 mediate response to respiratory syncytial virus. Nat Immunol 1: 398-401.

21. Sato, A., M. M. Linehan, and A. Iwasaki. 2006. Dual recognition of herpes simplex viruses by TLR2 and TLR9 in dendritic cells. Proc Natl Acad Sci U SA 103: 17343-17348.

22. Barbalat, R., L. Lau, R. M. Locksley, et al. 2009. Toll-like receptor 2 on inflammatory monocytes induces type I interferon in response to viral but not bacterial ligands. Nat Immunol 10: 1200-1207.

23. Bochud, P. Y., A. S. Magaret, D. M. Koelle, et al. 2007. Polymorphisms in TLR2 are associated with increased viral shedding and lesional rate in patients with genital herpes simplex virus Type 2 infection. J Infect Dis 196: 505-509.

24. Wang, J. P., E. A. Kurt-Jones, O. S. Shin, et al. 2005. Varicella-zoster virus activates inflammatory cytokines in human monocytes and macrophages via Toll-like receptor 2. J Virol 79: 12658-12666.

25. Diebold, S. S. 2008. Recognition of viral single-stranded RNA by Toll-like receptors. Adv Drug Deliv Rev 60: 813-823.

26. Kato, H., O. Takeuchi, S. Sato, et al. 2006. Differential roles of MDA5 and RIG-I helicases in the recognition of RNA viruses. Nature 441: 101-105.

27. Vandevenne, P., C. Sadzot-Delvaux, and J. Piette. 2010. Innate immune response and viral interference strategies developed by Human Herpesviruses. Biochem Pharmacol 80: 1955-1972.

28. Wilkins, C., and M. Gale, Jr. 2010. Recognition of viruses by cytoplasmic sensors. Curr Opin Immunol 22: 41-47.

29. Loo, Y. M., J. Fornek, N. Crochet, et al. 2008. Distinct RIG-I and M DA5 signaling by RNA viruses in innate immunity. J Virol 82: 335-345.

30. Saito, T., and M. Gale, Jr. 2008. Differential recognition of double-stranded RNA by RIG-I-like receptors in antiviral immunity. J Exp Med 205: 1523-1527.

31. Kato, H., O. Takeuchi, E. Mikamo-Satoh, et al. 2008. Length-dependent recognition of double-stranded ribonucleic acids by retinoic acid-inducible gene-I and melanoma differentiation-associated gene 5. J Exp M ed 205: 1601-1610.

32. Takaoka, A., Z Wang, M. K. Choi, et al. 2007. DAI (DLM-1/ZBP1) is a cytosolic DNA sensor and an activator of innate immune response. Nature 448: 501-505.

33. Hornung, V., and E. Latz. 2010. Intracellular DNA recognition. Nat Rev Immunol 10: 123-130.

34. van Vliet, S. J., J. J. Garcia-Vallejo, and Y. van Kooyk. 2008. Dendritic cells and C-type lectin receptors: coupling innate to adaptive immune responses. Immunol Cell Biol 86: 580-587.

35. Diebold, S. S. 2009. Activation of dendritic cells by toll-like receptors and C-type lectins. Handb Exp Pharmacol: 3-30. 
36. Geijtenbeek, T. B., and S. I. Gringhuis. 2009. Signalling through C-type lectin receptors: shaping immune responses. Nat Rev Immunol 9: 465-479.

37. Ichinohe, T., H. K. Lee, Y. Ogura, et al. 2009. Inflammasome recognition of influenza virus is essential for adaptive immune responses. J Exp M ed 206: 79-87.

38. Thomas, P. G., P. Dash, J. R. Aldridge, Jr., et al. 2009. The intracellular sensor NLRP3 mediates key innate and healing responses to influenza $A$ virus via the regulation of caspase-1. Immunity 30: 566-575.

39. Allen, I. C., M. A. Scull, C. B. Moore, et al. 2009. The NLRP3 inflammasome mediates in vivo innate immunity to influenza $A$ virus through recognition of viral RNA. Immunity 30: 556-565.

40. Muruve, D. A., V. Petrilli, A. K. Zaiss, et al. 2008. The inflammasome recognizes cytosolic microbial and host DNA and triggers an innate immune response. Nature 452: 103-107.

41. Delaloye, J., T. Roger, Q. G. Steiner-Tardivel, et al. 2009. Innate immune sensing of modified vaccinia virus Ankara (MVA) is mediated by TLR2-TLR6, MDA-5 and the NALP3 inflammasome. PLoS Pathog 5: e1000480.

42. Bryant, C., and K. A. Fitzgerald. 2009. Molecular mechanisms involved in inflammasome activation. Trends Cell Biol 19: 455-464.

43. Rathinam, V. A., Z Jiang, S. N. Waggoner, et al. 2010. The AlM2 inflammasome is essential for host defense against cytosolic bacteria and DNA viruses. Nat Immunol 11: 395-402.

44. Paludan, S. R., A. G. Bowie, K. A. Horan, et al. 2011. Recognition of herpesviruses by the innate immune system. Nat Rev Immunol 11: 143-154.

45. Pichlmair, A., and C. Reis e Sousa. 2007. Innate recognition of viruses. Immunity 27: 370-383.

46. Yeow, W. S., W. C. Au, Y. T. Juang, et al. 2000. Reconstitution of virus-mediated expression of interferon alpha genes in human fibroblast cells by ectopic interferon regulatory factor-7. J Biol Chem 275: 6313-6320.

47. Liu, Y. J. 2005. IPC: professional type 1 interferon-producing cells and plasmacytoid dendritic cell precursors. Annu Rev Immunol 23: 275-306.

48. Fitzgerald-Bocarsly, P., and D. Feng. 2007. The role of type I interferon production by dendritic cells in host defense. Biochimie 89: 843-855.

49. Lee, H. K., J. M. Lund, B. Ramanathan, et al. 2007. Autophagy-dependent viral recognition by plasmacytoid dendritic cells. Science 315: 1398-1401.

50. Ewald, S. E., B. L. Lee, L. Lau, et al. 2008. The ectodomain of Toll-like receptor 9 is cleaved to generate a functional receptor. Nature 456: 658-662.

51. Park, B., M. M. Brinkmann, E. Spooner, et al. 2008. Proteolytic cleavage in an endolysosomal compartment is required for activation of Toll-like receptor 9 . Nat Immunol 9: 1407-1414.

52. Kawai, T., and S. Akira. 2008. Toll-like receptor and RIG-l-like receptor signaling. Ann N Y Acad Sci 1143: 1-20. 
53. Kato, H., S. Sato, M. Yoneyama, et al. 2005. Cell type-specific involvement of RIG-I in antiviral response. Immunity 23: 19-28.

54. Wang, J., S. H. Basagoudanavar, X. Wang, et al. 2010. NF-kappa B RelA subunit is crucial for early IFN-beta expression and resistance to RNA virus replication. J Immunol 185: $1720-1729$.

55. Sato, M., H. Suemori, N. Hata, et al. 2000. Distinct and essential roles of transcription factors IRF-3 and IRF-7 in response to viruses for IFN-alpha/beta gene induction. Immunity 13: 539-548.

56. Taniguchi, T., and A. Takaoka. 2002. The interferon-alpha/beta system in antiviral responses: a multimodal machinery of gene regulation by the IRF family of transcription factors. Curr Opin Immunol 14: 111-116.

57. Kerkmann, M., S. Rothenfusser, V. Hornung, et al. 2003. Activation with CpG-A and CpG-B oligonucleotides reveals two distinct regulatory pathways of type I IFN synthesis in human plasmacytoid dendritic cells. J Immunol 170: 4465-4474.

58. Prakash, A., E. Smith, C. K. Lee, et al. 2005. Tissue-specific positive feedback requirements for production of type I interferon following virus infection. J Biol Chem 280: 18651-18657.

59. Izaguirre, A., B. J. Barnes, S. Amrute, et al. 2003. Comparative analysis of IRF and IFNalpha expression in human plasmacytoid and monocyte-derived dendritic cells. J Leukoc Biol 74: 1125-1138.

60. Ito, T., H. Kanzler, O. Duramad, et al. 2006. Specialization, kinetics, and repertoire of type 1 interferon responses by human plasmacytoid predendritic cells. Blood 107: 2423-2431.

61. Siegal, F. P., N. Kadowaki, M. Shodell, et al. 1999. The nature of the principal type 1 interferon-producing cells in human blood. Science 284: 1835-1837.

62. Colonna, M., G. Trinchieri, and Y. J. Liu. 2004. Plasmacytoid dendritic cells in immunity. Nat Immunol 5: 1219-1226.

63. Ito, T., R. Amakawa, T. Kaisho, et al. 2002. Interferon-alpha and interleukin-12 are induced differentially by Toll-like receptor 7 ligands in human blood dendritic cell subsets. J Exp Med 195: 1507-1512.

64. Gorden, K. B., K. S. Gorski, S. J. Gibson, et al. 2005. Synthetic TLR agonists reveal functional differences between human TLR7 and TLR8. J Immunol 174: 1259-1268.

65. Trinchieri, G. 2003. Interleukin-12 and the regulation of innate resistance and adaptive immunity. Nat Rev Immunol 3: 133-146.

66. Kramer, M., B. M. Schulte, D. Eleveld-Trancikova, et al. 2010. Cross-talk between human dendritic cell subsets influences expression of RNA sensors and inhibits picornavirus infection. J Innate Immun 2: 360-370.

67. Der, S. D., A. Zhou, B. R. Williams, et al. 1998. Identification of genes differentially regulated by interferon alpha, beta, or gamma using oligonucleotide arrays. Proc Natl Acad Sci U S A 95: 15623-15628.

68. O'Garra, A., and G. Trinchieri. 2004. Are dendritic cells afraid of commitment? Nat Immunol 5: 1206-1208. 
69. Sadler, A. J., and B. R. Williams. 2008. Interferon-inducible antiviral effectors. Nat Rev Immunol 8: 559-568.

70. Lu, G., J. T. Reinert, I. Pitha-Rowe, et al. 2006. ISG15 enhances the innate antiviral response by inhibition of IRF-3 degradation. Cell Mol Biol (Noisy-le-grand) 52: 29-41.

71. Takeuchi, T., T. Kobayashi, S. Tamura, et al. 2006. Negative regulation of protein phosphatase 2Cbeta by ISG15 conjugation. FEBS Lett 580: 4521-4526.

72. D'Cunha, J., S. Ramanujam, R. J. Wagner, et al. 1996. In vitro and in vivo secretion of human ISG15, an IFN-induced immunomodulatory cytokine. J Immunol 157: 41004108.

73. Kochs, G., and O. Haller. 1999. Interferon-induced human MXA GTPase blocks nuclear import of Thogoto virus nucleocapsids. Proc Natl Acad Sci U SA 96: 2082-2086.

74. Accola, M. A., B. Huang, A. Al Masri, et al. 2002. The antiviral dynamin family member, $M \times A$, tubulates lipids and localizes to the smooth endoplasmic reticulum. J Biol Chem 277: 21829-21835.

75. Kochs, G., C. Janzen, H. Hohenberg, et al. 2002. Antivirally active MxA protein sequesters La Crosse virus nucleocapsid protein into perinuclear complexes. Proc Natl Acad Sci U SA 99: 3153-3158.

76. Nakanishi, M., Y. Goto, and Y. Kitade. 2005. 2-5A induces a conformational change in the ankyrin-repeat domain of RNase L. Proteins 60: 131-138.

77. Dey, M., C. Cao, A. C. Dar, et al. 2005. Mechanistic link between PKR dimerization, autophosphorylation, and elF2alpha substrate recognition. Cell 122: 901-913.

78. Sakuma, T., T. Noda, S. Urata, et al. 2009. Inhibition of Lassa and Marburg virus production by tetherin. J Virol 83: 2382-2385.

79. Tokarev, A., M. Skasko, K. Fitzpatrick, et al. 2009. Antiviral activity of the interferoninduced cellular protein BST-2/tetherin. AIDS Res Hum Retroviruses 25: 1197-1210.

80. Jouvenet, N., S. J. Neil, M. Zhadina, et al. 2009. Broad-spectrum inhibition of retroviral and filoviral particle release by tetherin. J Virol 83: 1837-1844.

81. Peng, G., K. J. Lei, W. Jin, et al. 2006. Induction of APOBEC3 family proteins, a defensive maneuver underlying interferon-induced anti-HIV-1 activity. J Exp Med 203: 41-46.

82. Mangeat, B., P. Turelli, G. Caron, et al. 2003. Broad antiretroviral defence by human APOBEC3G through lethal editing of nascent reverse transcripts. Nature 424: 99-103.

83. Sastri, J., and E. M. Campbell. 2011. Recent insights into the mechanism and consequences of TRIM 5alpha retroviral restriction. AIDSRes Hum Retroviruses 27: 231238.

84. Adalid-Peralta, L., V. Godot, C. Colin, et al. 2008. Stimulation of the primary anti-HIV antibody response by IFN-alpha in patients with acute HIV-1 infection. J Leukoc Biol 83: 1060-1067.

85. Marrack, P., J. Kappler, and T. Mitchell. 1999. Type I interferons keep activated T cells alive. J Exp Med 189: 521-530.

86. Borden, E. C., G. C. Sen, G. Uze, et al. 2007. Interferons at age 50: past, current and future impact on biomedicine. Nat Rev Drug Discov 6: 975-990. 
87. Pedersen, I. M., G. Cheng, S. Wieland, et al. 2007. Interferon modulation of cellular microRNAs as an antiviral mechanism. Nature 449: 919-922.

88. Witwer, K. W., J. M. Sisk, L. Gama, et al. 2010. M icroRNA regulation of IFN-beta protein expression: rapid and sensitive modulation of the innate immune response. J Immunol 184: 2369-2376.

89. Murakami, Y., M. Tanaka, H. Toyoda, et al. 2010. Hepatic microRNA expression is associated with the response to interferon treatment of chronic hepatitis C. BMC M ed Genomics 3.

90. Bowie, A. G., and L. Unterholzner. 2008. Viral evasion and subversion of patternrecognition receptor signalling. Nat Rev Immunol 8: 911-922.

91. Garcia-Sastre, A. 2002. Mechanisms of inhibition of the host interferon alpha/betamediated antiviral responses by viruses. M icrobes Infect 4: 647-655.

92. Lu, L. L., M. Puri, C. M. Horvath, et al. 2008. Select paramyxoviral V proteins inhibit IRF3 activation by acting as alternative substrates for inhibitor of kappaB kinase epsilon (IKKe)/TBK1. J Biol Chem 283: 14269-14276.

93. Brzozka, K., S. Finke, and K. K. Conzelmann. 2005. Identification of the rabies virus alpha/ beta interferon antagonist: phosphoprotein $P$ interferes with phosphorylation of interferon regulatory factor 3. J Virol 79: 7673-7681.

94. Alcami, A., J. A. Symons, and G. L. Smith. 2000. The vaccinia virus soluble alpha/beta interferon (IFN) receptor binds to the cell surface and protects cells from the antiviral effects of IFN. J Virol 74: 11230-11239.

95. Colamonici, O. R., P. Domanski, S. M. Sweitzer, et al. 1995. Vaccinia virus B18R gene encodes a type I interferon-binding protein that blocks interferon alpha transmembrane signaling. J Biol Chem 270: 15974-15978.

96. Clementz, M. A., Z. Chen, B. S. Banach, et al. 2010. Deubiquitinating and interferon antagonism activities of coronavirus papain-like proteases. J Virol 84: 4619-4629.

97. Yuan, W., and R. M. Krug. 2001. Influenza B virus NS1 protein inhibits conjugation of the interferon (IFN)-induced ubiquitin-like ISG15 protein. EM BO J 20: 362-371.

98. Garaigorta, U., and F. V. Chisari. 2009. Hepatitis C virus blocks interferon effector function by inducing protein kinase R phosphorylation. Cell Host Microbe 6: 513-522.

99. Gale, M., Jr., and M. G. Katze. 1998. Molecular mechanisms of interferon resistance mediated by viral-directed inhibition of PKR, the interferon-induced protein kinase. Pharmacol Ther 78: 29-46.

100. Schmolke, M., and A. Garcia-Sastre. 2010. Evasion of innate and adaptive immune responses by influenza A virus. Cell M icrobiol 12: 873-880.

101. Hale, B. G., R. E. Randall, J. Ortin, et al. 2008. The multifunctional NS1 protein of influenza A viruses. J Gen Virol 89: 2359-2376.

102. Seo, S. H., E. Hoffmann, and R. G. Webster. 2002. Lethal H5N1 influenza viruses escape host anti-viral cytokine responses. Nat M ed 8: 950-954.

103. Cheung, C. Y., L. L. Poon, A. S. Lau, et al. 2002. Induction of proinflammatory cytokines in human macrophages by influenza $A(H 5 N 1)$ viruses: a mechanism for the unusual severity of human disease? Lancet 360: 1831-1837. 
104. de Jong, M. D., C. P. Simmons, T. T. Thanh, et al. 2006. Fatal outcome of human influenza $A$ (H5N1) is associated with high viral load and hypercytokinemia. Nat Med 12: 1203-1207.

105. Chan, M. C., C. Y. Cheung, W. H. Chui, et al. 2005. Proinflammatory cytokine responses induced by influenza A (H5N1) viruses in primary human alveolar and bronchial epithelial cells. Respir Res 6: 135.

106. Korteweg, C., and J. Gu. 2008. Pathology, molecular biology, and pathogenesis of avian influenza A (H5N1) infection in humans. Am J Pathol 172: 1155-1170.

107. Beigel, J. H., J. Farrar, A. M. Han, et al. 2005. Avian influenza A (H5N1) infection in humans. N Engl J Med 353: 1374-1385.

108. Taubenberger, J. K. 2006. The origin and virulence of the 1918 "Spanish" influenza virus. Proc Am Philos Soc 150: 86-112.

109. Kobasa, D., S. M. Jones, K. Shinya, et al. 2007. Aberrant innate immune response in lethal infection of macaques with the 1918 influenza virus. Nature 445: 319-323.

110. Kash, J. C., T. M. Tumpey, S. C. Proll, et al. 2006. Genomic analysis of increased host immune and cell death responses induced by 1918 influenza virus. Nature 443: 578581.

111. Kash, J. C., E. Muhlberger, V. Carter, et al. 2006. Global suppression of the host antiviral response by Ebola- and Marburgviruses: increased antagonism of the type I interferon response is associated with enhanced virulence. J Virol 80: 3009-3020.

112. Gupta, M., S. M ahanty, R. Ahmed, et al. 2001. M onocyte-derived human macrophages and peripheral blood mononuclear cells infected with ebola virus secrete M IP-1alpha and TNF-alpha and inhibit poly-IC-induced IFN-alpha in vitro. Virology 284: 20-25.

113. Howell, D. M., S. B. Feldman, P. Kloser, et al. 1994. Decreased frequency of functional natural interferon-producing cells in peripheral blood of patients with the acquired immune deficiency syndrome. Clin Immunol Immunopathol 71: 223-230.

114. Fitzgerald-Bocarsly, P., and E. S. Jacobs. 2010. Plasmacytoid dendritic cells in HIV infection: striking a delicate balance. J Leukoc Biol 87: 609-620.

115. Hong, H. S., N. Bhatnagar, M. Ballmaier, et al. 2009. Exogenous HIV-1 Vpr disrupts IFNalpha response by plasmacytoid dendritic cells ( $p D C s$ ) and subsequent $\mathrm{pDC} / \mathrm{NK}$ interplay. Immunol Lett 125: 100-104.

116. Van Damme, N., D. Goff, C. Katsura, et al. 2008. The interferon-induced protein BST-2 restricts HIV-1 release and is downregulated from the cell surface by the viral Vpu protein. Cell Host M icrobe 3: 245-252.

117. Herbeuval, J. P., and G. M. Shearer. 2007. HIV-1 immunopathogenesis: how good interferon turns bad. Clin Immunol 123: 121-128.

118. Vilcek, J. 2003. Boosting p53 with interferon and viruses. Nat Immunol 4: 825-826.

119. Herbeuval, J. P., J. Nilsson, A. Boasso, et al. 2006. Differential expression of IFN-alpha and TRAIL/DR5 in lymphoid tissue of progressor versus nonprogressor HIV-1-infected patients. Proc Natl Acad Sci U SA 103: 7000-7005.

120. Fried, M. W. 2002. Side effects of therapy of hepatitis $C$ and their management. Hepatology 36: S237-244. 
121. Medina, J., L. Garcia-Buey, J. A. Moreno-M onteagudo, et al. 2003. Combined antiviral options for the treatment of chronic hepatitis C. Antiviral Res 60: 135-143.

122. Lee, J., C. C. Wu, K. J. Lee, et al. 2006. Activation of anti-hepatitis C virus responses via Toll-like receptor 7. Proc Natl Acad Sci U SA 103: 1828-1833.

123. Baca-Regen, L, N. Heinzinger, M. Stevenson, et al. 1994. Alpha interferon-induced antiretroviral activities: restriction of viral nucleic acid synthesis and progeny virion production in human immunodeficiency virus type 1-infected monocytes. J Virol 68: 7559-7565.

124. Pitha, P. M. 1994. Multiple effects of interferon on the replication of human immunodeficiency virus type 1. Antiviral Res 24: 205-219.

125. Lane, H. C., V. Davey, J. A. Kovacs, et al. 1990. Interferon-alpha in patients with asymptomatic human immunodeficiency virus (HIV) infection. A randomized, placebocontrolled trial. Ann Intern Med 112: 805-811.

126. Hatzakis, A., P. Gargalianos, V. Kiosses, et al. 2001. Low-dose IFN-alpha monotherapy in treatment-naive individuals with HIV-1 infection: evidence of potent suppression of viral replication. J Interferon Cytokine Res 21: 861-869.

127. Rivero, J., M. Fraga, I. Cancio, et al. 1997. Long-term treatment with recombinant interferon alpha-2b prolongs survival of asymptomatic HIV-infected individuals. Biotherapy 10: 107-113.

128. Frissen, P. H., F. de Wolf, P. Reiss, et al. 1997. High-dose interferon-alpha2a exerts potent activity against human immunodeficiency virus type 1 not associated with antitumor activity in subjects with Kaposi's sarcoma. J Infect Dis 176: 811-814.

129. Skillman, D. R., J. L. Malone, C. F. Decker, et al. 1996. Phase I trial of interferon alfa-n3 in early-stage human immunodeficiency virus type 1 disease: evidence for drug safety, tolerance, and antiviral activity. J Infect Dis 173: 1107-1114.

130. Gao, L., S. Yu, Q. Chen, et al. 2010. A randomized controlled trial of low-dose recombinant human interferons alpha-2b nasal spray to prevent acute viral respiratory infections in military recruits. Vaccine 28: 4445-4451.

131. Contoli, M., S. D. Message, V. Laza-Stanca, et al. 2006. Role of deficient type III interferon-lambda production in asthma exacerbations. Nat Med 12: 1023-1026.

132. Mallia, P., S. D. M essage, V. Gielen, et al. 2011. Experimental rhinovirus infection as a human model of chronic obstructive pulmonary disease exacerbation. Am J Respir Crit Care Med 183: 734-742.

133. Loutfy, M. R., L. M. Blatt, K. A. Siminovitch, et al. 2003. Interferon alfacon-1 plus corticosteroids in severe acute respiratory syndrome: a preliminary study. JAM A 290: 3222-3228.

134. Stockman, L. J., R. Bellamy, and P. Garner. 2006. SARS: systematic review of treatment effects. PLoS Med 3: e343.

135. Zorzitto, J., C. L. Galligan, J. J. Ueng, et al. 2006. Characterization of the antiviral effects of interferon-alpha against a SARS-like coronoavirus infection in vitro. Cell Res 16: 220229. 
136. Cameron, M. J., J. F. Bermejo-Martin, A. Danesh, et al. 2008. Human immunopathogenesis of severe acute respiratory syndrome (SARS). Virus Res 133: 1319.

137. Lau, Y. L., and J. S. Peiris. 2005. Pathogenesis of severe acute respiratory syndrome. Curr Opin Immunol 17: 404-410.

138. Thiel, V., and F. Weber. 2008. Interferon and cytokine responses to SARS-coronavirus infection. Cytokine Growth Factor Rev 19: 121-132.

139. Wong, C. K., C. W. Lam, A. K. Wu, et al. 2004. Plasma inflammatory cytokines and chemokines in severe acute respiratory syndrome. Clin Exp Immunol 136: 95-103.

140. Jewell, N. A., T. Cline, S. E. Mertz, et al. 2010. Lambda interferon is the predominant interferon induced by influenza A virus infection in vivo. J Virol 84: 11515-11522.

141. Khaitov, M. R., V. Laza-Stanca, M. R. Edwards, et al. 2009. Respiratory virus induction of alpha-, beta- and lambda-interferons in bronchial epithelial cells and peripheral blood mononuclear cells. Allergy 64: 375-386.

142. Mordstein, M., E. Neugebauer, V. Ditt, et al. 2010. Lambda interferon renders epithelial cells of the respiratory and gastrointestinal tracts resistant to viral infections. J Virol 84: 5670-5677.

143. Svetlikova, D., P. Kabat, A. Ohradanova, et al. 2010. Influenza A virus replication is inhibited in IFN-lambda2 and IFN-lambda3 transfected or stimulated cells. Antiviral Res 88: 329-333.

144. Kanzler, H., F. J. Barrat, E. M. Hessel, et al. 2007. Therapeutic targeting of innate immunity with Toll-like receptor agonists and antagonists. Nat M ed 13: 552-559.

145. Krieg, A. M. 2006. Therapeutic potential of Toll-like receptor 9 activation. Nat Rev Drug Discov 5: 471-484.

146. Meyer, T., and E. Stockfleth. 2008. Clinical investigations of Toll-like receptor agonists. Expert Opin Investig Drugs 17: 1051-1065.

147. Pulendran, B., and R. Ahmed. 2006. Translating innate immunity into immunological memory: implications for vaccine development. Cell 124: 849-863.

148. Zhu, Q., C. Egelston, S. Gagnon, et al. 2010. Using 3 TLR ligands as a combination adjuvant induces qualitative changes in $T$ cell responses needed for antiviral protection in mice. J Clin Invest 120: 607-616.

149. Khan, S. J. J. Weterings, C. M. Britten, et al. 2009. Chirality of TLR-2 ligand Pam3CysSK4 in fully synthetic peptide conjugates critically influences the induction of specific CD8+ T-cells. Mol Immunol 46: 1084-1091.

150. Boivin, N., Y. Sergerie, S. Rivest, et al. 2008. Effect of pretreatment with toll-like receptor agonists in a mouse model of herpes simplex virus type 1 encephalitis. J Infect Dis 198: 664-672.

151. Gill, N., P. M. Deacon, B. Lichty, et al. 2006. Induction of innate immunity against herpes simplex virus type 2 infection via local delivery of Toll-like receptor ligands correlates with beta interferon production. J Virol 80: 9943-9950.

152. Svensson, A., L. Bellner, M. M agnusson, et al. 2007. Role of IFN-alpha/beta signaling in the prevention of genital herpes virus type 2 infection. J Reprod Immunol 74: 114-123. 
153. Wong, J. P., L. P. Nagata, M. E. Christopher, et al. 2005. Prophylaxis of acute respiratory virus infections using nucleic acid-based drugs. Vaccine 23: 2266-2268.

154. Hartmann, G., J. Battiany, H. Poeck, et al. 2003. Rational design of new CpG oligonucleotides that combine $B$ cell activation with high IFN-alpha induction in plasmacytoid dendritic cells. Eur J Immunol 33: 1633-1641.

155. Marshall, J. D., K. Fearon, C. Abbate, et al. 2003. Identification of a novel CpG DNA class and motif that optimally stimulate $\mathrm{B}$ cell and plasmacytoid dendritic cell functions. J Leukoc Biol 73: 781-792.

156. Vollmer, J., R. Weeratna, P. Payette, et al. 2004. Characterization of three CpG oligodeoxynucleotide classes with distinct immunostimulatory activities. Eur J Immunol 34: 251-262.

157. Hammerbeck, D. M., G. R. Burleson, C. J. Schuller, et al. 2007. Administration of a dual toll-like receptor 7 and toll-like receptor 8 agonist protects against influenza in rats. Antiviral Res 73: 1-11.

158. Gibson, S. J., J. M. Lindh, T. R. Riter, et al. 2002. Plasmacytoid dendritic cells produce cytokines and mature in response to the TLR7 agonists, imiquimod and resiquimod. Cell Immunol 218: 74-86.

159. Hemmi, H., T. Kaisho, O. Takeuchi, et al. 2002. Small anti-viral compounds activate immune cells via the TLR7 M yD88-dependent signaling pathway. Nat Immunol 3: 196200.

160. Heil, F., H. Hemmi, H. Hochrein, et al. 2004. Species-specific recognition of singlestranded RNA via toll-like receptor 7 and 8. Science 303: 1526-1529.

161. McCluskie, M. J., J. L. Cartier, A. J. Patrick, et al. 2006. Treatment of intravaginal HSV-2 infection in mice: a comparison of $\mathrm{CpG}$ oligodeoxynucleotides and resiquimod (R-848). Antiviral Res 69: 77-85.

162. Chang, Y. C., V. Madkan, R. Cook-Norris, et al. 2005. Current and potential uses of imiquimod. South Med J 98: 914-920.

163. Horsmans, Y., T. Berg, J. P. Desager, et al. 2005. Isatoribine, an agonist of TLR7, reduces plasma virus concentration in chronic hepatitis C infection. Hepatology 42: 724-731.

164. McHutchison, J. G., B. R. Bacon, S. C. Gordon, et al. 2007. Phase 1B, randomized, double-blind, dose-escalation trial of CPG 10101 in patients with chronic hepatitis C virus. Hepatology 46: 1341-1349.

165. Pockros, P. J., D. Guyader, H. Patton, et al. 2007. Oral resiquimod in chronic HCV infection: safety and efficacy in 2 placebo-controlled, double-blind phase lla studies. J Hepatol 47: 174-182.

166. Gonzalez, V. D., A. L. Landay, and J. K. Sandberg. 2010. Innate immunity and chronic immune activation in HCV/HIV-1 co-infection. Clin Immunol 135: 12-25.

167. Lore, K., M. R. Betts, J. M. Brenchley, et al. 2003. Toll-like receptor ligands modulate dendritic cells to augment cytomegalovirus- and HIV-1-specific T cell responses. J Immunol 171: 4320-4328.

168. Soumelis, V., I. Scott, F. Gheyas, et al. 2001. Depletion of circulating natural type 1 interferon-producing cells in HIV-infected AIDS patients. Blood 98: 906-912. 
169. Duan, X. Z., M. Wang, H. W. Li, et al. 2004. Decreased frequency and function of circulating plasmocytoid dendritic cells (pDC) in hepatitis B virus infected humans. J Clin Immunol 24: 637-646.

170. Kanto, T., M. Inoue, H. M iyatake, et al. 2004. Reduced numbers and impaired ability of myeloid and plasmacytoid dendritic cells to polarize T helper cells in chronic hepatitis C virus infection. J Infect Dis 190: 1919-1926.

171. Averill, L., W. M. Lee, and N. J. Karandikar. 2007. Differential dysfunction in dendritic cell subsets during chronic HCV infection. Clin Immunol 123: 40-49.

172. Salem, M. L., M. El-Demellawy, and A. R. El-Azm. 2010. The potential use of Toll-like receptor agonists to restore the dysfunctional immunity induced by hepatitis $C$ virus. Cell Immunol 262: 96-104.

173. Donaghy, H., A. Pozniak, B. Gazzard, et al. 2001. Loss of blood CD11c(+) myeloid and CD11c(-) plasmacytoid dendritic cells in patients with HIV-1 infection correlates with HIV-1 RNA virus load. Blood 98: 2574-2576.

174. Finke, J. S., M. Shodell, K. Shah, et al. 2004. Dendritic cell numbers in the blood of HIV1 infected patients before and after changes in antiretroviral therapy. J Clin Immunol 24: 647-652.

175. Sabado, R. L., M. O'Brien, A. Subedi, et al. 2010. Evidence of dysregulation of dendritic cells in primary HIV infection. Blood 116: 3839-3852.

176. Wang, H., N. Peters, and J. Schwarze. 2006. Plasmacytoid dendritic cells limit viral replication, pulmonary inflammation, and airway hyperresponsiveness in respiratory syncytial virus infection. J Immunol 177: 6263-6270.

177. Borchers, A. T., C. Selmi, F. J. Meyers, et al. 2009. Probiotics and immunity. J Gastroenterol 44: 26-46.

178. Maragkoudakis, P. A., W. Chingwaru, L. Gradisnik, et al. 2010. Lactic acid bacteria efficiently protect human and animal intestinal epithelial and immune cells from enteric virus infection. Int J Food Microbiol 141 Suppl 1: S91-97.

179. Vaarala, 0. 2003. Immunological effects of probiotics with special reference to lactobacilli. Clin Exp Allergy 33: 1634-1640.

180. Christensen, H. R., H. Frokiaer, and J. J. Pestka. 2002. Lactobacilli differentially modulate expression of cytokines and maturation surface markers in murine dendritic cells. J Immunol 168: 171-178.

181. Zeuthen, L. H., H. R. Christensen, and H. Frokiaer. 2006. Lactic acid bacteria inducing a weak interleukin-12 and tumor necrosis factor alpha response in human dendritic cells inhibit strongly stimulating lactic acid bacteria but act synergistically with gramnegative bacteria. Clin Vaccine Immunol 13: 365-375.

182. Weiss, G., S. Rasmussen, L. H. Zeuthen, et al. 2010. Lactobacillus acidophilus induces virus immune defence genes in murine dendritic cells by a Toll-like receptor-2dependent mechanism. Immunology 131: 268-281.

183. Pant, N., H. Marcotte, H. Brussow, et al. 2007. Effective prophylaxis against rotavirus diarrhea using a combination of Lactobacillus rhamnosus GG and antibodies. BMC Microbiol 7: 86. 
184. Maeda, N., R. Nakamura, Y. Hirose, et al. 2009. Oral administration of heat-killed Lactobacillus plantarum L-137 enhances protection against influenza virus infection by stimulation of type I interferon production in mice. Int Immunopharmacol 9: 11221125.

185. Vouloumanou, E. K., G. C. Makris, D. E. Karageorgopoulos, et al. 2009. Probiotics for the prevention of respiratory tract infections: a systematic review. Int J Antimicrob Agents 34: 197 e191-110.

186. Leyer, G. J., S. Li, M. E. M ubasher, et al. 2009. Probiotic effects on cold and influenzalike symptom incidence and duration in children. Pediatrics 124: e172-179.

187. Youn, H. N., D. H. Lee, Y. N. Lee, et al. 2012. Intranasal administration of live Lactobacillus species facilitates protection against influenza virus infection in mice. Antiviral Res 93: 138-143.

188. Gabryszewski, S. J., O. Bachar, K. D. Dyer, et al. 2011. Lactobacillus-mediated priming of the respiratory mucosa protects against lethal pneumovirus infection. J Immunol 186: 1151-1161.

189. O'Neill, L. A. 2006. Targeting signal transduction as a strategy to treat inflammatory diseases. Nat Rev Drug Discov 5: 549-563.

190. Johnson, C. L., D. M. Owen, and M. Gale, Jr. 2007. Functional and therapeutic analysis of hepatitis $\mathrm{C}$ virus NS3.4A protease control of antiviral immune defense. J Biol Chem 282: 10792-10803.

191. Krieg, A. M. 2002. CpG motifs in bacterial DNA and their immune effects. Annu Rev Immunol 20: 709-760.

192. Gilliet, M., W. Cao, and Y. J. Liu. 2008. Plasmacytoid dendritic cells: sensing nucleic acids in viral infection and autoimmune diseases. Nat Rev Immunol 8: 594-606.

193. Baccala, R., K. Hoebe, D. H. Kono, et al. 2007. TLR-dependent and TLR-independent pathways of type I interferon induction in systemic autoimmunity. Nat M ed 13: 543551.

194. Banchereau, J., and V. Pascual. 2006. Type I interferon in systemic lupus erythematosus and other autoimmune diseases. Immunity 25: 383-392.

195. Ronnblom, L. E., G. V. Alm, and K. E. Oberg. 1990. Possible induction of systemic lupus erythematosus by interferon-alpha treatment in a patient with a malignant carcinoid tumour. J Intern Med 227: 207-210.

196. Bave, U., M. Magnusson, M. L. Eloranta, et al. 2003. Fc gamma Rlla is expressed on natural IFN-alpha-producing cells (plasmacytoid dendritic cells) and is required for the IFN-alpha production induced by apoptotic cells combined with lupus IgG. J Immunol 171: 3296-3302.

197. Ronnblom, L. M. L. Eloranta, and G. V. Alm. 2003. Role of natural interferon-alpha producing cells (plasmacytoid dendritic cells) in autoimmunity. Autoimmunity 36: 463472.

198. Fornek, J. L., M. J. Korth, and M. G. Katze. 2007. Use of functional genomics to understand influenza-host interactions. Adv Virus Res 70: 81-100. 
199. Weeratna, R. D., S. R. Makinen, M. J. McCluskie, et al. 2005. TLR agonists as vaccine adjuvants: comparison of CpG ODN and Resiquimod (R-848). Vaccine 23: 5263-5270.

200. Hemmi, H., O. Takeuchi, T. Kawai, et al. 2000. A Toll-like receptor recognizes bacterial DNA. Nature 408: 740-745.

201. Martinson, J. A., A. Roman-Gonzalez, A. R. Tenorio, et al. 2007. Dendritic cells from HIV-1 infected individuals are less responsive to toll-like receptor (TLR) ligands. Cell Immunol 250: 75-84.

202. Gorden, K. K., X. X. Qiu, C. C. Binsfeld, et al. 2006. Cutting edge: activation of murine TLR8 by a combination of imidazoquinoline immune response modifiers and polyT oligodeoxynucleotides. J Immunol 177: 6584-6587.

203. Brawand, P., D. R. Fitzpatrick, B. W. Greenfield, et al. 2002. Murine plasmacytoid predendritic cells generated from Flt3 ligand-supplemented bone marrow cultures are immature APCs. J Immunol 169: 6711-6719.

204. Gilliet, M., A. Boonstra, C. Paturel, et al. 2002. The development of murine plasmacytoid dendritic cell precursors is differentially regulated by FLT3-ligand and granulocyte/macrophage colony-stimulating factor. J Exp M ed 195: 953-958.

205. Feldman, S. B., M. Ferraro, H. M. Zheng, et al. 1994. Viral induction of low frequency interferon-alpha producing cells. Virology 204: 1-7. 



\section{Chapter}

\section{CpG and poly(I:C) stimulation of dendritic cells and fibroblasts limits herpes simplex virus type 1 infection in an IFN $\beta$ - dependent and -independent way}

Giel R Gaajetaan, Tanja H Geelen, Gert E Grauls, Cathrien A Bruggeman, Frank R Stassen

Antiviral Research 2012 93(1):39-47 


\section{Abstract}

Viral activation of toll-like receptors (TLRs) on dendritic cells (DCS) leads to production of various cytokines, including antiviral type I interferons (IFNs). Synthetic ligands specific for TLRs are also able to induce the production of type I IFNs (IFN $\alpha / \beta$ ) by DCs, suggesting that these ligands have potential as antiviral drugs. In this in vitro study we extensively investigated the antiviral activity of various TLR ligands. Mouse bone marrow (BM) cells were differentiated into plasmacytoid and conventional DCs (pDCs and cDCs), stimulated with various TLR ligands and tested the antiviral abilities of collected supernatants in an in vitro herpes simplex virus type 1 (HSV-1) infection model. We observed a significant IFN $\beta$-, (but not IFN $\alpha$-) dependent reduction in HSV-1 infection when a mixed $\mathrm{pDC} / \mathrm{CDC}$ population was stimulated with the TLR9 ligand CpG. In the absence of pDCs, TLR stimulation resulted in less pronounced antiviral effects. The most pronounced antiviral effect was observed when both $D C$ subsets were stimulated with poly $(I: C)$. A similar noticeable antiviral effect was observed when fibroblasts (L929 cells) were stimulated directly with poly(l:C). These poly(l:C)-mediated antiviral effects were only partially IFN $\beta$-mediated and probably TLR independent. These data demonstrate that TLR ligands are not only able to produce type I IFN but can indeed act as antiviral drugs. In particular poly(l:C), which exerts its antiviral effects even in the absence of DCs, may become a promising drug e.g. to prevent respiratory infections by topical intranasal application. 


\section{Introduction}

Type I interferons (IFNs) are the key cytokines produced predominantly by innate immune cells to combat viral infections. After viral recognition the release of IFN induces the expression of so-called interferon stimulated genes (ISGs) which subsequently activate a variety of antiviral processes including amplification of IFN signalling and the activation of adaptive immunity ${ }^{1-4}$. This will ultimately result in the induction of a non-virus-specific antiviral state in infected cells, culminating in direct inhibition of viral replication while also enhancing the host's specific antiviral immune responses through IFN-related immunomodulatory stimuli.

Because of this strong antiviral activity, type I IFNs have also been used in clinical practice. For example, pegylated interferon alpha (Peg-IFN $\alpha$ ) in combination with ribavirin is currently recommended as standard-of-care treatment of chronic hepatitis $C$ virus infection. However, depending on the HCV genotype involved, success rates of Peg-IFNa/ribavirin treatment vary significantly. Moreover, in clinical practice approximately $10-15 \%$ of patients discontinue this therapy due to adverse effects which impacts most, if not all, organ systems ${ }^{5-7}$. Therefore, there is need for alternative therapies.

Although a large variety of immune as well as non-immune cells is able to produce type I IFNs, the most important cells in this respect are dendritic cells. In particular plasmacytoid, but also conventional dendritic cells are well able to produce significant amounts of type I IFNs (IFN $\alpha / \beta)$. The type I interferon response is usually initiated following recognition of viral components by pathogen recognition receptors e.g. toll-like receptors (TLRs) and cytoplasmic receptors ${ }^{8-12}$. The plasmacytoid $D C(p D C)$ senses single-stranded RNA (ssRNA) and CPG DNA from viruses via TLR7 and 9, respectively ${ }^{3,13-16}$. Conventional DC ( $C D C S$ ), on the other hand, sense the viral intermediate double-stranded RNA (dsRNA) via TLR3 3,16,17. Next to these TLRs it has previously been shown that also TLR2 and 4, located on human monocytes, are involved in viral detection ${ }^{18-21}$. Cytoplasmic receptors, on the other hand, are present in almost all cell types and recognize dsRNA during viral replication ${ }^{18,22}$.

As DCs express a specific repertoire of TLRs, it has been suggested that synthetic TLR ligands, targeting these receptors, may have a therapeutic 
potential as antiviral compounds. Yet, although it is well known that some TLR ligands are well able to initiate the release of type I interferons by DCs ${ }^{23-27}$, the direct antiviral effects of TLR-mediated DC activation have been studied less intensively. Therefore, in this study the antiviral potency of various TLR ligands was examined in an in vitro model of herpes simplex virus 1 (HSV-1) infection.

We found that in particular IFN $\beta$ (but not IFN $\alpha$ ), produced in large amounts by the CpG- and poly(I:C)-stimulated mixed DC population, was very effective in limiting HSV replication. Furthermore, L929 fibroblasts also induced an antiviral response when stimulated with poly $(l: C)$. This response was, however, only partially IFN $\beta$-mediated and suggests the importance of other antiviral pathways.

\section{Materials and methods}

\section{Mice}

Bone marrow was derived from male BALB/c mice (8-14 weeks of age), obtained from Charles River Laboratories and maintained under normal conditions. Mice were euthanized by intraperitoneal injection of Nembutal ${ }^{\circledR}$ (150 mg/kg, Sanofi Sante B.V., Maassluis, the Netherlands). The study was approved by the ethical committee for animal experiments of the Maastricht University.

\section{Isolation and differentiation of bone marrow cells}

Femur and tibia were removed and flushed with RPMI 1640 medium (Invitrogen, Grand Island, NY, USA) supplemented with 10\% FCS (Lonza, Verviers, Belgium) and $40 \mu \mathrm{g} / \mathrm{ml}$ gentamycin (Centrafarm, Etten-Leur, the Netherlands) to obtain the BM cells. BM cells were resuspended in $\mathrm{NH}_{4} \mathrm{Cl}$ buffer containing EDTA and incubated for $10 \mathrm{~min}$ on ice to lyse red blood cells. BM cells were cultured in 24-well tissue culture plates (Becton Dickinson, NJ, USA) at $10^{6}$ cells/ $\mathrm{ml}$ in RPMI 1640 medium (Invitrogen, Grand Island, NY, USA) with $10 \%$ FCS (Lonza, Verviers, Belgium) and $40 \mu \mathrm{g} / \mathrm{ml}$ gentamycin (Centrafarm, Etten-Leur, the Netherlands). The medium was supplemented 
with either $200 \mathrm{ng} / \mathrm{ml}$ human Flt-3L (M iltenyi Biotec, Leiden, the Netherlands) or $20 \mathrm{ng} / \mathrm{ml}$ GM-CSF (Miltenyi Biotec, Leiden, the Netherlands) for differentiation into pDCs and CDCs or CDCs only, respectively. When GM-CSF was used, the medium was refreshed 3 and 6 days after seeding the cells in the plates. Cells were allowed to differentiate for 8 days at $37^{\circ} \mathrm{C}$ and $5 \% \mathrm{CO}_{2}$ before stimulation with different TLR ligands was started.

\section{TLR ligands and stimulation}

Lipopolysaccharide (LPS) (Eschirichia Coli serotype 055:B5(L2880)) was obtained from Sigma (St Louis, USA). R-848, poly(I:C) LM W and CpG ODN 1585 were all obtained from Invivogen (San Diego, CA, USA). At day 8, the medium of the DCS was removed and replaced with medium containing different TLR ligands. Differentiated BM cells were stimulated with either LPS (100 ng/ml), R$848(1 \mathrm{en} 10 \mu \mathrm{g} / \mathrm{ml})$, poly $(\mathrm{l}: \mathrm{C})(50 \mu \mathrm{g} / \mathrm{ml})$ or CpG ODN $1585(0.1$ and $1 \mu \mathrm{M})$ for $24 \mathrm{~h}$ at $37^{\circ} \mathrm{C}$ and $5 \% \mathrm{CO}_{2}$. Afterwards, cells were snap-frozen in liquid nitrogen and stored at $-80^{\circ} \mathrm{C}$ for future gene expression analysis. Supernatants of the stimulated DCs were stored at $-20^{\circ} \mathrm{C}$ until further use.

\section{Cells and virus}

L929 cells (ATCC CCL-1) (Rockville, MD, USA) were cultured in Earle's Minimal essential medium (EMEM) (Invitrogen, Grand Island, NY, USA) supplemented with non-essential amino acids (MP Biomedicals, Solon, Ohio, USA), Lglutamine $(2 \mathrm{mmol} / \mathrm{L})$, sodium pyruvate $(1 \mathrm{mmol} / \mathrm{L})$ and $10 \%$ FCS (Lonza, Verviers, Belgium). Cells were allowed to grow in T75 flasks at $37^{\circ} \mathrm{C}$ and $5 \%$ $\mathrm{CO}_{2}$.

HSV-1 was obtained from ATCC (VR-539) and was propagated in Vero cells (ATCC CCL-81) (Rockville, MD, USA) in EMEM (Invitrogen, Grand Island, NY, USA) with 2\% FCS (Lonza, Verviers, Belgium), non-essential amino acids (MP Biomedicals, Solon, Ohio, USA), L-glutamine ( $2 \mathrm{mmol} / \mathrm{L}$ ) and sodium pyruvate ( $1 \mathrm{mmol} / \mathrm{L}$ ). When $100 \%$ cytopathogenic effect (CPE) was achieved, cell debris was removed by centrifugation and viral titers in the supernatant were determined by plaque assay. 


\section{Stimulation and infection protocol}

To test the antiviral potency of the conditioned media obtained from TLRstimulated DCs, L929 cells were grown in 24-well tissue culture plates (Becton Dickinson, NJ, USA) until confluency and, after washing with PBS, were exposed to the collected supernatants. After $18 \mathrm{~h}$ incubation, the conditioned medium was removed, cells were washed with PBS and infected with HSV-1 (MOI 0.1) in EMEM medium without FCS for $1 \mathrm{~h}$ at $37^{\circ} \mathrm{C}$ and $5 \% \mathrm{CO}_{2}$. Next, the HSV-1-containing supernatant was removed and replaced by normal EMEM medium without FCS. The cells were harvested $30 \mathrm{~h}$ post infection (p.i.), snapfrozen in liquid nitrogen and stored at $-80^{\circ} \mathrm{C}$ for DNA and RNA isolations. The supernatant was stored at $-80^{\circ} \mathrm{C}$ until used for plaque assay.

\section{Quantitive PCR (qPCR)}

DNA was extracted from frozen cell pellets according to the Wizard ${ }^{\circledR}$ Genomic DNA Purification Kit (Promega Benelux B.V., Leiden, the Netherlands) according to the manufacturer's instructions. DNA purity and quantity were measured with the Nanondrop ${ }^{\circledR N D}-1000$. The DNA isolates were amplified in a volume of $25 \mu$ l containing $12,5 \mu \mathrm{II} \mathrm{IM}^{\mathrm{TM}}$ Sybr green mix (Bio-Rad, Hercules, CA, USA), HSV-1 forward and reverse primer, and DNA sample. HSV-1 was detected by using a M yiQ Single-Color Real-Time PCR Detection System (BioRad, Hercules, CA, USA). Thermal cycling was started with uracil-N-glycosylase (UNG) activation for 2 min at $50^{\circ} \mathrm{C}$, followed by HotStarTaq activation during $15 \mathrm{~min}$ at $95^{\circ} \mathrm{C}$. Subsequently, 40 cycles of amplification were run consisting of $15 \mathrm{~s}$ at $95^{\circ} \mathrm{C}$ (denaturation) and $1 \mathrm{~min}$ at $60^{\circ} \mathrm{C}$ (annealing and attaching).

To determine the actual number of HSV-1 DNA copies, a DNA standard curve was used. Dilutions were made from a plasmid, which contains the HSV-1 PCRtarget sequence. Concentrations used ranged from $10^{7}$ to $10^{0}$ copies, with a dilution factor of 10. Copy numbers were quantified by the standard curve using the $\mathrm{iQ}^{\mathrm{TM}} 5$ version 2.0 Optical System Software. 


\section{RT-qPCR}

RNA was isolated from frozen cell pellets with the RNeasy kit (Qiagen, Hilden, Germany) according to the manufacturer's instructions. Remaining DNA was removed by DNAse treatment (Turbo DNA-free ${ }^{T M}$ kit, Ambion, Austin, TX, USA). Subsequently, RNA was reverse transcribed into CDNA using the iScript CDNA Synthesis Kit (Bio-Rad, Hercules, CA, USA). qPCR was performed as described above. Primer sets used are listed in table 1. To control for DNA contamination, in every PCR run a sample was included which was not reverse transcribed. Relative expressions were determined by using the $2^{-\Delta \mathrm{Ct}} 28$ method, normalized to GAPDH values. All samples were measured in duplicate.

Table 1. Primers used for DNA and mRNA expression analysis

\begin{tabular}{|c|c|c|}
\hline Gene & & Primers sequences $\left(5^{\prime}-3^{\prime}\right)$ \\
\hline \multirow[t]{2}{*}{$\overline{\mathrm{HSV}-1}$} & forward & TTCTCGTTCCTYACYGCCTCCC \\
\hline & reverse & GCAGGCACACGTAACGCACGCT \\
\hline \multirow[t]{2}{*}{ mIFNa4 } & forward & CAGGCACAGAGGCTGTGTाTCT \\
\hline & reverse & TGCTGGCTGTGAGGACATACT \\
\hline \multirow[t]{2}{*}{ mIFN $\beta$} & forward & ATGAGTGGTGGTTGCAGGC \\
\hline & reverse & TGACCTTTCAAATGCAGTAGATTCA \\
\hline \multirow[t]{2}{*}{ mGAPDH } & forward & CATTGTGGAAGGGCTCATGA \\
\hline & reverse & GCCCCACGGCCATCA \\
\hline \multirow[t]{2}{*}{ mTLR3 } & forward & CTGTGCAGAAGATTCAAGGTACATC \\
\hline & reverse & TTGCTCAATAGCTTGCTGAACTGC \\
\hline \multirow[t]{2}{*}{ mTLR4 } & forward & ССTCTGCCTTCACTACAGAGACTIT \\
\hline & reverse & TTGTGGAAGCCTTCCTGGAT \\
\hline \multirow[t]{2}{*}{ mTLR7 } & forward & GGAGCTCTGTCCTTGAGTGG \\
\hline & reverse & CAAGGCATGTCCTAGGTGGT \\
\hline \multirow[t]{2}{*}{ mTLR9 } & forward & GGCTGTCAATGGCTCTCAGTT \\
\hline & reverse & AGTGGTACAAGTCCAGTTTGTTATGG \\
\hline
\end{tabular}

$\mathrm{m}=$ mouse

\section{Plaque assay}

To determine the presence of infectious HSV-1 particles, collected supernatant from infected $L 929$ cells was added to Vero cells (ATCC CCL-81) (Rockville, MD, USA) grown until confluency in 24-well plates. After $1 \mathrm{~h}$ at $37^{\circ} \mathrm{C}$ and $5 \% \mathrm{CO}_{2}$, 
supernatant was removed and, after the cells had been washed with PBS, replaced by a medium-agarose mixture (1:1). This EMEM medium without phenol red (Invitrogen, Grand Island, NY, USA) was supplemented with 2\% FCS (Lonza, Verviers, Belgium), non-essential amino acids (MP Biomedicals, Solon, Ohio, USA), sodium pyruvate (1 mmol/L) and L-glutamine. After $72 \mathrm{~h}$ incubation at $37^{\circ} \mathrm{C}$ and $5 \% \mathrm{CO}_{2}$ cells were exposed to a $3.7 \%$ formaldehyde solution for $4 \mathrm{~h}$ and afterwards stained with $1 \%$ methylene blue.

\section{Neutralisation assay}

Pure or diluted (5x or $50 \mathrm{x}$ ) supernatant from stimulated DCs was incubated with IFN $\beta$-antibody $\left(2 \times 10^{3}\right.$ units/ml; PBL Biomedical Laboratories, NJ, USA) for $1 \mathrm{~h}$ at $37^{\circ} \mathrm{C}$ and $5 \% \mathrm{CO}_{2}$ to neutralize IFN $\beta$. L929 cells were seeded and allowed to grow until confluency in 96-well plates. These 2929 cells were then incubated with the conditioned, $H$ - antibody-containing supernatants for $18 \mathrm{~h}$ and were subsequently infected with HSV-1 according to the infection protocol and viral copies were determined by qPCR.

\section{Detection of IFN 6 production}

An enzyme-linked immunosorbent assay (PBL Biomedical Laboratories, NJ, USA) was used to detect IFN $\beta$ in the supernatant of stimulated DCs.

\section{Statistical analysis}

The Student's t-test was used to analyse differences between control and stimulated samples. Differences between multiple groups were determined by one-way ANOVA with a Bonferroni post hoc test. Values of $p<0.05$ were considered statistically significant. Data are expressed as mean \pm SEM , unless stated otherwise. 


\section{Results}

Supernatant of TLR-stimulated DCs limits viral infection of L929 cells

As illustrated in figure 1A, HSV-1 infection of 2929 cells could be inhibited significantly when cells were pre-treated for $18 \mathrm{~h}$ with conditioned supernatants collected from FIt-3L (FL) BM-DC cultures stimulated with either LPS, poly $(\mathrm{l}: \mathrm{C})$ or $\mathrm{CpG}(1 \mu \mathrm{M})$ for $24 \mathrm{~h}$. No reduction in viral copy number was observed when supernatants of R-848-stimulated FL BM-DC cultures were used. Likewise, poly(I:C) stimulation of GM-CSF (GM) BM-DC cultures resulted in a strong reduction of viral DNA copies, while viral copy numbers were also reduced following pre-treatment with either LPS or CpG (1 $\mu \mathrm{M})$ (figure 1B). Moreover, also R-848 induced a small, though significant decrease in viral copy numbers.

A

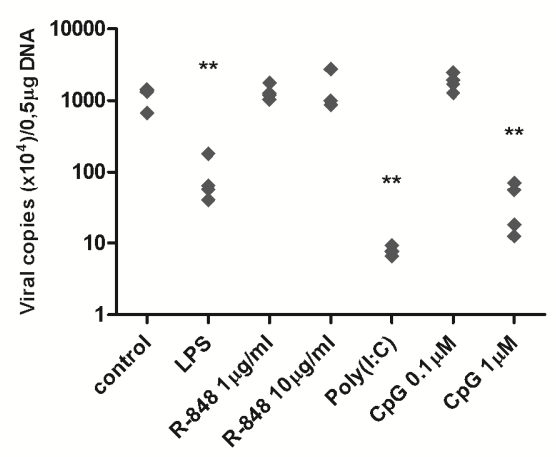

B

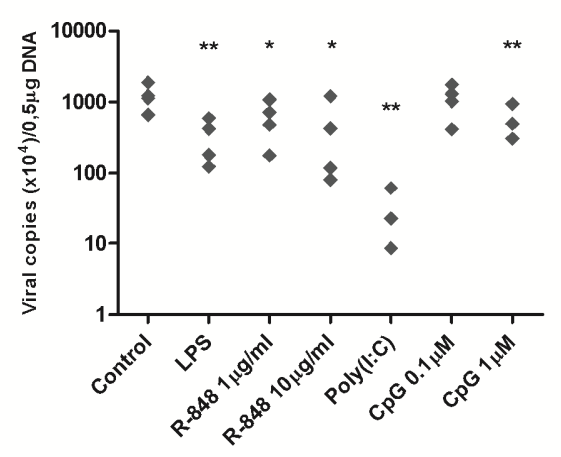

Figure 1. Differential reduction of HSV-1 DNA levels by TLR ligands. Antiviral effect of supernatant from TLR stimulated FL BM-DCs (A) or GM BM-DCs (B) on L929 cells subsequently infected with HSV-1. Symbols indicate BM-DC supernatant from individual mice $(n=4)$. Viral copies were determined by $\mathrm{qPCR}$. $* *=\mathrm{P} \varangle 0.01$ and $*=\mathrm{P} \varangle 0.05$ versus control.

The inhibition of viral replication by the TLR ligands was also determined at the mRNA levels. In accordance with the reduction in DNA copy numbers (figure 1), HSV-1 mRNA expression was significantly reduced in L929 cells treated with conditioned medium from either LPS-, poly(l:C)- or CpG-stimulated FL BM-DCS (figure 2A). In contrast, only conditioned medium from LPS- or poly(I:C)- 
stimulated GM BM-DCs significantly reduced HSV-1 mRNA, while no effect was observed when conditioned medium from GM BM-DC stimulated with CpG was used (figure 2B).

A

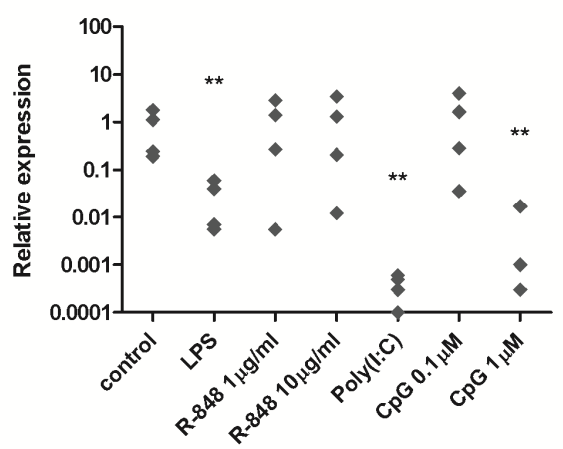

B

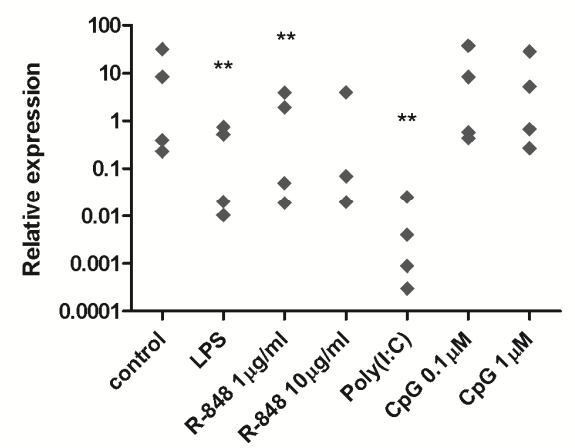

Figure 2. Differential reduction of HSV-1 mRNA levels by TLR ligands. Effect of supernatant from TLR stimulated FL BM-DCs (A) or GM BM-DCs (B) on L929 cells subsequently infected with HSV-1. HSV-1 is displayed as relative expression compared to GAPDH values. Symbols indicate BM -DC supernatant from individual mice $(n=4)$. ** $=P \varangle 0.01$ and $*=P \varangle 0.05$ versus control.

Moreover, the earlier observed R-848-induced reduction in viral copies DNA copies was at the mRNA level only confirmed after stimulation with $1 \mu \mathrm{g} / \mathrm{ml}$ (but not $10 \mu \mathrm{g} / \mathrm{ml}$ ) R-848. Overall, our data showed pronounced antiviral effects of poly(I:C), CpG and LPS, while the effects of R848 were rather limited. To control for antiviral effects due to TLR ligands still present in the supernatant of stimulated DCs, TLR ligands were administered directly to L929 cells $18 \mathrm{~h}$ before infection (figure 3 ). Except for poly(l:C), no reduction in HSV-1 copies was observed. This indicates that the observed antiviral effect of TLR ligands is dependent on stimulation of BM-DCs, with the exception of poly $(I: C)$, which significantly reduced viral copies in 2929 cells independent of the BMDCs. 


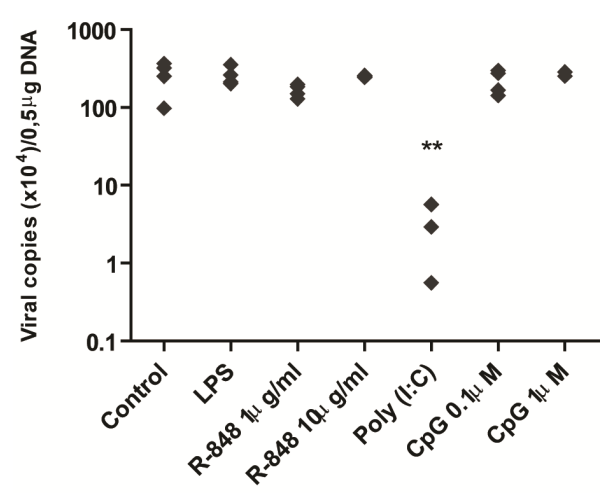

Figure 3. HSV-1 inhibition by TLR ligands requires BM-DCs. TLR ligands were directly administered to $L 929$ cells. Symbols indicate independent experiments $(n=4)$. Viral copies were determined by qPCR. $* *=P \varangle .01$ and $*=$ $P \varangle 0.05$ versus control.

Next, the potency of various TLR ligands to prevent the formation of infectious HSV-1 virus particles was analysed with a plaque assay. After administration of conditioned BM-DC supernatants to the L929 cells and subsequent infection with HSV- 1 for $30 \mathrm{~h}$, the presence of infectious particles in the supernatants of infected L929 cells was examined. Vero cells were incubated for $1 \mathrm{~h}$ with the L929 supernatant and plaque formation was determined after $72 \mathrm{~h}$. Again, the degree of plaque formation corresponded with the results at DNA and mRNA levels as the number of plaques were drastically reduced when $L 929$ cells were pre-treated with the conditioned supernatant of LPS-, poly(I:C)- or CpG (1 $\mu \mathrm{M})$ stimulated FL BM-DCs (figure 4B). Analogous to the DNA and mRNA data, limited reduction of plaque formation was achieved after R-848- and LPStreatment of GM BM-DCs while stimulation with poly $(I: C)$ was most protective (figure $4 \mathrm{C}$ ). Furthermore, a strong reduction of plaque formation was once more observed when poly $(I: C)$ was directly added to $L 929$ cells thereby demonstrating again that poly $(\mathrm{I}: \mathrm{C})$ can induce $\mathrm{DC}$-independent antiviral effects (figure 4D).

These data clearly demonstrate that stimulation of DCS with various TLR ligands results in significant antiviral effects. Moreover, FL BM -DCs seem more potent than GM BM-DCs in preventing viral replication and a strong DCindependent antiviral effect of poly $(\mathrm{I}: \mathrm{C})$ was observed. 
A

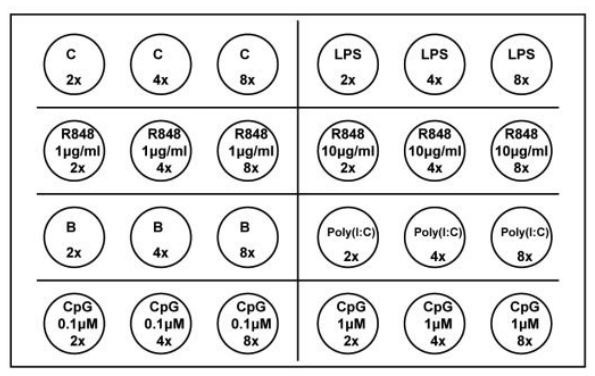

C

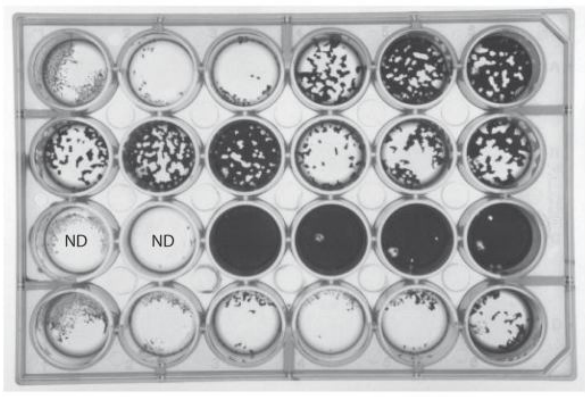

B

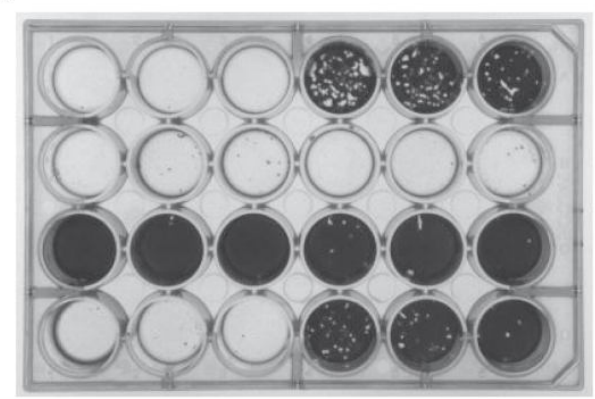

D

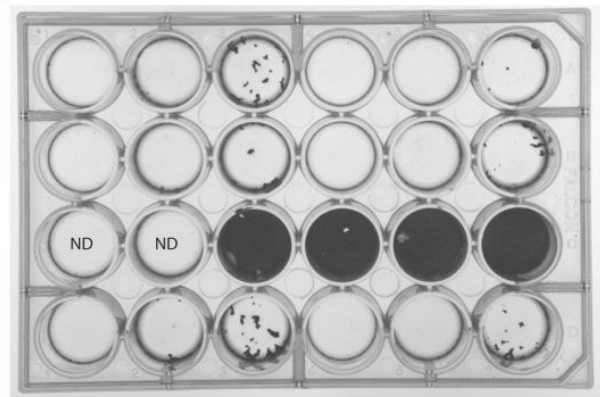

Figure 4. Differential reduction of infectious HSV-1 by TLR ligands. Vero cells were exposed to supernatant from infected L929 cells after stimulation with supernatant from TLR-stimulated DCs. Schematic figure representing the different samples and dilutions (A). Viral solutions obtained from $L 929$ cells stimulated with supernatant from FL BM-DCs (B), GM BM-DCs (C) and directly stimulated $L 929$ cells (D) show various degrees of infection. Figures are representative of three independent experiments. $C=$ control, $B=B l a n k$. ND=not done.

IFNB inhibits HSV-1 replication

To investigate the mechanisms involved in the observed antiviral effects, the mRNA expression of IFN- $\alpha 4$ and $-\beta$ in the differentiated BM-DCs was determined. These cytokines are normally the first antiviral mediators produced in mice during viral infection ${ }^{17,29}$. Basal IFNa4 mRNA expression was low in both DC cell cultures. Surprisingly, however, only a slight (nonsignificant) increase was observed when FL BM-DCs were stimulated with poly $(\mathrm{I}: \mathrm{C})$ or $\mathrm{CpG}(1 \mu \mathrm{M})$ (data not shown), which implicates that IFNa4 might play only a minor role in the observed antiviral effect. Yet, in the same samples the expression of IFN $\beta$ mRNA was strongly enhanced following LPS, CPG or poly $(I: C)$ stimulation (figure $5 \mathrm{~A}$ ). Importantly, the IFN $\beta$ expression in these 60 
samples correlated with the antiviral effect of these TLR ligands in the HSV-1 infection assay. R-848 $(10 \mu \mathrm{g} / \mathrm{ml})$ resulted in a minor increase in IFN $\beta$ expression, which is probably not sufficient for a detectable antiviral effect, as observed in Figs. 2 and 4. In GM BM-DCs, on the other hand, both IFNa4 (data not shown) and IFN $\beta$ expression remained very low in all conditions (figure $5 \mathrm{~B}$ ).

A

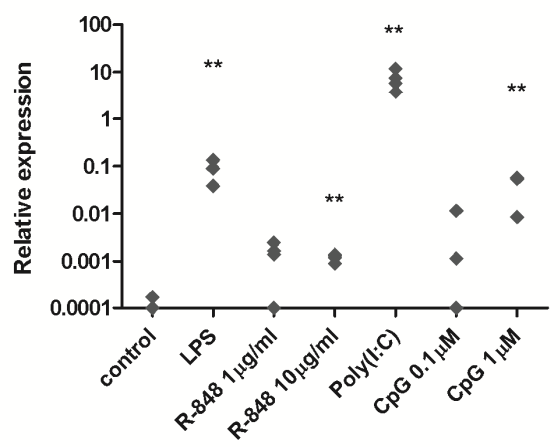

B

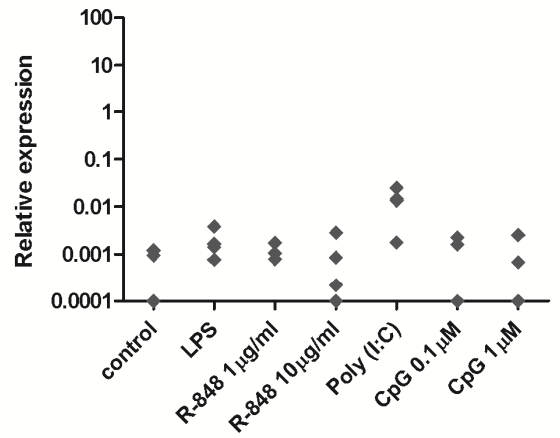

Figure 5. Differential IFN $\beta$ expression in both BM-DC subsets. IFN $\beta$ expression in FL BM-DCS (A) and GM BM-DCs (B). IFN is displayed as relative expression compared to GAPDH values. Symbols indicate BM-DCs from individual mice $(n=4)$. $* *=P \varangle 0.01$ and $*=P \varangle 0.05$ versus control.

These results indicate that IFN $\beta$ is the most important cytokine in the antiviral effect observed following (FL) BM-DC stimulation with various TLR ligands. To further explore the role of IFN $\beta$ we performed neutralization experiments. Therefore, a IFN $\beta$ neutralizing antibody was added to the supernatants of LPS-, poly(l:C)- and CpG $(1 \mu \mathrm{M})$-stimulated FL BM-DCs. Subsequently, after a $1 \mathrm{~h}$ preincubation period at $37^{\circ} \mathrm{C}$ these supernatants were added to $\mathrm{L929}$ cells prior to HSV-1 infection. As expected, neutralizing IFN $\beta$ significantly reduced the antiviral effect of the conditioned media (figure $6 \mathrm{~A}, \mathrm{C}, \mathrm{E}$ ). In similar experiments using an IFN $\alpha$ neutralizing antibody no effect of the antibody was observed (data not shown), further emphasizing the predominant role of IFN $\beta$ in the observed antiviral effect.

Stimulation of GM BM-DCs with poly(I:C), and to a lesser extent R-848 and LPS, also induced an antiviral effect in our HSV-1 infection assay. However, RT-qPCR results demonstrated that the expression of IFN $\beta$ mRNA in GM BM-DC is low and not significantly enhanced after stimulation with the respective TLR 
ligands (figure 5B). Despite the low IFN $\beta$ mRNA expression, the antiviral effect of the LPS and R848 could be inhibited by the IFN $\beta$ neutralizing antibody (figure 6B,D,F). The neutralizing effect in poly(I:C)-stimulated GM BM-DCs was less pronounced compared to the effect observed with poly(l:C)-stimulated $\mathrm{FL}$ BM-DCs. This suggests that other cytokines than IFN $\beta$ may be important in mediating the antiviral effects of poly(l:C).

A

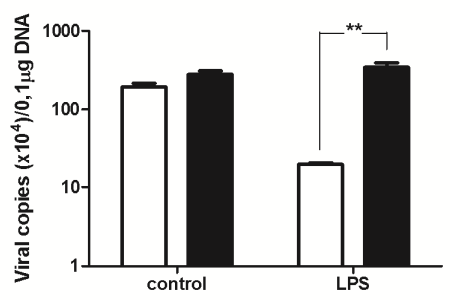

C

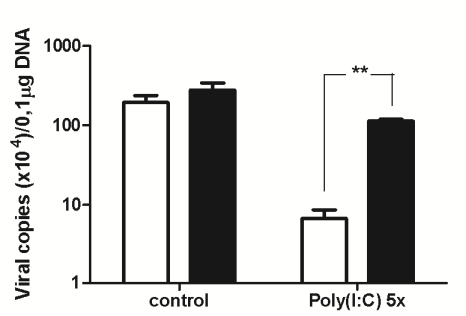

E

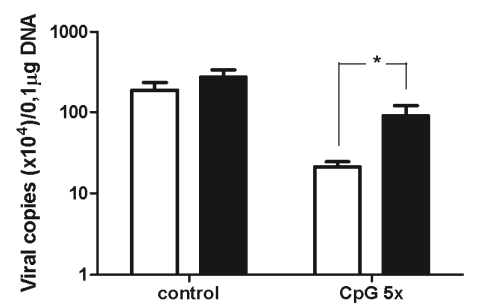

B

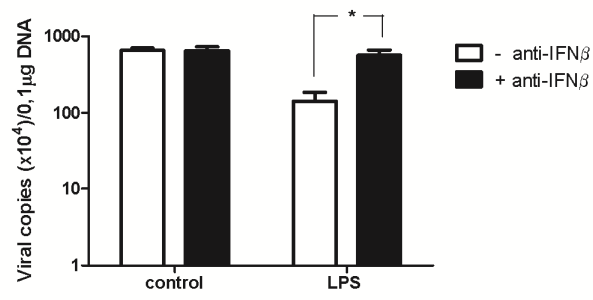

D

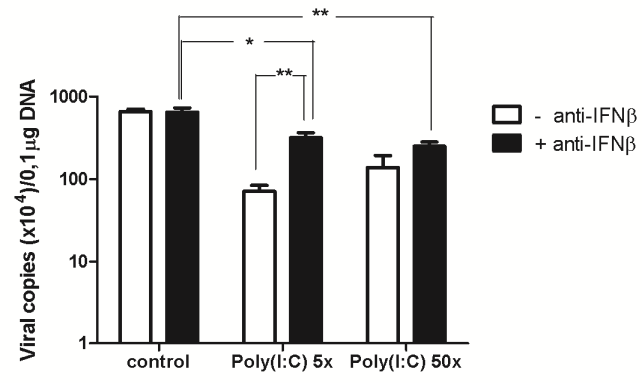

$\mathbf{F}$

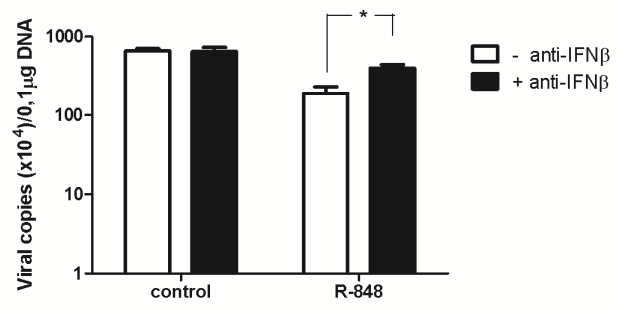

Figure 6. IFN $\beta$ is essential for inhibition of viral replication. IFN $\beta$ neutralisation of supernatant from FL BM-DCS $(A, C, E)$ and GM BM-DCs $(B, D, F)$. $5 x$ or $50 x$ indicates dilution factor of supernatant. Data represent the mean \pm SEM of three or four independent experiments. $* *=P$ $\varangle 0.01$ and $*=\mathrm{P} \varangle 0.05$ versus control.

Stimulation of GM BM-DCs with poly(I:C), and to a lesser extent R-848 and LPS, also induced an antiviral effect in our HSV-1 infection assay. However, RT-qPCR 62 
results demonstrated that the expression of IFN $\beta$ mRNA in GM BM-DC is low and not significantly enhanced after stimulation with the respective TLR ligands (figure $5 B$ ). Despite the low IFN $\beta$ mRNA expression, the antiviral effect of the LPS and R848 could be inhibited by the IFN $\beta$ neutralizing antibody (figure $6 B, D, F)$. The neutralizing effect in poly(l:C)-stimulated GM BM-DCs was less pronounced compared to the effect observed with poly(l:C)-stimulated $\mathrm{FL}$ BM-DCs. This suggests that other cytokines than IFN $\beta$ may be important in mediating the antiviral effects of poly $(I: C)$.

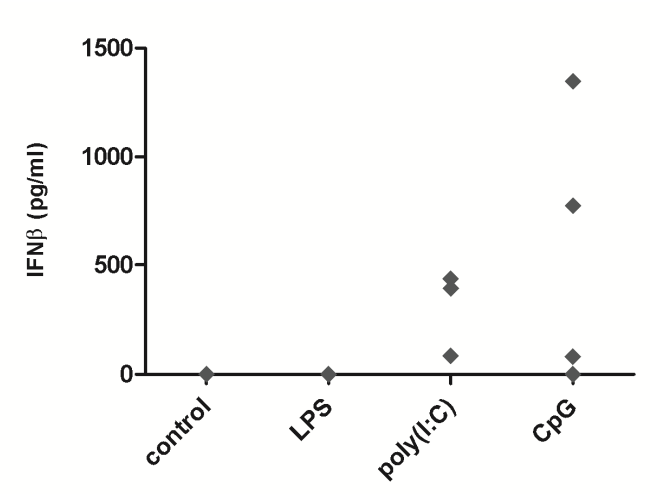

Figure 7. Variable IFN $\beta$ production in supernatant of TLR-stimulated FL BMDCs. IFN $\beta$ was measured in the supernatant from stimulated BM-DCs by ELISA. Symbols indicate FL BM-DC supernatant from individual mice $(n=4)$.

These expression analyses and neutralization assays suggest that especially in FL BM-DCs, IFN $\beta$ is the key cytokine in the TLR-mediated antiviral effect. These results were confirmed by an IFN $\beta$ ELISA, which showed exclusive production of IFN $\beta$ by FL BM-DCs stimulated with poly(I:C) or CpG (1 $\mu \mathrm{M})$ (figure 7) while the IFN $\beta$ production in all other samples was below the detection limit (15.6 $\mathrm{pg} / \mathrm{ml}$, data not shown).

\section{Effect of poly(l:C) on L929 cells}

Of all the TLR ligands tested, poly(l:C) was the most potent inhibitor of HSV-1 replication. This antiviral effect seems DC-independent as similar effects were observed when $L 929$ cells were stimulated directly by poly(l:C) $18 \mathrm{~h}$ before infection. In contrast to stimulation of both subsets of BM-DCs, stimulation of L929 cells by poly $(\mathrm{l}: \mathrm{C})$ did not induce significant expression of IFN $\beta$ mRNA (figure 8A). Moreover, the direct antiviral effect of poly(l:C) on $L 929$ could only be partially prevented by the IFN $\beta$ neutralizing antibodies (figure 8B), 
suggesting that the antiviral effects of poly $(\mathrm{I}: \mathrm{C})$ on these cells are probably mediated by additional IFNs or other antiviral compounds.

A

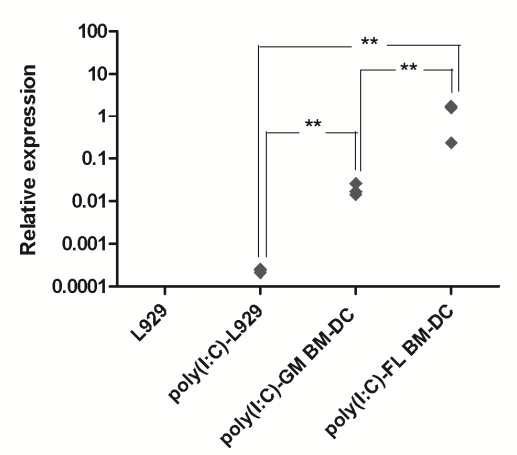

B

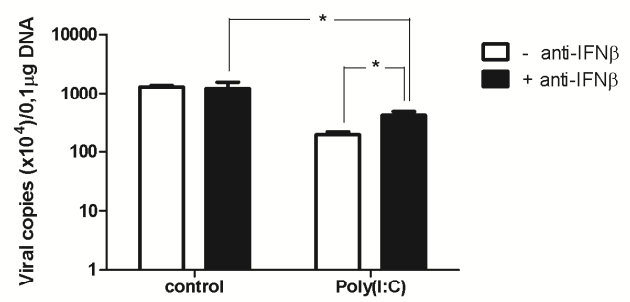

Figure 8. Limited role for IFN $\beta$ in poly(I:C) stimulated L929 cells. (A) IFN $\beta$ expression in L929 cells after poly $(\mathrm{I}: \mathrm{C})$ stimulation compared to expression in poly(l:C)-stimulated BM-DCs IFN is displayed as relative expression compared to GAPDH values. Symbols indicate individual experiments with $L 929$ cells or BM-DCs from individual mice $(n=3)$. (B) IFN $\beta$ neutralisation from supernatant of poly(I:C) stimulated $L 929$ cells. Data represent the mean \pm SEM of three independent experiments. ${ }^{*}=\mathrm{P} \varangle 0.01$ and $*=\mathrm{P} \varangle 0.05$ versus control

\section{Discussion}

Although it is well recognized that certain TLR ligands are able to stimulate the release of type I IFN e.g. by DC, their real antiviral potential has been studied less extensively. In this study we demonstrated that stimulation of both $\mathrm{pDC}$ as CDC with different TLR ligands (in particular CpG and Poly $(I: C)$ ) indeed inhibits viral infection. We also demonstrated that in this setting not IFN $\alpha$, but IFN $\beta$ is the most important type I IFN, although we cannot exclude that other IFNs contribute to the TLR-mediated antiviral effects. Interestingly, the TLR3 ligand poly $(I: C)$ showed the most pronounced antiviral effect, which was even maintained in the absence of DCs.

Although both DC subtypes are involved in the antiviral response, it has been shown that primarily the stimulation of the pDC via either TLR7 or TLR9 induces the release of massive amounts of type I IFNs, which is crucial for the initiation of an adequate immune response ${ }^{30-32}$. Whether this indeed results in an adequate antiviral response has been studied less extensively. Here we 64 
demonstrate that stimulation of the FL BM-DC culture with the TLR9 ligand CPG produces an antiviral "cocktail" which markedly inhibited HSV-1 infection of $L 929$ cells. The high mRNA expression of TLR9 (figure 9A) in the FL BM-DCs strengthens the observation that the CpG-dependent antiviral effect is mediated through stimulation of TLR9. Although TLR9 mRNA could also be detected in GM BM-DCs, CpG stimulation of this cell population seems inadequate to inhibit HSV-1 infection. These results are in line with previous data demonstrating that in particular pDCs respond to CpG via TLR9 resulting in the release of high amounts of type I IFN 23, 33, 34 .

Although earlier studies demonstrated immunomodulating effects and IFNa production by R848-stimulated pDCs ${ }^{23,26,35}$, we did not observe significant antiviral effect when FL BM-DCs were stimulated with the TLR7 agonist R848. Also, no or only little evidence was found for the production of type I IFN despite the fact that significant amounts of TLR7 mRNA could be detected in the cell cultures (figure 9B). The reason for this discrepancy is not entirely clear, but could be due to the fact that others have used pDC-enriched cell populations ${ }^{23,26,35}$, while differentiation of murine bone marrow cells with Flt$3 \mathrm{~L}$ results in a mixed population of predominantly pDCs, but also CDCs ${ }^{25,36,37}$. Also, there might be a species difference as most studies demonstrating the release of massive amounts of type I IFN have used human pDCs. Furthermore, our data are in line with Kim et al. who used a similar method to differentiate immature murine BM cells and also found little evidence for type I IFN production by R848-stimulated FL BM-DC ${ }^{38}$. Overall, these data suggest that, at least in mice, the antiviral potency of TLR7 agonists seems limited.

Protective effects of intranasal LPS administration have previously been shown in a mouse model of HSV-1 encephalitis ${ }^{39}$. Here, we also demonstrate a significant antiviral effect of supernatants from both LPS-stimulated FL and GM BM-DC cultures, which corresponds with the presence of TLR4 mRNA in both cell cultures (figure 9C). However, this protective effect was limited compared to the antiviral effect of $\mathrm{CpG}$ stimulation. Despite this observed antiviral effect of LPS, in vivo LPS treatment usually results in the release of pro-inflammatory cytokines. Therefore, despite the observed antiviral effects the therapeutic use of this TLR ligand as an antiviral drug will be limited.

Regarding the TLR3 ligand poly $(l: C)$, the supernatants of both poly(l:C)stimulated FL and GM BM-DC cultures impressively limited HSV-1 infection 
demonstrating that this dsRNA mimic is clearly a strong inducer of antiviral responses. Interestingly, poly $(\mathrm{l}: \mathrm{C})$ also strongly inhibited HSV-1 infection when directly added to L929 cells. However, in L929 cells the mRNA expression of TLR3, the receptor for poly(l:C), is very low compared to BM-DCs (figure 9D).

This indicates that the stimulation of $L 929$ cells by poly(l:C) is probably not exclusively a TLR3-mediated event but may rely on activation of cytoplasmic receptors. Indeed, melanoma-differentiation-associated gene 5 (MDA5) has been shown to be a receptor for poly(I:C) and is present in most cells ${ }^{10,18,40,41}$.

A

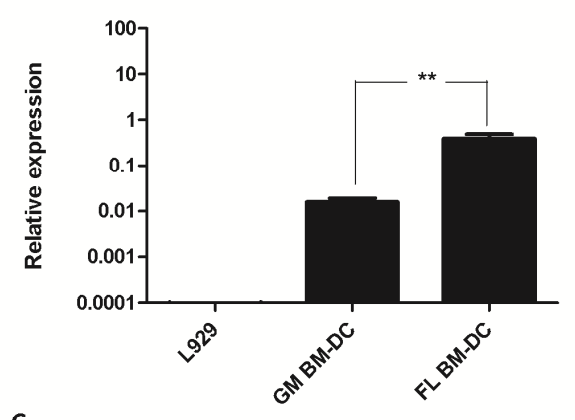

C

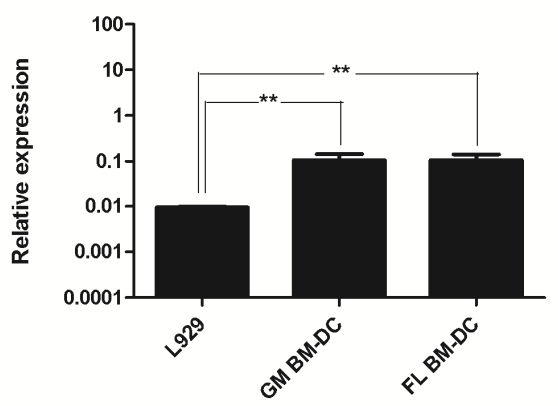

B

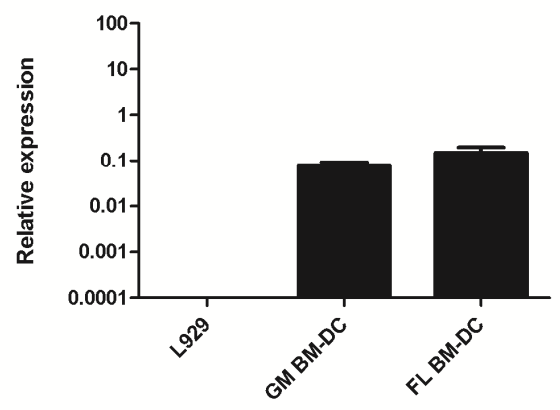

D

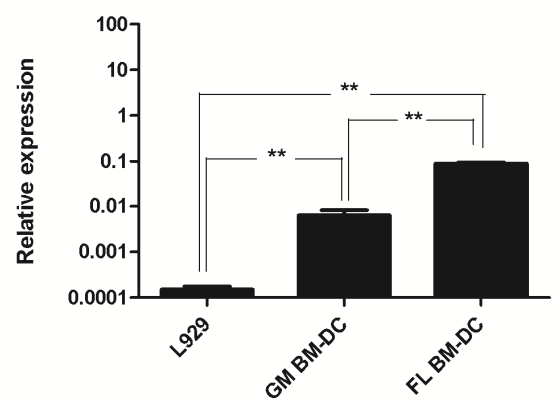

Figure 9. Differential TLR mRNA expression in the different cell types. Expression of TLR9 (A), TLR7 (B), TLR4 (C) and TLR3 (D). TLRs are displayed as relative expression compared to GAPDH values. The figure shows mean values $H$ - SEM. Data represent the mean $H$ - SEM of three independent experiments. ${ }^{* *}=\mathrm{P} \varangle 0.01$ and $*=\mathrm{P} \varangle 0.05$ versus control.

Additional experiments have to confirm whether MDA5 acts as a receptor for poly $(\mathrm{I}: \mathrm{C})$ in $\mathrm{L} 929$ cells, but our results show that poly(l:C) might be a promising future antiviral drug. This is supported by recent data showing that prophylactic treatment with poly $(\mathrm{I}: \mathrm{C})$ provides a high level of protection against challenge with different viruses ${ }^{39,42,43}$. 
Surprisingly, the TLR-mediated antiviral effects were basically IFN $\beta$ independent. Usually this IFN subtype is one of the first IFNs produced following a viral infection ${ }^{17,29}$. However, we were unable to detect significant amounts IFN $\alpha 4$ mRNA in any of the cell cultures and this observation was supported by neutralization assays using an IFN $\beta$ antibody. In contrast, we found high levels of both IFN $\beta$ mRNA and protein in TLR-stimulated FL BM-DC cell cultures while the antiviral effects of these TLR ligands were almost completely abolished with an IFN $\beta$ neutralizing antibody. This strongly suggests that the antiviral effect induced by stimulation of FL BM-DCs with TLR ligands largely depends on the production of IFN $\beta$.

Alternatively, recent data demonstrated that GM BM-DCs are less able to produce IFN $\beta^{44}$ in response to various TLR ligands. Also in our hands TLR stimulation did not markedly enhance the expression of IFN $\beta$ mRNA in GM BM DCs. M oreover, the antiviral effect of TLR-stimulated GM BM-DC supernatants could only partially be blocked by the IFN $\beta$ antibody, suggesting that other pathways also contribute significantly to the observed antiviral effects. Interestingly, Lauterbach et al ${ }^{45}$ recently demonstrated that $C D C$ in response to poly(I:C) release large amounts of IFN- $\lambda$ (a type III IFN), a recently identified new member of IFN family with potent antiviral effects against a variety of viruses including HSV- ${ }^{46}$.

Also the DC-independent antiviral effects of poly(I:C) seem to rely only partially on IFN $\beta$ Stimulation of $L 929$ cells with poly $(I: C)$ only marginally increased the expression of IFN $\beta$ mRNA and the neutralization assay confirmed that the protective effect was indeed not entirely due to IFN $\beta$. Nevertheless, a strong antiviral effect was observed when $L 929$ cells were stimulated with this TLR ligand. Future experiments are mandatory to further unravel whether type III IFNs also contribute to this DC-independent effect of poly $(\mathrm{I}: \mathrm{C})$ or whether other molecular pathways are involved.

In conclusion, in this study we have demonstrated that certain TLR ligands (e.g CpG) do have a strong DC-dependent antiviral capacity. In particular the presence of pDCs strongly enhances the antiviral effects of the TLR ligands. Interestingly, we found that IFNa seems dispensable for the TLR-induced antiviral effects and that IFN $\beta$ might be more important than IFN $\alpha$. Moreover, we demonstrated a strong antiviral effect of the dsRNA mimic poly(I:C), which did not require the presence of DCS and may involve other IFNs than type I 
IFNs. In particular type III IFNs, which have recently been shown to have a prominent role against e.g. respiratory infections, might be engaged. This opens attractive opportunities for the use of such dsRNA mimics as prophylactic antiviral therapies e.g. for COPD patients who suffer frequently from acute exacerbations related to respiratory viral infections.

\section{Acknowledgment}

We thank Maikel Breuer for technical assistance.

\section{References}

1. Sadler, A. J., and B. R. Williams. 2008. Interferon-inducible antiviral effectors. Nat Rev Immunol 8: 559-568.

2. Borden, E. C., G. C. Sen, G. Uze, et al. 2007. Interferons at age 50: past, current and future impact on biomedicine. Nat Rev Drug Discov 6: 975-990.

3. Fitzgerald-Bocarsly, P., and D. Feng. 2007. The role of type I interferon production by dendritic cells in host defense. Biochimie 89: 843-855.

4. Der, S. D., A. Zhou, B. R. Williams, et al. 1998. Identification of genes differentially regulated by interferon alpha, beta, or gamma using oligonucleotide arrays. Proc Natl Acad Sci U SA 95: 15623-15628.

5. Sulkowski, M. S., C. Cooper, B. Hunyady, et al. 2011. Management of adverse effects of Peg-IFN and ribavirin therapy for hepatitis C. Nat Rev Gastroenterol Hepatol 8: 212223.

6. Rustgi, V. K. 2010. Safety of small molecules in combination with interferon-based therapy for hepatitis C virus. Expert Opin Drug Saf 9: 883-892.

7. McHutchison, J. G., E. J. Lawitz, M. L. Shiffman, et al. 2009. Peginterferon alfa-2b or alfa-2a with ribavirin for treatment of hepatitis Cinfection. N Engl J M ed 361: 580-593.

8. Bowie, A. G., and L. Unterholzner. 2008. Viral evasion and subversion of patternrecognition receptor signalling. Nat Rev Immunol 8: 911-922.

9. Trinchieri, G., and A. Sher. 2007. Cooperation of Toll-like receptor signals in innate immune defence. Nat Rev Immunol 7: 179-190.

10. Kato, H., O. Takeuchi, S. Sato, et al. 2006. Differential roles of MDA5 and RIG-I helicases in the recognition of RNA viruses. Nature 441: 101-105.

11. Katze, M. G., J. L. Fornek, R. E. Palermo, et al. 2008. Innate immune modulation by RNA viruses: emerging insights from functional genomics. Nat Rev Immunol 8: 644-654.

12. Haller, O., G. Kochs, and F. Weber. 2006. The interferon response circuit: induction and suppression by pathogenic viruses. Virology 344: 119-130. 
13. Ito, T., H. Kanzler, O. Duramad, et al. 2006. Specialization, kinetics, and repertoire of type 1 interferon responses by human plasmacytoid predendritic cells. Blood 107: 2423-2431.

14. Fitzgerald-Bocarsly, P., J. Dai, and S. Singh. 2008. Plasmacytoid dendritic cells and type I IFN: 50 years of convergent history. Cytokine Growth Factor Rev 19: 3-19.

15. Barchet, W., M. Cella, and M. Colonna. 2005. Plasmacytoid dendritic cells--virus experts of innate immunity. Semin Immunol 17: 253-261.

16. Blasius, A. L, and B. Beutler. Intracellular toll-like receptors. Immunity 32: 305-315.

17. Baig, E., and E. N. Fish. 2008. Distinct signature type I interferon responses are determined by the infecting virus and the target cell. Antivir Ther 13: 409-422.

18. Kawai, T., and S. Akira. 2010. The role of pattern-recognition receptors in innate immunity: update on Toll-like receptors. Nat Immunol 11: 373-384.

19. Kurt-Jones, E. A., L. Popova, L. Kwinn, et al. 2000. Pattern recognition receptors TLR4 and CD14 mediate response to respiratory syncytial virus. Nat Immunol 1: 398-401.

20. Kurt-Jones, E. A., M. Chan, S. Zhou, et al. 2004. Herpes simplex virus 1 interaction with Toll-like receptor 2 contributes to lethal encephalitis. Proc Natl Acad Sci U S A 101: 1315-1320.

21. Compton, T., E. A. Kurt-Jones, K. W. Boehme, et al. 2003. Human cytomegalovirus activates inflammatory cytokine responses via CD14 and Toll-like receptor 2. J Virol 77: 4588-4596.

22. Yoneyama, M., and T. Fujita. 2009. RNA recognition and signal transduction by RIG-Ilike receptors. Immunol Rev 227: 54-65.

23. Lore, K., M. R. Betts, J. M. Brenchley, et al. 2003. Toll-like receptor ligands modulate dendritic cells to augment cytomegalovirus- and HIV-1-specific T cell responses. J Immunol 171: 4320-4328.

24. Gautier, G., M. Humbert, F. Deauvieau, et al. 2005. A type I interferon autocrineparacrine loop is involved in Toll-like receptor-induced interleukin-12p70 secretion by dendritic cells. J Exp M ed 201: 1435-1446.

25. Brawand, P., D. R. Fitzpatrick, B. W. Greenfield, et al. 2002. Murine plasmacytoid predendritic cells generated from Flt3 ligand-supplemented bone marrow cultures are immature APCs. J Immunol 169: 6711-6719.

26. Gibson, S. J., J. M. Lindh, T. R. Riter, et al. 2002. Plasmacytoid dendritic cells produce cytokines and mature in response to the TLR7 agonists, imiquimod and resiquimod. Cell Immunol 218: 74-86.

27. Coccia, E. M., M. Severa, E. Giacomini, et al. 2004. Viral infection and Toll-like receptor agonists induce a differential expression of type I and lambda interferons in human plasmacytoid and monocyte-derived dendritic cells. Eur J Immunol 34: 796-805.

28. Schmittgen, T. D., and K. J. Livak. 2008. Analyzing real-time PCR data by the comparative C(T) method. Nat Protoc 3: 1101-1108.

29. Katze, M. G., Y. He, and M. Gale, Jr. 2002. Viruses and interferon: a fight for supremacy. Nat Rev Immunol 2: 675-687. 
30. Ito, T., Y. H. Wang, and Y. J. Liu. 2005. Plasmacytoid dendritic cell precursors/type I interferon-producing cells sense viral infection by Toll-like receptor (TLR) 7 and TLR9. Springer Semin Immunopathol 26: 221-229.

31. Cao, W., and Y. J. Liu. 2007. Innate immune functions of plasmacytoid dendritic cells. Curr Opin Immunol 19: 24-30.

32. Liu, Y. J. 2005. IPC: professional type 1 interferon-producing cells and plasmacytoid dendritic cell precursors. Annu Rev Immunol 23: 275-306.

33. Krug, A., S. Rothenfusser, V. Hornung, et al. 2001. Identification of CpG oligonucleotide sequences with high induction of IFN-alpha/beta in plasmacytoid dendritic cells. Eur J Immunol 31: 2154-2163.

34. Guiducci, C., G. Ott, J. H. Chan, et al. 2006. Properties regulating the nature of the plasmacytoid dendritic cell response to Toll-like receptor 9 activation. J Exp M ed 203: 1999-2008.

35. Hemmi, H., T. Kaisho, O. Takeuchi, et al. 2002. Small anti-viral compounds activate immune cells via the TLR7 M yD88-dependent signaling pathway. Nat Immunol 3: 196200.

36. Gilliet, M., A. Boonstra, C. Paturel, et al. 2002. The development of murine plasmacytoid dendritic cell precursors is differentially regulated by FLT3-ligand and granulocyte/macrophage colony-stimulating factor. J Exp M ed 195: 953-958.

37. Yasuda, K., C. Richez, M. B. Uccellini, et al. 2009. Requirement for DNA CpG content in TLR9-dependent dendritic cell activation induced by DNA-containing immune complexes. J Immunol 183: 3109-3117.

38. Kim, T. W., K. Staschke, K. Bulek, et al. 2007. A critical role for IRAK4 kinase activity in Toll-like receptor-mediated innate immunity. J Exp M ed 204: 1025-1036.

39. Boivin, N., Y. Sergerie, S. Rivest, et al. 2008. Effect of pretreatment with toll-like receptor agonists in a mouse model of herpes simplex virus type 1 encephalitis. J Infect Dis 198: 664-672.

40. Wilkins, C., and M. Gale, Jr. 2010. Recognition of viruses by cytoplasmic sensors. Curr Opin Immunol 22: 41-47.

41. Gitlin, L., W. Barchet, S. Gilfillan, et al. 2006. Essential role of mda-5 in type I IFN responses to polyriboinosinic:polyribocytidylic acid and encephalomyocarditis picornavirus. Proc Natl Acad Sci U SA 103: 8459-8464.

42. Wong, J. P., M. E. Christopher, S. Viswanathan, et al. 2009. Activation of toll-like receptor signaling pathway for protection against influenza virus infection. Vaccine 27: 3481-3483.

43. Gill, N., P. M. Deacon, B. Lichty, et al. 2006. Induction of innate immunity against herpes simplex virus type 2 infection via local delivery of Toll-like receptor ligands correlates with beta interferon production. J Virol 80: 9943-9950.

44. Schmitz, F., A. Heit, S. Guggemoos, et al. 2007. Interferon-regulatory-factor 1 controls Toll-like receptor 9-mediated IFN-beta production in myeloid dendritic cells. Eur J Immunol 37: 315-327. 
CpG and poly(I:C) stimulation limits HSV-1 infection

45. Lauterbach, H., B. Bathke, S. Gilles, et al. 2010. Mouse CD8alpha+ DCs and human BDCA3+DCs are major producers of IFN-lambda in response to poly IC. J Exp M ed 207: 2703-2717.

46. Li, J., S. Hu, L. Zhou, et al. 2011. Interferon lambda inhibits herpes simplex virus type I infection of human astrocytes and neurons. Glia 59: 58-67. 



\section{Chapter 4}

\section{Lactobacilli limit herpes simplex virus Type 1 infection through stimulation of a dendritic cell-dependent antiviral mechanism}

Giel R Gaajetaan, Tanja H Geelen, Johan Garssen, Belinda van't Land, Gert E Grauls, Cathrien A Bruggeman, Frank R Stassen

Manuscript in preparation 


\section{Abstract}

Dendritic cells (DCs) are the main producers of the antiviral type I interferons (IFNs) after engagement of their toll-like receptors (TLRs). The administration of type I IFNs and synthetic ligands for TLRs on DCs can induce protection against viral infections. In this in vitro study we investigated if specific probiotics, which are live bacteria with immunomodulatory properties, can also induce antiviral effects via stimulation of DCs. For this, we differentiated mouse bone marrow (BM) cells into plasmacytoid and conventional DCs (pDCs and CDCs) and stimulated them with specific probiotic strains (Bifidobacterium breve, Lactobacillus rhamnosus and casei). Afterwards, we tested the antiviral properties of the collected supernatants in an in vitro herpes simplex virus type 1 (HSV-1) infection model. We observed a significant reduction in HSV-1 infection when a mixed $\mathrm{pDC} / \mathrm{CDC}$ population was stimulated with the Lactobacillus rhamnosus or the Lactobacillus casei but not the Bifidobacterium breve in the concentration tested. In contrast, no antiviral effect was observed when only CDCs were stimulated with the probiotic strains. The observed antiviral effect after lactobacilli stimulation of the mixed $\mathrm{pDC} / \mathrm{CDC}$ population correlates with high IFN $\beta$ mRNA expression levels. These data demonstrated that lactobacilli not only have immunomodulatory properties but also induce strong antiviral effects when pDCs are present. 


\section{Introduction}

Type I interferons (IFNs) are the first antiviral cytokines produced by various cells during viral infection to limit replication and dissemination of the virus. These type I IFNs (IFN $\alpha / \beta)$ stimulate the interferon receptor (IFNAR), present on almost all cells, which results in the expression of many so-called interferon-stimulated genes (ISGs) ${ }^{1,2}$. After ISG activation, cells acquire an antiviral state and thereby hinder viral replication and dissemination. In addition, dendritic cells (DCs) are activated and stimulate $B$ and T-cells to eradicate the virus or virally-infected cells, respectively ${ }^{1,3-5}$. Therefore, type I IFNs are the main orchestrators of the immune response towards viral infections.

After recognition of viral components using toll-like receptors (TLRS), DCs and plasmacytoid DCs (pDCs) in particular are able to produce large quantities of these type I IFNs. While conventional DCs (CDCs) mainly sense viruses by TLR3 and cytoplasmic receptors, pDCs use TLR7 and 9 to recognize viral RNA or DNA, respectively ${ }^{6-10}$. As pDCs are relatively unique in their TLR-repertoire and their massive production of type I IFNs, these DCs are indispensable for the immediate antiviral response. Previously we and others have demonstrated that specific TLR-ligands display profound antiviral effects both in vitro and in vivo ${ }^{11-16}$. Also the direct application of type I IFNs has a protective effect against viral infections ${ }^{17-19}$. In addition to the TLR ligands and IFNs, immunomodulating effects have also been attributed to specific probiotic strains $^{20,21}$.

Probiotics is a generalized term usually defining specific live micro-organisms which, when administered in adequate amounts, confer a health benefit on the host through modulation of both mucosal and systemic immune responses. This beneficial effect is usually achieved through colonization of the gastrointestinal tract, thereby preventing infection of the gut by potentially pathogenic bacteria ${ }^{20}$. More recently, also antiviral effects have been attributed to certain probiotic strains. For example, recent studies have shown a positive effect of specific Lactobacillus species in the treatment of rotavirus infections in children ${ }^{22}{ }^{23}$. Moreover, Grabryszewski and colleagues demonstrated that priming of the respiratory mucosa with specific 
Lactobacillus species markedly protected mice from the lethal sequelae of a severe respiratory virus infection, which was probably due to markedly diminished inflammatory responses upon a viral challenge ${ }^{24}$.

Alternatively, bacterial strains have the capacity to stimulate dendritic cells resulting in the release of different cytokines (including IFN $\beta$ ) depending on the species or strains used ${ }^{25}$. However, it remains to be determined whether stimulation of DC subsets with different bacterial strains is sufficient to limit viral replication. Therefore, we investigated the antiviral activity of specific Lactobacillus rhamnosus, Lactobacillus casei and Bifidobacterium breve strains in an in vitro bioassay model as described previously ${ }^{12}$. Furthermore, we analyzed which DC subsets are most important and whether IFNs are involved in the antiviral effect detected.

\section{Materials \& M ethods}

\section{Mice}

Bone marrow was derived from male BALB/c mice (Charles River, 8-14 weeks of age). Mice were euthanized by intraperitoneal injection of Nembutal ${ }^{\circledR}$ $(150 \mathrm{mg} / \mathrm{kg}$, Sanofi Sante B.V. Maassluis, the Netherlands). The study was approved by the ethical committee for animal experiments of the Maastricht University.

\section{Isolation and differentiation of bone marrow cells}

Bone marrow (BM) cells were isolated as described previously ${ }^{12}$. BM cells were cultured in 24-well tissue culture plates (Becton Dickinson, NJ, USA) at $10^{6}$ cells/ml in RPMI 1640 medium (Invitrogen, Grand Island, NY, USA) with 10\% FCS (Lonza, Verviers, Belgium). The medium was supplemented with either 200 $\mathrm{ng} / \mathrm{ml}$ human Flt-3L or $20 \mathrm{ng} / \mathrm{ml}$ GM-CSF (both from Miltenyi Biotec, Leiden, the Netherlands) for differentiation into a mixed culture of pDCs and CDCs or a monoculture of CDCs only, respectively. When GM-CSF was used, the medium was refreshed 3 and 6 days after seeding the cells in the plates. Cells were 
allowed to differentiate for 8 days at $37^{\circ} \mathrm{C}$ and $5 \% \mathrm{CO}_{2}$ before stimulation with specific bacterial strains was started.

\section{Bacterial fermentation and enumeration}

Two different Lactobacillus strains (NumRes1 and DN-114 001) and a Bifidobacterium strain (NumRes204) were grown at $37^{\circ} \mathrm{C}$ in a $400 \mathrm{ml}$ reactor containing MRS supplemented with $0.5 \mathrm{~g} / \mathrm{l} \mathrm{L}$-cysteine for bifidobacteria. The $\mathrm{pH}$ was maintained at 6.5 by addition of $\mathrm{NaOH}$. To ensure anaerobic conditions the headspace was flushed with $\mathrm{N}_{2}$ or a gas mixture consisting of $5 \% \mathrm{H}_{2}, 5 \%$ $\mathrm{CO}_{2}$ and $90 \% \mathrm{~N}_{2}$ for bifidobacteria. Bacteria were harvested in the early stationary phase, washed in PBS and stored with glycerol $20 \%$ (w/v), in aliquots at $-80^{\circ} \mathrm{C}$. Cell counts were determined by plating serial dilutions (CFU) and fluorescent microscopy by staining with DAPI.

\section{Stimulation of DCs}

At day 8 , the medium of the DCs was removed and replaced with medium containing $150 \mu \mathrm{g} / \mathrm{ml}$ gentamycin (Eurovet, Bladel, the Netherlands) and one of the bacterial strains $\left(10^{7}\right.$ bacteria/ml). Differentiated BM cells were stimulated with Lactobacillus rhamonusus (L. rhamnosus), Bifidobacterium breve (B. breve) or Lactobacillus casei (L. casei) for $24 \mathrm{~h}$ at $37^{\circ} \mathrm{C}$ and $5 \% \mathrm{CO}_{2}$. Afterwards, cells were snap-frozen in liquid nitrogen and stored at $-80^{\circ} \mathrm{C}$ for future gene expression analysis. Supernatants of the stimulated DCs were stored at $-80^{\circ} \mathrm{C}$ until further use.

\section{Cells and virus}

L929 cells (CCL-1, ATCC) (Rockville, MD, USA) were cultured in Earle's Minimal essential medium (EMEM) (Invitrogen) supplemented with non-essential amino acids (MP Biomedicals, Solon, Ohio, USA), L-glutamine $(2 \mathrm{mmol} / \mathrm{L})$, sodium pyruvate $(1 \mathrm{mmol} / \mathrm{L}$ ) and $10 \%$ FCS (Lonza). Cells were allowed to grow in $\mathrm{T} 75$ flasks at $37^{\circ} \mathrm{C}$ and $5 \% \mathrm{CO}_{2}$.

HSV-1 was obtained from ATCC (VR-539) and was propagated in Vero cells (ATCC CCL-81) in EMEM (Invitrogen) with 2\% FCS (Lonza), non-essential amino 
acids (MP Biomedicals), L-glutamine $(2 \mathrm{mmol} / \mathrm{L})$ and sodium pyruvate (1mmol/L). When $100 \%$ cytopathogenic effect (CPE) was achieved, cell debris was removed by centrifugation and viral titres in the supernatant were determined by plaque assay.

\section{Stimulation and infection protocol}

The antiviral potency of the conditioned media were tested in a bioassay as described previously ${ }^{12}$. Briefly, $L 929$ cells were exposed to the conditioned media for $18 \mathrm{~h}$. After removal, cells were infected with HSV-1 (MOI 0.1), harvested $30 \mathrm{~h}$ post infection (p.i.), snap-frozen in liquid nitrogen and stored at $-80^{\circ} \mathrm{C}$ for DNA isolation. The supernatant was stored at $-80^{\circ} \mathrm{C}$ until being used for cytopathogenic effect (CPE) test.

\section{Quantitative PCR (qPCR)}

DNA was extracted from frozen cell pellets according to the Wizard ${ }^{\circledR}$ Genomic DNA Purification Kit (Promega Benelux B.V. Leiden, the Netherlands) according to the manufacturer's instructions. DNA purity and quantity were measured with the Nanondrop ${ }^{\circledR} N D-1000$. The DNA isolates were amplified in a volume of $25 \mu$ containing $5 \mu \mathrm{l} \mathrm{HOT} \mathrm{FIREPol}{ }^{\circledR}$ EvaGreen ${ }^{\circledR}$ qPCR mix plus (Solis BioDyne, Tartu, Estonia), HSV-1 forward and reverse primer, and DNA sample. HSV-1 was detected by using a MyiQ Single-Color Real-Time PCR Detection System (Bio-Rad, Hercules, CA, USA). Thermal cycling was started with UNG activation for $2 \mathrm{~min}$ at $50^{\circ} \mathrm{C}$, followed by HotStarTaq activation during $15 \mathrm{~min}$ at $95^{\circ} \mathrm{C}$. Subsequently, 40 cycles of amplification were run consisting of $15 \mathrm{~s}$ at $95^{\circ} \mathrm{C}$ (denaturation) and $1 \mathrm{~min}$ at $60^{\circ} \mathrm{C}$ (annealing and attaching).

To determine the actual number of HSV-1 DNA copies, a DNA standard curve was used. Dilutions were made from a plasmid, which contains the HSV-1 PCRtarget sequence. Used concentrations ranged from $10^{7}$ to $10^{0}$ copies, with a dilution factor of 10. Copy numbers were quantified by the standard curve using the $\mathrm{iQ}^{\mathrm{TM}} 5$ version 2.0 Optical System Software. 


\section{RT-qPCR}

RNA was isolated from frozen cell pellets with the RNeasy kit (Qiagen, Hilden, Germany) according to the manufacturer's instructions. Remaining DNA was removed by DNAse treatment (Turbo DNA-free ${ }^{T M}$ kit, Ambion, Austin, TX, USA). Subsequently, RNA was reverse transcribed into cDNA using the iScript CDNA Synthesis Kit (Bio-Rad). qPCR was performed as described above. Primer sets used are listed in table 1. To control for DNA contamination, in every PCR run a sample was included which was not reverse transcribed. Relative expressions were determined by using the $2^{-\Delta \mathrm{Ct}}$, normalized to GAPDH values. All samples were measured in duplicate.

Table 1. Primers used for DNA and mRNA expression analysis

\begin{tabular}{lll}
\hline Gene & & Primers sequences $\left(5^{\prime}-3^{\prime}\right)$ \\
\hline HSV-1 & forward & TTCTCGTCCTYACYGCCTCCC \\
& reverse & GCAGGCACACGTAACGCACGCT \\
mIFNa4 & forward & CAGGCACAGAGGCTGTGTTCTT \\
& reverse & TGCTGGCTGTGAGGACATACT \\
mIFN $\beta$ & forward & ATGAGTGGTGGTTGCAGGC \\
mGAPDH & reverse & TGACCTTCAAATGCAGTAGATTCA \\
& forward & CATTGTGGAGGGCTCATGA \\
& reverse & GCCCCACGGCCATCA \\
\hline
\end{tabular}

$\mathrm{m}=$ mouse

\section{CPE test}

To determine the presence of infectious HSV-1 particles, collected supernatant from infected $L 929$ cells ( $2 x, 4 x$ and $8 x$ diluted) was added to Vero cells (ATCC $\mathrm{CCL}-81$ ) grown until being confluent in 24 -well plates. After $48 \mathrm{~h}$ incubation at $37^{\circ} \mathrm{C}$ and $5 \% \mathrm{CO}_{2}$, CPE was visualized by staining and fixation with $0.13 \%$ crystal violet in $5 \%$ formaldehyde. 


\section{Statistical analysis}

Statistical analysis was carried out in SPSS 18.0. The Mann-Whitney $U$ test was used to analyse differences between groups. Values of $p \leq 0.05$ were considered statistically significant.

\section{Results}

Supernatant of lactobacilli-stimulated DCs limits viral infection of L929 cells

HSV-1 infection of $L 929$ cells could be inhibited significantly when cells were pre-treated for $18 \mathrm{~h}$ with conditioned supernatants collected from FIt-3L (FL) BM-DC cultures, which had been stimulated prior with both lactobacilli strains for $24 \mathrm{~h}$ (figure 1A). In contrast, when FL BM-DC were treated with the Bifidobacterium strain, no antiviral effects were observed in the bioassay. Remarkably, when GM-CSF (GM) BM-DCs were stimulated with the bacterial strains, no significant reduction in viral copies was observed (figure 1B).

A

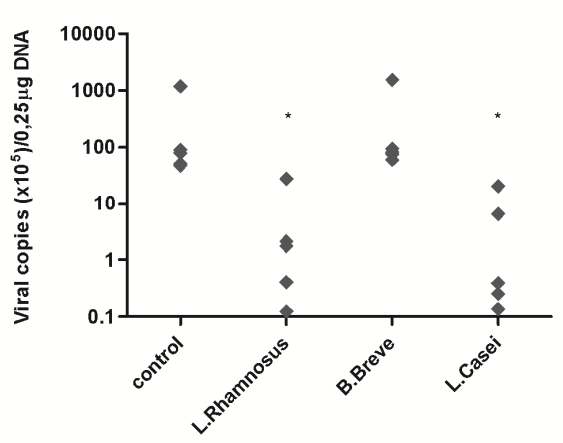

B

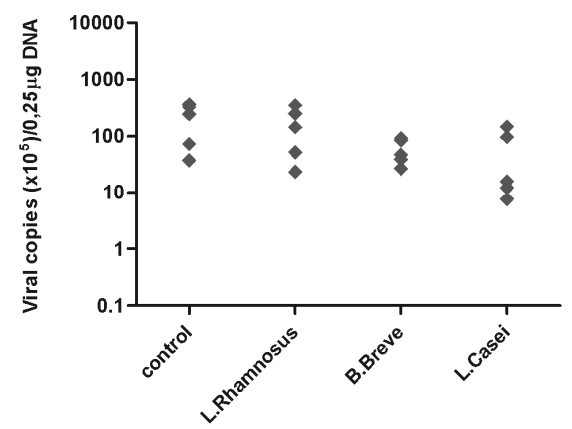

Figure 1. Viral copy numbers after BM-DC stimulation with probiotics. Antiviral properties of the supernatants, derived from bacterial stimulation of FL BM-DCs (A) or GM BM-DCs (B) stimulated with different strains, on $L 929$ cells subsequently infected with HSV-1. Symbols indicate BM-DC supernatant from individual mice $(n=5)$. Viral copies were determined by qPCR. $*=\mathrm{P} \leq 0.05$ versus control.

To control for possible antiviral effects because of bacteria still present in the supernatant of stimulated DCs, all strains were administered directly to L929 cells for $18 \mathrm{~h}$. However, direct application of all strains had no antiviral effect 80 
at all, demonstrating that the observed antiviral effect was clearly DC dependent (figure 2).

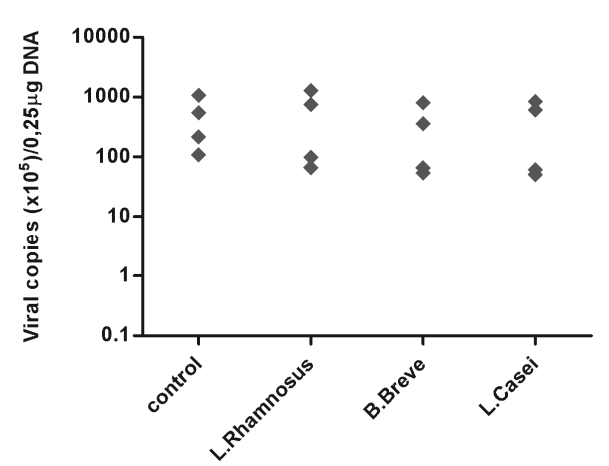

Figure 2. Viral copy number after direct stimulation of $\mathbf{L 9 2 9}$ cells with bacteria. All bacteria were administered directly to $\mathbf{L 9 2 9}$ cells for $18 \mathrm{~h}$. Symbols indicate independent experiments $(n=4)$. Viral copies were determined by $q P C R$.

In addition to the DNA-levels, we also investigated if the bacterial strains were able to reduce the formation of infectious virus particles. Therefore, Vero cells were exposed to supernatants collected from infected L929 cells, which had been treated prior with different conditioned media from DC cultures. In agreement with the reduced viral DNA copies, the observed CPE in the Vero cells was also significantly diminished when cells were treated with supernatants from $L 929$ cells pre-treated with conditioned media from lactobacilli-treated FL BM-DCs (figure 3B). In contrast, stimulation of FL BMDCs with B.breve was not sufficient to prevent the formation of infectious particles in the bioassay. Moreover, and also in concert with the viral DNA levels found in $L 929$ cells, the antiviral effect was absent after GM BM-DC stimulation. L.casei exposure resulted in reduced viral DNA copies in some, but not all trials and the degree of CPE was also variable between trials (figure $3 \mathrm{C}$ and D). Also, stimulation of GM BM-DCs with either L.rhamnosus or B.breve was not sufficient to limit CPE. Direct stimulation of 2929 cells (figure 3E) did not confer any reduction of CPE.

Overall, these data imply that stimulation of FL BM-DCs, but not GM BM-DCs, with the two Lactobacillus strains resulted in a pronounced antiviral effect, while B.breve-dependent effects were practically absent. 
A

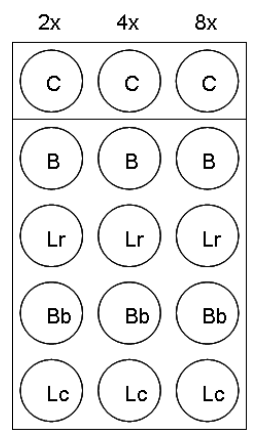

B

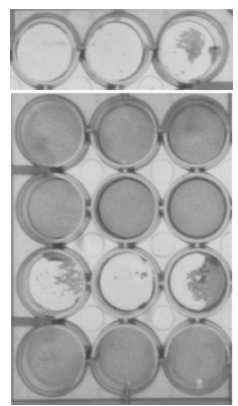

C

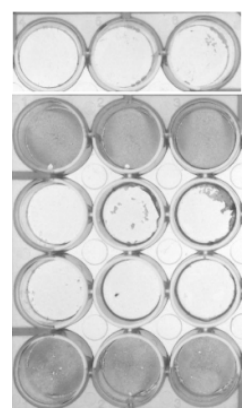

D

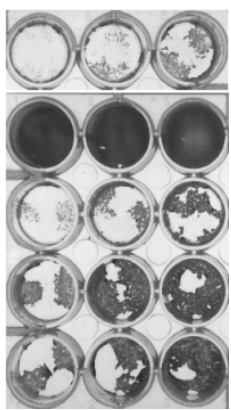

$\mathbf{E}$

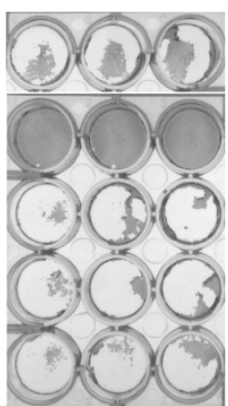

Figure 3. Effect of bacterial co-culture on production of infectious virus particles. Vero cells were exposed to supernatant from infected L929 cells after stimulation with supernatant from DCs prior stimulated with different strains. Schematic figure (A) representing the different samples and dilutions on the culture plate. Viral solutions obtained from $L 929$ cells stimulated with supernatant from FL BM-DCs (B), GM BM-DCs (C and D) and directly stimulated L929 cells (E) show various degrees of $C P E$. Figures are representative of $4-5$ independent experiments. $C=$ control, $\mathrm{B}=\mathrm{Blank}, \mathrm{Lr}=\mathrm{L}$.rhamnosus, $\mathrm{Bb}=\mathrm{B}$. breve and $\mathrm{LC}=\mathrm{L}$.casei.

IFNB is associated with the antiviral effects following Lactobacilli-stimulation of FLBM-DCS

Next, we investigated whether IFN $\beta$ is required for the induction of the antiviral effects. Normally, both high levels of IFN $\beta$ as well as IFN $\alpha$ are produced after viral infection which exerts potent antiviral effects. Since stimulation of BM-DCs with the two Lactobacillus strains resulted in clear antiviral effects, we determined the mRNA levels of IFN $\beta$ in the stimulated BM $D C s$. As expected, the IFN $\beta$-levels were significantly increased when FL BM-DCs were exposed to either the Lactobacillus strains (figure 4A). The IFN $\beta$ mRNA expression after B.breve stimulation of FL BM-DCs was also increased (nonsignificant), but levels were significantly lower compared to Lactobacillusinduced IFN $\beta$ mRNA expression and, as demonstrated above, insufficient to reduce viral copy numbers or CPE. No significant increase in IFN $\beta$ mRNA was detected in GM BM-DCs or $L 929$ cells following stimulation with either of the bacterial strains tested (figure $4 \mathrm{~B}$ and 5 , respectively). 
A

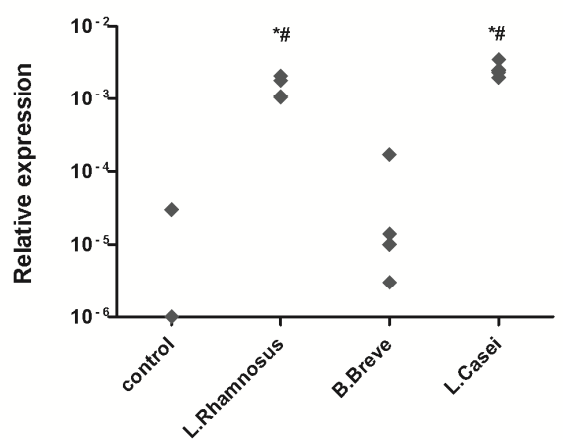

B

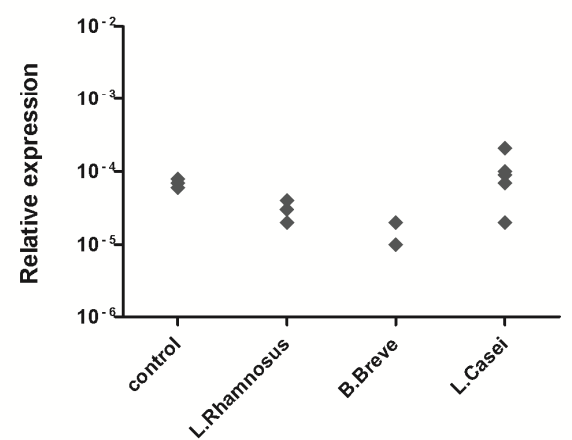

Figure 4. IFN $\beta$ expression in BM-DC subsets stimulated with different probiotics. IFN $\beta$ expression in FL BM-DCS (A) and GM BM-DCs (B). IFN $\beta$ is displayed as relative expression compared to GAPDH values. Symbols indicate BM-DCs from individual mice $(n=5)$. * $=P \leq 0.05$ versus control. \#=P $\leq 0.05$ of Lactobacillus versus Bifidobacterium.

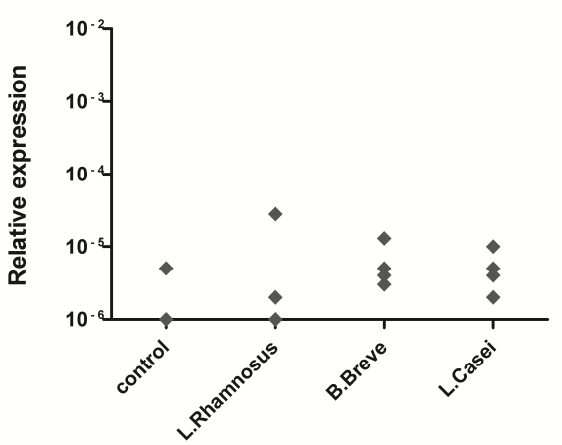

Figure 5. IFN $\beta$ expression in L929 cells stimulated with different probiotics. IFN $\beta$ expression in $\mathbf{L 9 2 9}$ cells. IFN is displayed as relative expression compared to GAPDH values. Symbols indicate independent experiments $(n=5)$.

Next to IFN $\beta$, also the IFN $\alpha 4$ subtype belongs to the primary IFN responders in mice ${ }^{26}$. However, IFN $\alpha 4$ mRNA levels, which are barely detectable under basal conditions, remained extremely low after bacterial stimulation of FL BM-DCS (with all three strains; data not shown).

\section{Discussion}

In this study we demonstrated that specific bacterial strains can stimulate antiviral immunity. The pronounced antiviral effects were only observed when a mixed population of pDCs and cDCs was exposed to the lactobacilli strains. 
On the other hand, stimulation with the specific Bifidobacterium breve strain remains without any effect in the concentration tested. Moreover, we showed that this antiviral effect was associated with high IFN $\beta$ mRNA levels.

In general, probiotic bacteria are primarily thought to be effective in the gastrointestinal tract by preventing colonization or infection by pathogenic microorganisms. Additionally, the immunomodulatory properties of probiotics are now being more and more recognized. Recent data revealed that certain probiotics trigger the expression of viral defence and may as such have a role in the prevention or treatment of viral infections ${ }^{27,}{ }^{28}$. Yet, additional studies are required to compare the antiviral potency of specific strains and how this is mediated.

Bacteria interact with TLRs and other pattern recognition receptors (PRRs) on DCs, which results in the activation of the immune system ${ }^{21,29-31}$. Since DCs are the central players in the antiviral response, we initially tested whether exposure of these cells to three different bacterial strains resulted in any antiviral effect. Interestingly, both lactobacilli induced strong antiviral effects in contrast to the Bifidobacterium strain, an effect that is most likely mediated by high IFN $\beta$ levels. Such variability in immunomodulating properties of different probiotics has also been reported recently by Weiss and colleagues ${ }^{25}$. In an elaborate study, they tested the capacity of 27 lactobacilli and 16 bifidobacteria strains to stimulate the release of different cytokines by GM BM-DC. They demonstrated that certain Lactobacillus strains are well able to stimulate the release of IFN $\beta$ and other inflammatory cytokines by BM-DC, whilst other strains lacked this capacity. In the present paper we demonstrate a similar phenomenon as stimulation of GM BM-DC with L.casei revealed in some trials in an antiviral effect while this effect was virtually absent when cells were stimulated with L.rhamnosus. Moreover, in our study as well as in the study by Weiss, less IFN $\beta$ was found when GM BM-DCs were stimulated with any of the bifidobacteria (non-significant).

In the study by Weiss mentioned above, only GM BM-DCs were used. Here, we demonstrated that the antiviral effect of lactobacilli is strongly enhanced when pDCs were present in the cell culture. pDCs are the principal producers of large amounts of type I IFN. Thus, pDCs probably recognize specific components of lactobacilli which results in the production of IFN $\beta$. In a previous study, we observed a pronounced antiviral effect when FL BM-DCs were stimulated with 84 
unmethylated $\mathrm{CpG}$ oligodeoxynucleotides (CPG ODNs) ${ }^{12}$, a well-recognized TLR9 ligand. This was only observed in the FL BM-DC subset, but not in the GM $B M-D C$ subset and the antiviral effect was also IFN $\beta$-dependent. In the present study a similar difference was observed when the two DC subsets were stimulated with the probiotics. This suggests that the antiviral effects are most likely TLR9 mediated, which is supported by the fact that unmethylated CpG motifs are also widely present in bacteria ${ }^{6,10,20,32}$. Thus, the intracellular TLR9 might be the receptor engaged in pDCs after phagocytosis of the lactobacilli. This is supported by recent data from Plantinga et al, who demonstrated that the same lactobacilli strains as used the present study, indeed stimulated primary immune cells through TLR9 ${ }^{33}$. Remarkably, although TLR9 is also present in $\mathrm{CDCS}^{34-36}$, this does not seem to result in protection against viral infection ${ }^{12}$ and it has been speculated that in these cells TLR9 might be primarily involved in immune responses towards fungal pathogens ${ }^{34-36}$. Alternatively, other studies have shown the involvement of different TLRs or intracellular receptors in the immunomodulating effects of probiotics and further research is required to unravel the molecular pathways which are implicated in the observed antiviral effects.

Overall, combining the observed pronounced antiviral effects with the nonpathogenic nature of probiotics, a possible role for probiotics and lactobacilli in particular, as therapeutic or prophylactic agents in viral disease seems plausible. In vivo studies already showed protective effects against respiratory viruses in mice intranasally exposed to lactobacilli ${ }^{24,37}$. Nevertheless, further studies are warranted to establish the role of the respiratory mucosa in the detection of lactobacilli and the effect of this species against (respiratory) viruses in human trials.

\section{Acknowledgements}

This work was funded by the Dutch Top Institute Pharma (grant D1.101-0). We thank the microbiology team of Jan Knol for their input and supply of bacteria. 


\section{References}

1. Gaajetaan, G. R., C. A. Bruggeman, and F. R. Stassen. 2011. The type I interferon response during viral infections: a "SWOT" analysis. Rev M ed Virol.

2. Sadler, A. J., and B. R. Williams. 2008. Interferon-inducible antiviral effectors. Nat Rev Immunol 8: 559-568.

3. Fitzgerald-Bocarsly, P., J. Dai, and S. Singh. 2008. Plasmacytoid dendritic cells and type I IFN: 50 years of convergent history. Cytokine Growth Factor Rev 19: 3-19.

4. Fitzgerald-Bocarsly, P., and D. Feng. 2007. The role of type I interferon production by dendritic cells in host defense. Biochimie 89: 843-855.

5. Seo, Y. J., and B. Hahm. 2010. Type I interferon modulates the battle of host immune system against viruses. Adv Appl Microbiol 73: 83-101.

6. Barchet, W., M. Cella, and M. Colonna. 2005. Plasmacytoid dendritic cells--virus experts of innate immunity. Semin Immunol 17: 253-261.

7. Lande, R., and M. Gilliet. 2010. Plasmacytoid dendritic cells: key players in the initiation and regulation of immune responses. Ann N Y Acad Sci 1183: 89-103.

8. Bauer, S., T. Muller, and S. Hamm. 2009. Pattern recognition by Toll-like receptors. Adv Exp Med Biol 653: 15-34.

9. Ito, T., Y. H. Wang, and Y. J. Liu. 2005. Plasmacytoid dendritic cell precursors/type I interferon-producing cells sense viral infection by Toll-like receptor (TLR) 7 and TLR9. Springer Semin Immunopathol 26: 221-229.

10. Kawai, T., and S. Akira. 2010. The role of pattern-recognition receptors in innate immunity: update on Toll-like receptors. Nat Immunol 11: 373-384.

11. Boivin, N., Y. Sergerie, S. Rivest, et al. 2008. Effect of pretreatment with toll-like receptor agonists in a mouse model of herpes simplex virus type 1 encephalitis. J Infect Dis 198: 664-672.

12. Gaajetaan, G. R., T. H. Geelen, G. E. Grauls, et al. 2012. CpG and poly(l:C) stimulation of dendritic cells and fibroblasts limits herpes simplex virus type 1 infection in an IFNbeta-dependent and -independent way. Antiviral Res 93: 39-47.

13. Hammerbeck, D. M., G. R. Burleson, C. J. Schuller, et al. 2007. Administration of a dual toll-like receptor 7 and toll-like receptor 8 agonist protects against influenza in rats. Antiviral Res 73: 1-11.

14. Horsmans, Y., T. Berg, J. P. Desager, et al. 2005. Isatoribine, an agonist of TLR7, reduces plasma virus concentration in chronic hepatitis Cinfection. Hepatology 42: 724-731.

15. Ashkar, A. A., X. D. Yao, N. Gill, et al. 2004. Toll-like receptor (TLR)-3, but not TLR4, agonist protects against genital herpes infection in the absence of inflammation seen with CpG DNA. J Infect Dis 190: 1841-1849.

16. Liang, Z., S. Wu, Y. Li, et al. 2011. Activation of Toll-like receptor 3 impairs the dengue virus serotype 2 replication through induction of IFN-beta in cultured hepatoma cells. PLOSONE 6: e23346.

17. Cakebread, J. A., Y. Xu, C. Grainge, et al. 2011. Exogenous IFN-beta has antiviral and anti-inflammatory properties in primary bronchial epithelial cells from asthmatic subjects exposed to rhinovirus. J Allergy Clin Immunol 127: 1148-1154 e1149. 
18. Gao, L., S. Yu, Q. Chen, et al. 2010. A randomized controlled trial of low-dose recombinant human interferons alpha-2b nasal spray to prevent acute viral respiratory infections in military recruits. Vaccine 28: 4445-4451.

19. Simon, H. U., H. Seelbach, R. Ehmann, et al. 2003. Clinical and immunological effects of low-dose IFN-alpha treatment in patients with corticosteroid-resistant asthma. Allergy 58: $1250-1255$.

20. Borchers, A. T., C. Selmi, F. J. Meyers, et al. 2009. Probiotics and immunity. J Gastroenterol 44: 26-46.

21. Vaarala, 0. 2003. Immunological effects of probiotics with special reference to lactobacilli. Clin Exp Allergy 33: 1634-1640.

22. Fang, S. B., H. C. Lee, J. J. Hu, et al. 2009. Dose-dependent effect of Lactobacillus rhamnosus on quantitative reduction of faecal rotavirus shedding in children. J Trop Pediatr 55: 297-301.

23. Szajewska, H., M. Wanke, and B. Patro. 2011. Meta-analysis: the effects of Lactobacillus rhamnosus GG supplementation for the prevention of healthcareassociated diarrhoea in children. Aliment Pharmacol Ther 34: 1079-1087.

24. Gabryszewski, S. J., O. Bachar, K. D. Dyer, et al. 2011. Lactobacillus-mediated priming of the respiratory mucosa protects against lethal pneumovirus infection. J Immunol 186: 1151-1161.

25. Weiss, G., H. R. Christensen, L. H. Zeuthen, et al. 2011. Lactobacilli and bifidobacteria induce differential interferon-beta profiles in dendritic cells. Cytokine 56: 520-530.

26. Baig, E., and E. N. Fish. 2008. Distinct signature type I interferon responses are determined by the infecting virus and the target cell. Antivir Ther 13: 409-422.

27. Maragkoudakis, P. A., W. Chingwaru, L. Gradisnik, et al. 2010. Lactic acid bacteria efficiently protect human and animal intestinal epithelial and immune cells from enteric virus infection. Int J Food Microbiol 141 Suppl 1: S91-97.

28. Pant, N., H. Marcotte, H. Brussow, et al. 2007. Effective prophylaxis against rotavirus diarrhea using a combination of Lactobacillus rhamnosus GG and antibodies. BMC Microbiol 7: 86.

29. Christensen, H. R., H. Frokiaer, and J. J. Pestka. 2002. Lactobacilli differentially modulate expression of cytokines and maturation surface markers in murine dendritic cells. J Immunol 168: 171-178.

30. Weiss, G., S. Rasmussen, L. H. Zeuthen, et al. 2010. Lactobacillus acidophilus induces virus immune defence genes in murine dendritic cells by a Toll-like receptor-2dependent mechanism. Immunology 131: 268-281.

31. Zeuthen, L. H., H. R. Christensen, and H. Frokiaer. 2006. Lactic acid bacteria inducing a weak interleukin-12 and tumor necrosis factor alpha response in human dendritic cells inhibit strongly stimulating lactic acid bacteria but act synergistically with gramnegative bacteria. Clin Vaccine Immunol 13: 365-375.

32. Albiger, B., S. Dahlberg, A. Sandgren, et al. 2007. Toll-like receptor 9 acts at an early stage in host defence against pneumococcal infection. Cell Microbiol 9: 633-644.

33. Plantinga, T. S., W. W. van Maren, J. van Bergenhenegouwen, et al. 2011. Differential Toll-like receptor recognition and induction of cytokine profile by Bifidobacterium breve and Lactobacillus strains of probiotics. Clin Vaccine Immunol 18: 621-628. 
34. Miyazato, A., K. Nakamura, N. Yamamoto, et al. 2009. Toll-like receptor 9-dependent activation of myeloid dendritic cells by Deoxynucleic acids from Candida albicans. Infect Immun 77: 3056-3064.

35. Xiao, G., A. Miyazato, Y. Abe, et al. 2010. Activation of myeloid dendritic cells by deoxynucleic acids from Cordyceps sinensis via a Toll-like receptor 9-dependent pathway. Cell Immunol 263: 241-250.

36. Tanaka, M., K. Ishii, Y. Nakamura, et al. 2012. Toll-Like Receptor 9-Dependent Activation of Bone Marrow-Derived Dendritic Cells by URA5 DNA from Cryptococcus neoformans. Infect Immun 80: 778-786.

37. Youn, H. N., D. H. Lee, Y. N. Lee, et al. 2012. Intranasal administration of live Lactobacillus species facilitates protection against influenza virus infection in mice. Antiviral Res 93: 138-143. 


\section{Chapter}

\section{The effects of a specific mixture of oligosaccharides on a systemic infection with cytomegalovirus in mice}

Giel R Gaajetaan, Belinda van 't land, Arjan P Vos, Gert E Grauls, Johan Garssen, Cathrien A Bruggeman, Frank R Stassen

Manuscript in preparation 


\section{Abstract}

Dietary supplementation with a specific prebiotic mixture of oligosaccharides has been shown to modulate systemic vaccination responses. This prompted us to evaluate the effects of a specific prebiotic mixture on a systemic viral infection, using a murine model for cytomegalovirus infection.

C57BL/6J mice received a regular diet or a diet containing a mixture of prebiotics 2 weeks prior to infection and were then infected with mouse cytomegalovirus (MCMV). The prebiotic diet contained $2 \%(\mathrm{w} / \mathrm{w})$ of a specific mixture of short-chain galactooligosaccharides (scGOS), long-chain fructooligosaccharides (ICFOS) and pectin-derived acidic oligosaccharides (pAOS). The viral load at $36 \mathrm{~h}$ post infection was measured in several organs using qPCR. Macrophage influx in the liver after infection was analysed by immunostaining. To investigate effects on immunity, we used FACS analysis to determine activation and percentages of various immune cells in spleen and mesenteric lymph nodes (MLNs). In addition, plasma IFNa levels were analysed by ELISA.

The organs of the prebiotic group and the control group showed comparable MCMV copy numbers $36 \mathrm{~h}$ post infection. Additionally, the influx of macrophages was not different between the two groups. There were also no significant immunomodulating or antiviral effects observed after supplementation with prebiotics as IFNa levels were not increased and no major differences in percentages or activation of immune cells were detected. In conclusion, this study shows that dietary supplementation with a specific prebiotic oligosaccharide mixture has no protective or immunomodulating effect on the course of a systemic M CMV infection in C57BL/6J mice. 


\section{Introduction}

The gut microbiome is not only essential to prevent colonisation by pathogenic microbes, it is also crucial for the modulation of various immune responses. For example, stimulating the growth of certain bacteria within the gut (e.g. with specific prebiotic carbohydrates) may increase resistance to viral infections ${ }^{1,2}$. Prebiotic carbohydrates are non-digestible food ingredients which stimulate the growth of beneficial bacteria, such as lactobacilli and bifidobacteria ${ }^{3}$, and have therefore (indirect) immunomodulatory properties. Local intestinal effects have been shown such as modulation of cytokine production and increased B-cell cellularity in Peyer's patches, as well as enhanced intestinal IgA secretion ${ }^{4-7}$. Recently, dietary supplementation of human immune deficiency (HIV)-infected individuals with a prebiotic oligosaccharide mixture resulted in an improvement of the gut microbiota composition exemplified by an increase in the number of bifidobacteria while pathogenic Clostridium levels were decreased. Additionally, an increased activity of natural killer (NK) cells was observed ${ }^{8}$. Systemic effects have been reported also. Buddington and coworkers ${ }^{9}$ demonstrated that dietary fructans increased the resistance to bacterial infections in mice. Interestingly, a specific mixture of short-chain galacto-oligosaccharides (scGOS), long-chain fructooligosaccharides (ICFOS) and pectin-derived acidic oligosaccharides (pAOS) enhanced systemic, vaccine-specific delayed-type hypersensitivity (DTH) responses in C57BL/6J mice ${ }^{10,11}$, suggesting a role for this prebiotic mixture in the antiviral defence. Indeed, prebiotic administration reduced intestinal and, possibly, respiratory infections in healthy infants during the first year of age ${ }^{12}$. These data prompted us to evaluate the antiviral and immunomodulatory effects of this prebiotic mixture during a systemic viral infection, using a mouse model for cytomegalovirus infection.

Cytomegalovirus (CMV) is a species-specific member of the $\beta$-herpes virus family. Primary infection occurs most frequently during childhood or adolescence. In the immune competent host, infection is usually associated with no or only mild clinical symptoms. After clearance of the primary infection, the virus remains latent with episodes of endogenous reactivation. However, in immune-compromised hosts, primary infection or reactivation of 
CMV can lead to disease manifestations like pneumonia, gastrointestinal disease, hepatitis, or retinitis ${ }^{13,14}$.

M urine CMV (MCMV) infection resembles CMV infection in humans to a large extent and is often used as an animal model for human infections ${ }^{13}$. The primary infection results in the activation of plasmacytoid dendritic cells (pDCs) which subsequently produce large amounts of type I IFN (IFN $\alpha / \beta)^{15-17}$. The type I IFN is essential for orchestration of antiviral responses and in concert with IL-12, produced by conventional DCs (CDCs), promotes NK cell activation, proliferation and cytotoxicity ${ }^{18-21}$. During the initial response to $\mathrm{CMV}$, the CDCS are also required to initiate acquired immune responses ${ }^{22}$.

In this study, we investigated the effects of dietary supplementation with a specific prebiotic mixture of oligosaccharides on the course of a MCMV infection as well as the possible modulation of the antiviral response by this prebiotic mixture.

\section{Materials and Methods}

\section{Mice}

Eight-week-old male specific pathogen-free (spf) C57BL/6J mice were obtained from Charles River Laboratories and housed under standard housing conditions with a $12 \mathrm{~h}$ dark and light cycle. All animals had free access to tap water and the control or supplemented semi-purified AIN-93G diet (Research Diet Services, Wijk bij Duurstede, The Netherlands). The study protocol was reviewed and approved by the Animal Experimental Committee of the University of M aastricht.

\section{Virus stocks and infection}

The MCMV (Smith strain) stock used for inoculation was prepared by homogenization of salivary glands isolated from C57BL/ 6 that had both been infected with $5 \times 10^{3}$ plaque-forming units (PFU) of MCMV 3 weeks before sacrifice. Titration of the M CM V stock was determined by plaque assay. 


\section{Nutrition}

Semi-purified AIN-93G diet contains approximately 40\% cornstarch, 13\% dextrinized cornstarch, $10 \%$ sucrose and $5 \%$ cellulose, adding up to a total carbohydrate content of $68 \%$. In the supplemented diets, $2 \%$ of the oligosaccharide mixture was exchanged for the same weight of total carbohydrates in the diet. The oligosaccharide mixture consisted for $50 \%$ of a combination of scGOS and ICFOS (ScGOS/ICFOS) and for $50 \%$ of pAOS. The mixture was blended with the AIN-93G diet and pressed into pellets. scGOS/IcFOS is a spray-dried powder mix of trans-Galactooligosaccharides (Vivinal GOS, Borculo Domo, Zwolle, the Netherlands) and IcFOS (Raftlinine HP, Orafti, Wijchen, The Netherlands), in a 9:1 ratio. It consists of approximately 51\% GOS and FOS oligosaccharides, 19\% maltodextrin, 16\% lactose and 14\% glucose. pAOS contains partially unsaturated and partially methylated galacturonic acids (kindly provided by Südzucker AG, Mannheim, Germany). It consists of approximately $75 \%$ multimeric pectin-derived sugar molecules, $10 \%$ monomeric sugars, and $15 \%$ of ash and other components.

\section{Infection protocol and tissue collection}

C57BL/6J mice were infected by intra-peritoneal injection with $5 \times 10^{3}$ PFU MCMV and sacrificed at $36 \mathrm{~h}$ post infection ( $\mathrm{n}=12$ per group). Dietary supplementation was started two weeks prior to infection and continued throughout the experiment. Prior to sacrifice, mice were anaesthetized using pentobarbital (Nembutal ${ }^{\circledR}$, Sanofi Sante B.V. Maassluis, the Netherlands) and blood was collected by left ventricular puncture. After anaesthesia, the arterial tree was perfused with PBS $+1 \%$ DEPc via a catheter introduced into the apex. Subsequently, spleen, lung, liver, heart and intestine were removed and stored directly at $-80^{\circ} \mathrm{C}$ for DNA extraction or snap-frozen in isopentane and stored at $-80^{\circ} \mathrm{C}$ until histological analysis (liver). M LNs and parts of the spleen were used for generation of a single cell suspension and subsequent staining for flow cytometry analysis. 


\section{DNA qPCR}

DNA was isolated from all organs using the Wizard genomic DNA purification kit (Promega Benelux B.V., Leiden, the Netherlands) according to the manufacturer. DNA purity and quantity were measured with the Nanondrop ${ }^{\circledR}$ ND-1000. MCMV genome copy numbers were measured using a MyiQ SingleColor Real-Time PCR Detection System (Bio-Rad). DNA was amplified in a volume of $25 \mu \mathrm{l}$ containing $12,5 \mu \mathrm{IIQ}{ }^{\mathrm{TM}}$ supermix (Bio-rad), primers and probes for the detection of MCMV and DNA sample $(10 \mu \mathrm{l})$. Primers and probe were based on the MCMV glycoprotein B sequence (forward primer 5'AGGGCTTGGAGAGGACCTACA-3', reverse primer 5'GCCC GTCGGCAGTCTAGTC$3^{\prime}$ and probe 5'-AGCTAGACGACAGCCAACGCAACGA-3'). The probe carried a 5'TAM reporter and a 3'TAMRA quencher group. The PCR reaction was performed by the TaqMan protocol. This means that thermal cycling started with uracil-N-glycosylase (UNG) activation for $2 \mathrm{~min}$ at $50^{\circ} \mathrm{C}$, followed by HotStarTaq activation during $15 \mathrm{~min}$ at $95^{\circ} \mathrm{C}$. Subsequently, 40 cycles of amplification were run consisting of $15 \mathrm{~s}$ at $95^{\circ} \mathrm{C}$ (denaturation) and $1 \mathrm{~min}$ at $60^{\circ} \mathrm{C}$ (annealing and attaching). To determine the actual number of MCMV DNA copies, a DNA standard curve was used. Serial dilutions were made from a plasmid, which contains the MCM V gB-target sequence. The standard curve ranged from $10^{6}$ to $10^{0}$ copies, with a dilution factor of 10 . Copy numbers were quantified by the standard curve using the $\mathrm{M}_{\mathrm{yiQ}}{ }^{\mathrm{TM}}$ Optical System Software. All samples were measured in duplicate.

\section{Plasma IFNa analysis}

An enzyme-linked immunosorbent assay (ELISA; PBL Biomedical Laboratories, $\mathrm{NJ}$, USA) with sensitivity range $10-500 \mathrm{pg} / \mathrm{ml}$ was used to detect IFNa in the plasma.

\section{Immunohistochemical detection of macrophages}

Four $\mu \mathrm{m}$ thick liver sections were stained with biotin-labeled rat anti-mouse CD68 (1/50 in PBS $+0.05 \%$ BSA; Serotec) antibody for $30 \mathrm{~min}$ at room temperature. Subsequently, slides were incubated with strept-ABComplex/HRP 
(Dako) for $30 \mathrm{~min}$ at room temperature. Afterwards, diaminobenzidin (DAB) solution was added for $10 \mathrm{~min}$. Finally, slides were counterstained with hematoxylin and analysed microscopically.

\section{Single cell suspension, antibodies and flow cytometry analysis}

A single cell suspension was obtained after passing spleens through a $70 \mu \mathrm{m}$ cell strainer. Afterward, red blood cells were lysed and splenocytes were cultured at $10^{6}$ cells $/ \mathrm{ml}$ in 96 - wells point-bottom plates. Cells were washed in PBS $+1 \%$ BSA and stained with antibodies for phenotypic analysis. Antibodies used were mPDCA-1-PE and Ly6C-FITC (Miltenyi Biotec, Germany) for pDC detection, NK1.1-PerCP and CD69-PE (BD bioscience) for NK-cell activation and CD11b-PE, CD4-FITC, CD8 $\alpha$-PerCP and CD11C-APC (BD Pharmingen) for CDC detection. Nonspecific antibody binding was examined by staining cells with fluorochrome-labeled isotype-matched normal mouse IgGs. Stained cells were analysed by a FACSort flow cytometer (BD Biosciences).

\section{Statistical analysis}

The Student's t-test was used to analyse differences between control and the prebiotics group. Values of $p \leq 0.05$ were considered statistically significant. Data are expressed as mean \pm SEM , unless stated otherwise.

\section{RESULTS}

No differences in viral load between control and prebiotic groups

Two weeks prior to infection, the C57BL/6J mice received a control diet or a diet containing the specific prebiotic mixture of oligosaccharides, which was continued throughout the experiment. MCMV copy numbers were measured at $36 \mathrm{~h}$ p.i. in various organs using a MCMV specific qPCR (figure $1 A-E$ ). High MCM V copy numbers were detected in spleen and liver (figure 1A-B), while low copy numbers were found in heart, lung and intestine (figure $1 \mathrm{C}-\mathrm{E}$ ). No significant differences in copy numbers were observed between the individual 
organs of the prebiotic and the control groups, indicating that the prebiotics used in this model did not contribute to the antiviral response.

A

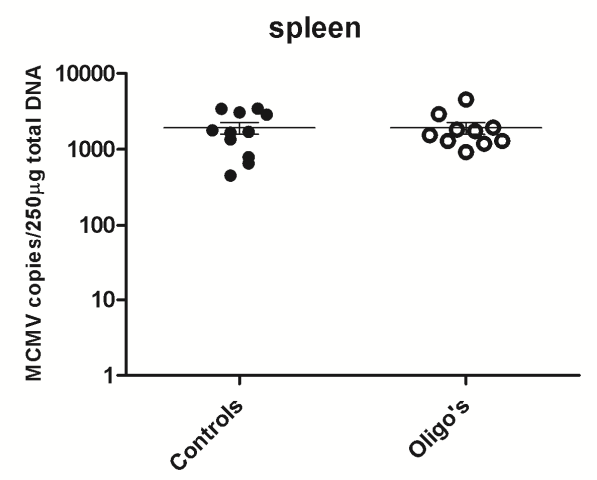

C

heart

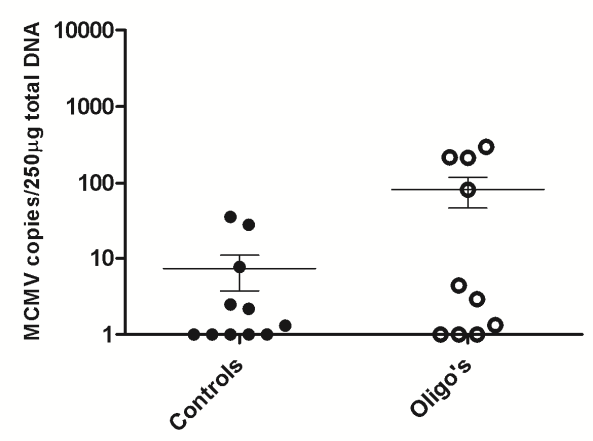

E

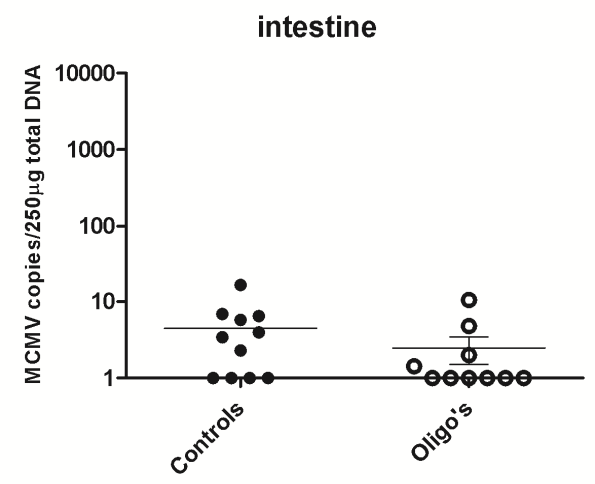

B

liver

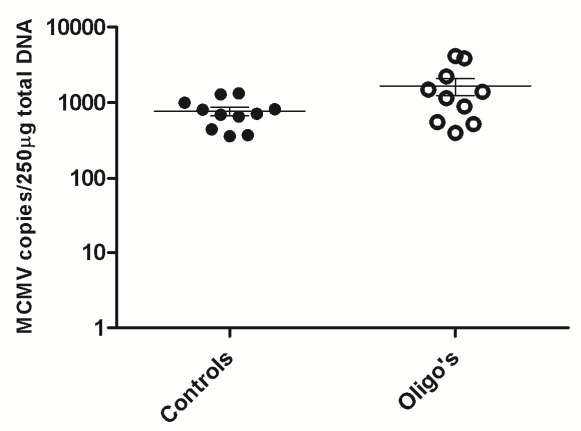

D

Lung

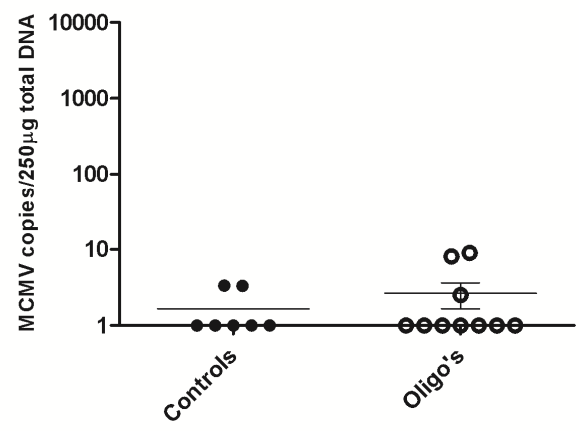

Figure 1. MCMV load in organs of C57BL/6] mice after control or prebiotic diet $(n=10 / 11$ per group). The animals were sacrificed and spleen (A), liver (B), heart (C), lung (D) and intestine (E) were harvested for examination of MCMV copy numbers by qPCR. Viral load is presented as DNA copy numbers per $250 \mu \mathrm{g}$ total DNA. 
No effect of the prebiotic mixture on CM V-induced liver inflammation

Normally, acute MCM V infection results in the accumulation of inflammatory cells (especially macrophages) in the liver. To assess if the prebiotic mixture has an effect on the influx of inflammatory cells in the liver, we analyzed the presence of macrophages in the liver $36 \mathrm{~h}$ after infection. Frozen liver sections were stained with CD68 antibody to detect the presence of macrophages. The liver sections of mice from the control group and the prebiotic group after infection showed comparable levels of CD68+ macrophages (data not shown). Thus, prebiotics did not stimulate infiltration of macrophages in the liver.

\section{Plasma levels of IFN- $\alpha$ are not increased in supplemented $C 57 B L / 6 J$ mice}

IFNa is produced by pDCs and infected cells and is essential in the antiviral defence. During acute MCMV infection, maximum levels of IFN $\alpha$ can be measured at $36 \mathrm{~h}$ after infection $20,23,24$. To determine if the prebiotic diet stimulated IFN $\alpha$ production, we measured the plasma IFN $\alpha$ levels at $36 \mathrm{~h}$ p.i. in all mice. As shown in figure 2, IFNa-levels were not increased in the plasma of mice from the prebiotic group compared to the control group, indicating that IFN $\alpha$ production is not stimulated by the prebiotics.

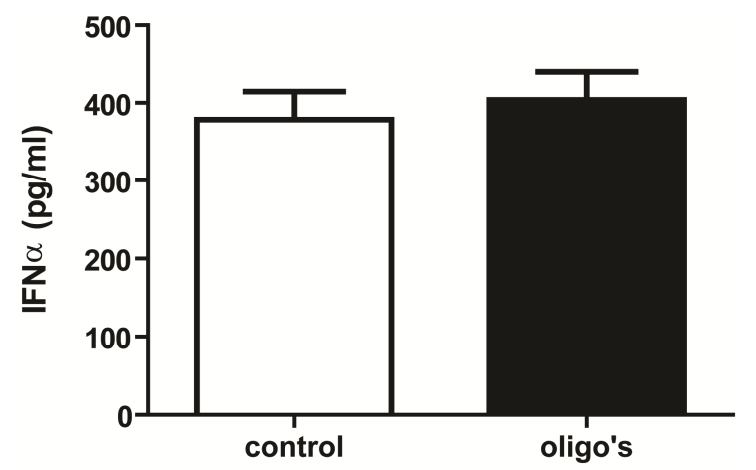

Figure 2. IFNa levels in plasma of MCMV-infected mice. Plasma IFNa samples from mice in control and prebiotic group were taken at $36 \mathrm{~h}$ p.i.. Data are presented as means per group \pm SEM.

Prebiotic supplementation does not result in augmented antiviral responses

To investigate whether mice from the prebiotic group displayed an augmented innate immune response towards MCMV, we analysed the presence of cells involved in the early phase of antiviral immunity. As pDCs are the orchestrators 
of the antiviral response, we used flow cytometry to determine if the pDC population in the spleen of mice on the prebiotic diet was elevated after infection compared to the controls. However, no significant differences were observed between the two groups. In addition, no increased proliferation or activation (NK-CD69) of NK cells was observed in the prebiotic group. Finally, CDC markers CD11b and CD8 $\alpha$ were not significantly higher in mice fed the prebiotic diet (figure $3 \mathrm{~A}$ ).

As prebiotics exert their beneficial effects mainly in the intestines where the (probiotic) bacteria reside, we also investigated innate immune cells in the M LNs. Both pDCs and NK cells were not detected in the M LNs of both groups. Interestingly, high levels of two DC groups (CD4+CD11b+ and CD8+CD11b+) were detected in the MLNs which were absent in the spleen. These DCs were however, not elevated in the MLNs of mice on the prebiotic diet (figure 3B). Thus, the prebiotics in this in vivo model have no effect on the various immune cell populations.

A

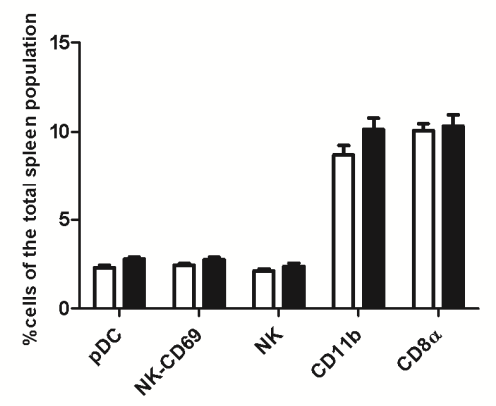

B

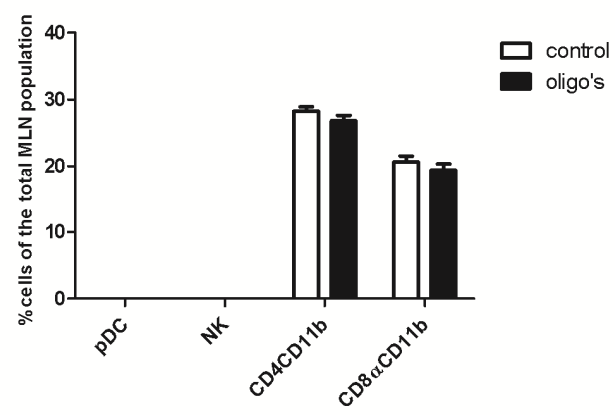

Figure 3. Immune cells in spleen and MLNs of MCMV-infected mice. Innate immune cells involved in antiviral responses were measured in spleen (A) and MLNs (B) by flow cytometry. mPDCA and LY-6C antibodies were used to detect pDCs, NK1.1 and CD69 expression was to determine NK-cell activation and all other cell surface markers were used to determine the presence of certain CDCs. Data are presented as means per group \pm SEM .

\section{DISCUSSION}

Dietary supplementation with specific oligosaccharides has been described to modulate various immune functions, suggesting that their application is able to 
increase resistance to infection ${ }^{25}$. However, the present study demonstrated that dietary supplementation with a specific mixture of oligosaccharides did not improve the antiviral effect towards a $\beta$-herpes virus as the viral loads in several organs were comparable to controls. In addition, the influx of macrophages in the liver, the plasma levels of IFN $\alpha$ and the innate immune cells involved in the initial antiviral response were not increased indicating that the early immune response towards MCMV is not enhanced in C57BL6 mice fed a prebiotic diet.

In this in vivo study, mice were sacrificed $36 \mathrm{~h}$ p.i. when NK-cell activation and plasma levels of IFN $\alpha$ peak ${ }^{18,20,22-24}$. Following primary CMV infection of an adult immunocompetent host, virus replication takes place in various tissues. Likewise, in our hands high M CMV copy numbers were detected in spleen and liver of infected mice, as has been shown previously by others ${ }^{13,26-28}$. However, the viral loads were comparable between the mice from the prebiotic and control group, indicating no protective effect of the prebiotic diet against acute MCMV infection. Normally, viral loads are undetectable or low in lung and heart early in the MCMV infection ${ }^{26}$. Accordingly, at $36 \mathrm{~h} \mathrm{p.i.} \mathrm{viral} \mathrm{loads} \mathrm{in}$ heart and lung were almost undetectable. Viral loads were also low in the intestine. Also at later time points when viral loads are higher, no differences were detected between the two groups (data not shown). This suggests that based on the viral load data, the prebiotic mixture has possibly only minor antiviral effects, which cannot override the immune evasive effects of MCM V 29,30 .

As recent data showed that a specific mixture of oligosaccharides can have immunomodulatory effects ${ }^{11}$, we were interested if this specific mixture also amplified antiviral responses. Normally, high amounts of type I IFNs are produced after acute CMV infection ${ }^{13,23}$. Thus, we measured plasma levels of IFN $\alpha$. In previous experiments we were unable to detect measurable levels of IFN $\beta$ in plasma following MCMV infections (data not shown) and therefore this type I IFN was not included in the current study. However, no increase in plasma IFNa-levels was observed in mice fed the prebiotic diet, which is in line with the unchanged viral loads in the various organs.

As pDCs are the major type I IFN producer upon MCMV challenge ${ }^{23}$, we also investigated $\mathrm{pDC}$ levels in the spleen $36 \mathrm{~h}$ after infection. pDC levels were not increased in the spleens of mice from the prebiotic group, which is in concert 
with the equal levels of IFNa in both groups. However, pDCs normally remain at homeostatic levels throughout the early phase of MCMV infection (0-3 days) 20 . This suggests that $\mathrm{pDC}$ numbers are probably also not increased after prebiotic stimulation. In contrast to the pDC numbers, IFNa production is increased after infection or stimulation of pDCs $20,23,31$. Thus, antiviral responses were not amplified in the mice on the prebiotic diet as IFN $\alpha$ levels were not increased and this is illustrated by the comparable viral loads in the two groups. Furthermore, markers for CDC subsets (CD8 $\alpha$ and CD11b) were unchanged after supplementation suggesting no additional stimulation of the adaptive immune response. This is in agreement with Vos et al. ${ }^{11}$, who showed that $T$ and $B$ cells in the spleen of mice were not increased after feeding the same prebiotic diet.

Although no reduction in viral load was observed, the prebiotic mixture might still have an effect on inflammation. During acute MCMV infection, macrophages migrate to the liver ${ }^{32}, 33$. However, numbers of infiltrated macrophages were also not elevated in the livers of the mice on the prebiotic diet. Interestingly, other studies showed that macrophage activity, including phagocytic activity, nitric oxide and cytokine production, was increased in mice or rats after feeding a probiotic diet ${ }^{34-36}$. This suggest that despite the unchanged numbers of macrophages in the liver, activity levels might be different between the control and prebiotics groups, although the difference in macrophage activity can also be a result of the use of probiotics instead of prebiotics.

Finally, we investigated NK cell numbers and activation status as these cells play an essential role in the innate control of the infection in C57BL/ 6 mice ${ }^{37}$. However, in line with the unchanged $\mathrm{pDC} / \mathrm{CDC}$ amounts and IFN $\alpha$ production, NK cell numbers and activation status were also not increased after supplementation with prebiotics, which is confirmed by the study of Vos et al. ${ }^{11}$. In contrast, other types of oligosaccharides have been reported in literature to stimulate NK cell cytotoxicity ${ }^{38,39}$. Nigero-oligosaccharides augmented NK activity of hepatic mononuclear cells against YAC1 cells in vitro and improved survival curves of mice injected with tumour cells ${ }^{38}$. In addition, kappacarrageenan oligosaccharides inhibited sarcoma growth in mice and increased the activity of various immune parameters including NK-cell activity ${ }^{39}$. Possibly, these oligosaccharides are more appropriate to enhance innate 100 
immune responses (towards MCMV) infection than the diet used in our experiments.

Interestingly, the presently tested mixture of oligosaccharides has been shown to increase the proportions of bifidobacteria and lactobacilli in the large intestine ${ }^{11}$, as well as the levels of fecal short-chain fatty acids (SCFA) ${ }^{10}$. Immunomodulatory properties, including the augmentation of NK cell activity, have been attributed to SCFA ${ }^{40}$ and probiotic strains of bifidobacteria and lactobacilli ${ }^{41,42}$. Unfortunately, the levels of SCFA and probiotic strains were not evaluated in this study. Possibly, the increase in SCFA or growth of these probiotics was not sufficiently stimulated by the diet, which explains the unchanged immunity and the absence of possible antiviral effects. In addition, the mice used in our study were obtained from a different supplier than the mice from the studies by Vos et al ${ }^{10,11}$ and perhaps the initial microbiome in the intestines of these mice is different from the microbiome in our mice.

Because prebiotics promote the growth of beneficial bacteria present in the intestinal tract, the prebiotic diet may primarily act on immune cell populations in the mesenteric lymph nodes instead of the spleen. Nonetheless, neither pDCs nor NK cells were detected in the MLNs. In addition, CD4 and CD8 $\alpha$-positive CD11b DCs, required for stimulation of T cell subsets ${ }^{43,44}$, which were absent in the spleen, were also not elevated in the MLNs after supplementation. Thus, even in close proximity to probiotic strains, no increased levels of immune cells were observed. This further suggests that the prebiotic diet did not sufficiently enhance the growth of probiotic strains to stimulate immunity in the MLNs (and systemically). Therefore, future studies are essential to investigate the antiviral effect of probiotics or the combination of pre -and probiotics.

In conclusion, our data show no antiviral or immunomodulatory effects after using a specific prebiotic mixture of oligosaccharides during an acute MCM V infection. This suggests that the current diet has perhaps not enough immunomodulatory power to induce detectable antiviral effects or is only effective during infections of the gastrointestinal tract ${ }^{12}$. Nevertheless, supplementation with prebiotics, possibly in combination with probiotic treatment, might be useful to raise the threshold of a successful gastrointestinal infection or to counteract periodical reactivation of 
herpesviruses. Thus, further studies are required to investigate the antiviral effect of prebiotics in particular in combinations with probiotic strains.

\section{References}

1. Gori, A., C. Tincati, G. Rizzardini, et al. 2008. Early impairment of gut function and gut flora supporting a role for alteration of gastrointestinal mucosa in human immunodeficiency virus pathogenesis. J Clin M icrobiol 46: 757-758.

2. Kawase, M., F. He, A. Kubota, et al. 2010. Oral administration of lactobacilli from human intestinal tract protects mice against influenza virus infection. Lett Appl Microbiol 51: 6-10.

3. Gibson, G. R., and M. B. Roberfroid. 1995. Dietary modulation of the human colonic microbiota: introducing the concept of prebiotics. J Nutr 125: 1401-1412.

4. Hosono, A., A. Ozawa, R. Kato, et al. 2003. Dietary fructooligosaccharides induce immunoregulation of intestinal IgA secretion by murine Peyer's patch cells. Biosci Biotechnol Biochem 67: 758-764.

5. Manhart, N., A. Spittler, H. Bergmeister, et al. 2003. Influence of fructooligosaccharides on Peyer's patch lymphocyte numbers in healthy and endotoxemic mice. Nutrition 19: 657-660.

6. Nakamura, Y., S. Nosaka, M. Suzuki, et al. 2004. Dietary fructooligosaccharides upregulate immunoglobulin $A$ response and polymeric immunoglobulin receptor expression in intestines of infant mice. Clin Exp Immunol 137: 52-58.

7. Roller, M., G. Rechkemmer, and B. Watzl. 2004. Prebiotic inulin enriched with oligofructose in combination with the probiotics Lactobacillus rhamnosus and Bifidobacterium lactis modulates intestinal immune functions in rats. J Nutr 134: 153156.

8. Gori, A., G. Rizzardini, B. Van't Land, et al. 2011. Specific prebiotics modulate gut microbiota and immune activation in HAART-naive HIV-infected adults: results of the "COPA" pilot randomized trial. Mucosal Immunol 4: 554-563.

9. Buddington, K. K., J. B. Donahoo, and R. K. Buddington. 2002. Dietary oligofructose and inulin protect mice from enteric and systemic pathogens and tumor inducers. J Nutr 132: $472-477$.

10. Vos, A. P., M. Haarman, A. Buco, et al. 2006. A specific prebiotic oligosaccharide mixture stimulates delayed-type hypersensitivity in a murine influenza vaccination model. Int Immunopharmacol 6: 1277-1286.

11. Vos, A. P., M. Haarman, J. W. van Ginkel, et al. 2007. Dietary supplementation of neutral and acidic oligosaccharides enhances Th1-dependent vaccination responses in mice. Pediatr Allergy Immunol 18: 304-312.

12. Bruzzese, E., M. Volpicelli, V. Squeglia, et al. 2009. A formula containing galacto- and fructo-oligosaccharides prevents intestinal and extra-intestinal infections: an observational study. Clin Nutr 28: 156-161.

13. Krmpotic, A., I. Bubic, B. Polic, et al. 2003. Pathogenesis of murine cytomegalovirus infection. Microbes Infect 5: 1263-1277. 
14. Sweet, C. 1999. The pathogenicity of cytomegalovirus. FEM S Microbiol Rev 23: 457482.

15. Liu, Y. J. 2005. IPC: professional type 1 interferon-producing cells and plasmacytoid dendritic cell precursors. Annu Rev Immunol 23: 275-306.

16. Fitzgerald-Bocarsly, P., J. Dai, and S. Singh. 2008. Plasmacytoid dendritic cells and type I IFN: 50 years of convergent history. Cytokine Growth Factor Rev 19: 3-19.

17. Gaajetaan, G. R., C. A. Bruggeman, and F. R. Stassen. 2011. The type I interferon response during viral infections: a "SWOT" analysis. Rev M ed Virol.

18. Krug, A., A. R. French, W. Barchet, et al. 2004. TLR9-dependent recognition of MCM V by IPC and DC generates coordinated cytokine responses that activate antiviral NK cell function. Immunity 21: 107-119.

19. Nguyen, K. B., T. P. Salazar-M ather, M. Y. Dalod, et al. 2002. Coordinated and distinct roles for IFN-alpha beta, IL-12, and IL-15 regulation of NK cell responses to viral infection. J Immunol 169: 4279-4287.

20. Robbins, S. H., G. Bessou, A. Cornillon, et al. 2007. Natural killer cells promote early CD8 T cell responses against cytomegalovirus. PLoS Pathog 3: e123.

21. Trinchieri, G. 2003. Interleukin-12 and the regulation of innate resistance and adaptive immunity. Nat Rev Immunol 3: 133-146.

22. Dalod, M., T. Hamilton, R. Salomon, et al. 2003. Dendritic cell responses to early murine cytomegalovirus infection: subset functional specialization and differential regulation by interferon alpha/beta. J Exp Med 197: 885-898.

23. Zucchini, N., G. Bessou, S. H. Robbins, et al. 2008. Individual plasmacytoid dendritic cells are major contributors to the production of multiple innate cytokines in an organspecific manner during viral infection. Int Immunol 20: 45-56.

24. Delale, T., A. Paquin, C. Asselin-Paturel, et al. 2005. MyD88-dependent and independent murine cytomegalovirus sensing for IFN-alpha release and initiation of immune responses in vivo. J Immunol 175: 6723-6732.

25. Vos, A. P., L. M 'Rabet, B. Stahl, et al. 2007. Immune-modulatory effects and potential working mechanisms of orally applied nondigestible carbohydrates. Crit Rev Immunol 27: $97-140$.

26. Vliegen, I., S. Herngreen, G. Grauls, et al. 2003. Improved detection and quantification of mouse cytomegalovirus by real-time PCR. Virus Res 98: 17-25.

27. Andrews, D. M., H. E. Farrell, E. H. Densley, et al. 2001. NK1.1+ cells and murine cytomegalovirus infection: what happens in situ? J Immunol 166: 1796-1802.

28. Bolger, G., N. Lapeyre, M. Rheaume, et al. 1999. Acute murine cytomegalovirus infection: a model for determining antiviral activity against CMV induced hepatitis. Antiviral Res 44: 155-165.

29. Krmpotic, A., D. H. Busch, I. Bubic, et al. 2002. M CMV glycoprotein gp40 confers virus resistance to CD8+T cells and NK cells in vivo. Nat Immunol 3: 529-535.

30. Hasan, M., A. Krmpotic, Z. Ruzsics, et al. 2005. Selective down-regulation of the NKG2D ligand $\mathrm{H} 60$ by mouse cytomegalovirus $\mathrm{m} 155$ glycoprotein. J Virol 79: 2920-2930.

31. Yrlid, U., S. W. Milling, J. L. Miller, et al. 2006. Regulation of intestinal dendritic cell migration and activation by plasmacytoid dendritic cells, TNF-alpha and type 1 IFNs after feeding a TLR7/ 8 ligand. J Immunol 176: 5205-5212. 
32. Hokeness, K. L., W. A. Kuziel, C. A. Biron, et al. 2005. Monocyte chemoattractant protein-1 and CCR2 interactions are required for IFN-alpha/ beta-induced inflammatory responses and antiviral defense in liver. J Immunol 174: 1549-1556.

33. Salazar-Mather, T. P., C. A. Lewis, and C. A. Biron. 2002. Type I interferons regulate inflammatory cell trafficking and macrophage inflammatory protein lalpha delivery to the liver. J Clin Invest 110: 321-330.

34. Ishida-Fujii, K., R. Sato, S. Goto, et al. 2007. Prevention of pathogenic Escherichia coli infection in mice and stimulation of macrophage activation in rats by an oral administration of probiotic Lactobacillus casei I-5. Biosci Biotechnol Biochem 71: 866873.

35. Jain, S., H. Yadav, and P. R. Sinha. 2008. Stimulation of innate immunity by oral administration of dahi containing probiotic Lactobacillus casei in mice. J M ed Food 11: 652-656.

36. Kaushal, D., and V. K. Kansal. 2011. Age-related decline in macrophage and lymphocyte functions in mice and its alleviation by treatment with probiotic Dahi containing Lactobacillus acidophilus and Bifidobacterium bifidum. J Dairy Res 78: 404-411.

37. Daniels, K. A., G. Devora, W. C. Lai, et al. 2001. M urine cytomegalovirus is regulated by a discrete subset of natural killer cells reactive with monoclonal antibody to $\mathrm{Ly} 49 \mathrm{H}$. J Exp Med 194: 29-44.

38. Murosak, S., K. Muroyama, Y. Yamamoto, et al. 2002. Nigerooligosaccharides augments natural killer activity of hepatic mononuclear cells in mice. Int Immunopharmacol 2: 151-159.

39. Yuan, H., J. Song, X. Li, et al. 2006. Immunomodulation and antitumor activity of kappa-carrageenan oligosaccharides. Cancer Lett 243: 228-234.

40. Pratt, V. C., K. A. Tappenden, M. I. McBurney, et al. 1996. Short-chain fatty acidsupplemented total parenteral nutrition improves nonspecific immunity after intestinal resection in rats. JPEN J Parenter Enteral Nutr 20: 264-271.

41. Gill, H. S., K. J. Rutherfurd, M. L. Cross, et al. 2001. Enhancement of immunity in the elderly by dietary supplementation with the probiotic Bifidobacterium lactis HN019. Am J Clin Nutr 74: 833-839.

42. Takeda, K., and K. Okumura. 2007. Effects of a fermented milk drink containing Lactobacillus casei strain Shirota on the human NK-cell activity. J Nutr 137: 791S-793S.

43. Ruiz, S., C. Beauvillain, M. N. Mevelec, et al. 2005. A novel CD4CD8alpha+CD205+CD11b- murine spleen dendritic cell line: establishment, characterization and functional analysis in a model of vaccination to toxoplasmosis. Cell Microbiol 7: 1659-1671.

44. Chung, Y., J. H. Chang, B. S. Kim, et al. 2007. Anatomic location defines antigen presentation by dendritic cells to $T$ cells in response to intravenous soluble antigens. Eur J Immunol 37: 1453-1462. 


\section{Chapter}

\section{Interferon- $\beta$ induces a long-lasting antiviral state in human respiratory epithelial cells}

Giel R Gaajetaan, Tanja H Geelen, Juanita H Vernooy, M ieke A Dentener, Niki Reynaert, Gernot G Rohde, Erik V Beuken, Gert E Grauls, Cathrien A Bruggeman, Frank R Stassen

Submitted 


\section{Abstract}

Interferon- $\beta$ induces strong antiviral effects and is therefore an attractive agent to prevent or reduce the incidence of virus-mediated exacerbations in asthmatic or COPD patients. However, therapeutic use of interferon- $\beta$ induces severe side effects during repetitive and systemic application. We therefore investigated the effects of prophylactic interferon- $\beta$ on respiratory epithelial cells infected with rhinovirus. A549 cells and primary bronchial epithelial cells were exposed for $18 \mathrm{~h}$ to interferon- $\beta$. Then, interferon- $\beta$ was either removed or maintained in the supernatant for the rest of the experiment and cells were infected with rhinovirus-1B at $\mathrm{t}=0$ or $72 \mathrm{~h}$ after the initial exposure to interferon- $\beta$. Viral RNA levels were decreased in both cell types. Furthermore, both viral RNA and infectious virus levels in the supernatant of infected A549 cells were still significantly reduced at $72 \mathrm{~h}$ after removal of interferon- $\beta$. This pronounced antiviral effect was associated with increased expression of the antiviral genes ISGI5 and $M x 1$ and the effect was maintained when interferon$\beta$ levels in the supernatant of A549 cells were undetectable. These data show that interferon- $\beta$ has not only a strong, but also a long-lasting protective effect against rhinovirus infection of respiratory epithelium and opens new opportunities for prophylactic treatment of viral respiratory infections. 


\section{Introduction}

Acute exacerbations (AE) of asthma and chronic obstructive pulmonary disease (COPD) patients are strongly associated with viral infections of the respiratory tract ${ }^{1-4}$. AE induced by viruses are more severe than non-viral $A E$ and require longer hospitalization ${ }^{5-7}$. Rhinoviruses (RVs) are the most common viral pathogens associated with $A E^{4,8-11}$. In healthy persons, RV infections typically result in common colds and mild upper respiratory tract (URT) illness. However, asthma and COPD patients are more susceptible and develop more severe lower respiratory tract symptoms. Unfortunately, treatment of $A E$ is currently limited and new therapies are therefore essential.

Viral respiratory infections trigger the release of interferon- $\beta$ (IFN $\beta$ ) and IFN $\lambda$ by bronchial epithelial cells ${ }^{12}$. However, it has been shown that bronchial epithelial cells from asthma patients are (partially) deficient in their production of IFN $\beta$ and/or IFN $\lambda^{13,14}$, which could explain the increased susceptibility and more severe complications of viral respiratory infection in these patients. Similarly, experimental infections with RVs resulted in higher viral loads and more pronounced inflammation in lungs of COPD patients compared to healthy controls, which correlated with the reduced IFN $\beta$ levels in bronchoalveolar lavage cells of the COPD group ${ }^{15}$.

The deficient production of various IFNs in asthma and COPD patients suggest that exogenous application of these IFNs might be useful to prevent or limit virus-associated AE. Indeed, IFNs already showed beneficial effects in one uncontrolled open label study with asthmatic patients ${ }^{16}$, but additional in vitro studies are required to investigate the protection of respiratory epithelial cells against viral infection by IFNs and how the often observed side effects during systemic, prolonged and repetitive application of IFNs can be limited ${ }^{17,18}$. In the present study we confirmed earlier observations showing that IFN $\beta$ is extremely potent as antiviral agent in human respiratory epithelial cells ${ }^{19}$, but more importantly, we could also demonstrate that even low amounts of IFN $\beta$ are able to induce a long-lasting antiviral state in human respiratory epithelial cells. 


\section{Materials \& M ethods}

\section{Cell Culture}

A549 cells (CCL-185, ATCC, Rockville, MD, USA) were cultured in RPMI 1640 medium (Invitrogen, Grand Island, NY, USA) supplemented with 10\% FCS (Lonza, Verviers, Belgium). Cells were allowed to grow in 775 flasks at $37^{\circ} \mathrm{C}$ and $5 \% \mathrm{CO}_{2}$.

Primary bronchial epithelial cells (PBECs) were obtained from bronchus rings harvested from patients $(n=4)$ undergoing surgery for solitary pulmonary nodules, mostly suspicious of lung cancer. Lung tissue used for isolation of PBECs was macroscopically free of cancer and located at greatest possible distance to the nodule. Formal permission was obtained from the local M edical Ethical Committee and patients were informed and gave permission the day before surgery.

PBECs were isolated and cultured as previously described ${ }^{20}$. Briefly, the cells were isolated by protease digestion using protease XIV (182 mg/ml, sigma, St. Louis, M O, USA). After incubation, cells were scraped carefully from the tissue and washed once with PBS. Cells were seeded in coated 6-wells plates in KSFM medium supplemented with epidermal growth factor (EGF; $0.2 \mathrm{mg} / \mathrm{ml}$, Invitrogen), bovine pituitary extract (BPE; $25 \mu \mathrm{g} / \mathrm{ml}$, Invitrogen), isoproterenol ( $1 \mu \mathrm{M}$, Sigma) and antibiotics. Coating consisted of pure collagen $(30 \mu \mathrm{g} / \mathrm{ml}$, advanced biomatrix), fibronectin (10 $\mu \mathrm{g} / \mathrm{ml}$, Sigma) and bovine serum albumin (BSA; $10 \mu \mathrm{g} / \mathrm{ml}$, sigma) in PBS. Medium was refreshed three times a week. Epithelial origin of cells was confirmed immunohistochemically by the expression of cytokeratin 5, 6, 8, and 17.

M RC5 fibroblasts (CCL-171 ATCC) were maintained in Earle's M inimal essential medium (EMEM) (Invitrogen) supplemented with non-essential amino acids (MP Biomedicals, Solon, Ohio, USA) L-glutamine ( $2 \mathrm{mmol} / \mathrm{L}$ ) and $10 \%$ FCS. Cells were allowed to grow in $\mathrm{T} 75$ flasks at $37^{\circ} \mathrm{C}$ and $5 \% \mathrm{CO}_{2}$. 


\section{Virus culture}

RV-1B was obtained from ATCC (VR-1645) and was propagated in M RC5 cells in EMEM (Invitrogen) with $2 \%$ FCS (Lonza), non-essential amino acids, Lglutamine $(2 \mathrm{mmol} / \mathrm{L})$ and sodium pyruvate $(1 \mathrm{mmol} / \mathrm{L})$. When $100 \%$ cytopathogenic effect (CPE) was achieved, cell debris was removed by centrifugation and viral titers in the supernatant were determined by TCID50. For infection, cells were washed with PBS and infected with RV-1B (MOI 1) in RPMI 1640 medium with $2 \%$ FCS (for A549 cells) or BD starvation medium (for PBECS) for $4 \mathrm{~h}$ at $33^{\circ} \mathrm{C}$ and $5 \% \mathrm{CO}_{2}$.

\section{Thiazolyl blue tetrazolium bromide (MTT) test}

The cytotoxicity of IFN $\beta$ was analysed by using the colorometric MTT (Sigma) assay. A549 cells were allowed to grow in 96-well plates until they were confluent. Afterwards, the medium was removed and cells were exposed for $138 \mathrm{~h}$ to all concentrations of IFN $\beta$ (dissolved in RPMI 1640 with $2 \%$ FCS) used in the main experiments. Subsequently, the $M T$ assay was performed according to the manufacturer's instructions. The percentage of metabolic activity of the A549 cells was calculated by comparing to non-exposed controls (absorbance exposed/ absorbance non-exposed x 100\%).

\section{Stimulation and infection protocol}

A549 cells were seeded in 24-well tissue culture plates (Becton Dickinson, NJ, USA) and allowed to grow until being confluent. Then, various IFN $\beta$ (PBL Biomedical Laboratories, NJ, USA) concentrations $(500,250,125,62$ or 31 units/ $\mathrm{ml}$ ) were added for $18 \mathrm{~h}$ to the A549 cells in RPMI 1640 medium with 2\% $\mathrm{FCS}$ at $37^{\circ} \mathrm{C}$ and $5 \% \mathrm{CO}_{2}$. PBECs (passage 2) were grown in Greiner 24 wells plates in $\mathrm{BD}$ medium which contains $50 \%$ bronchial epithelium growth medium (BEGM; Lonza), 50\% DMEM (Gibco), supplemented with BEGM single quots (Lonza) and BSA (1,5 $\mathrm{g} / \mathrm{ml}$; Sigma). $24 \mathrm{~h}$ before stimulation/infection, when cells were $80 \%$ confluent, growth medium was replaced by BD starvation medium (BD medium without EGF, BPE, BSA and gentamycin). PBECs were 
exposed to 500 or 31 units/ml IFN $\beta$ for $18 \mathrm{~h}$ in $\mathrm{BD}$ starvation medium at $37^{\circ} \mathrm{C}$ and $5 \% \mathrm{CO}_{2}$.

In the first part of the study we investigated whether transient exposure to IFN $\beta$ is able to protect epithelial cells for a prolonged period against RV infections. After $18 \mathrm{~h}$ of exposure to IFN $\beta$, the IFN $\beta$-containing medium from cells included in the pretreatment experiments was replaced by IFN $\beta$-free RPMI 1640 ( $2 \%$ FCS) and cells were infected either immediately ( $t=0 \mathrm{~h}$ ) or after $72 \mathrm{~h}$ (figure 1).

In the second part we tested the protective effect of IFN $\beta$ when IFN $\beta$ was present for the duration of the whole experimental procedure. Therefore, after the initial $18 \mathrm{~h}$ pretreatment period, culture media were not refreshed and cells were infected in the presence of IFN $\beta$. After the $4 \mathrm{~h}$ of infection, this $\mathrm{RV}$ containing medium was then removed and replaced by RV-free but IFN $\beta$ containing medium. Since IFN $\beta$ may have been metabolized or, by e.g. autocrine signaling, may have induced the release of additional antiviral components during the pretreatment period, we decided to replace the RV/IFN $\beta$ containing medium not with fresh medium containing new IFN $\beta$, but with medium collected from cells cultured in parallel $(H-$ IFN $\beta$ ) with the infected cells. Thus, in these continuous experiments, after $18 \mathrm{~h}$ the IFN $\beta$ containing medium was not replaced and RV-1B was added directly to the cells. Then, after $4 \mathrm{~h}$ of infection, this IFN $\beta$ and RV-1B containing medium was replaced by medium collected from cells cultured in parallel in an identical way ( $H$-IFN $\beta$ for $18 \mathrm{~h}$ or $18+72 \mathrm{~h}$ ). The experimental procedure is schematically displayed in figure 1 .

After the infection, cells were maintained for an additional $48 \mathrm{~h}$ at $37^{\circ} \mathrm{C}$ and $5 \%$ $\mathrm{CO}_{2}$. Finally, cells and supernatant were collected for RNA extraction and determination of $\mathrm{CPE}$, respectively. 
A

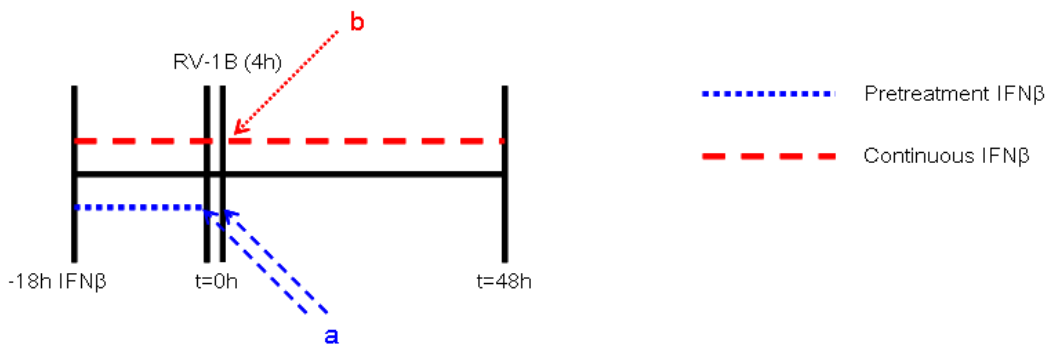

B

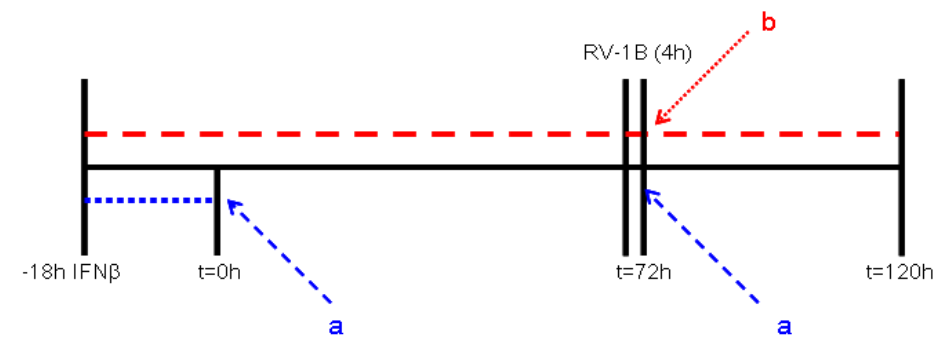

Figure 1. Schematic representation of the stimulation and infection model. A549 cells were either infected immediately (fig. A) or after $72 \mathrm{~h}$ (fig. B). During the pre-treatment experiment, cells were stimulated with IFN $\beta$ for $18 \mathrm{~h}$ and the conditioned medium was removed and replaced by new medium (a). Subsequently, cells were infected immediately (fig. A) or after $72 \mathrm{~h}$ (fig. B) with RV-1B for $4 \mathrm{~h}$. Then, the RV-1B containing medium was removed and again replaced by new medium for $48 \mathrm{~h}$. During the continuous experiment, cells were also stimulated with IFN $\beta$ for 18 $\mathrm{h}$ but the medium was not removed before RV-infection. After $4 \mathrm{~h}$ RV-infection, the medium with RV-1B was removed and replaced by parallel medium (b). This medium was obtained from cells cultured in an identical way, which were cultured in an identical way and also stimulated with IFN $\beta$ for $18 \mathrm{~h}$ (fig. A) or $18 \mathrm{~h}+72 \mathrm{~h}$ (fig. B), but were not infected.

\section{Total RNA extraction and RT-qPCR}

RNA was isolated from frozen cell pellets and reverse transcribed into cDNA as described previously ${ }^{21}$. CDNA was amplified in a volume of $25 \mu \mathrm{l}$ containing $12,5 \mu \mathrm{lIQ} \mathrm{IM}^{\mathrm{TM}}$ Supermix (Bio-Rad, Hercules, CA, USA), RV probe, forward and reverse primer. For all other genes, HOT FIREPol ${ }^{\circledR}$ EvaGreen ${ }^{\circledR}$ qPCR mix plus (Solis BioDyne, Tartu, Estonia) was used. The sequences of the primers/probe are listed in table 1. qPCR run was performed as described previously ${ }^{21}$. To control for DNA contamination, in every PCR run a sample was included which was not reverse transcribed. Fold changes or relative expression levels were determined by using the $2^{-\Delta \Delta \mathrm{ct}}$ or $2^{-\Delta \mathrm{ct}}$ method, respectively and normalized to $\beta$-actin levels. All samples were measured in duplicate ${ }^{22}$. 
Table 1. Primers used for mRNA expression analysis

\begin{tabular}{lll}
\hline Gene & & Primer sequences $\left(5^{\prime}-3^{\prime}\right)$ \\
\hline RV & forward & TGGACAGGGTGTGAAGAGC \\
& reverse & CAAAGTAGTCGGTCCCATCC \\
& probe & TCCTCCGGCCCCTGAATG \\
forward & GGTGGTGGACAAGTGCGATG \\
& reverse & CGAAGGTCAGCCAGAACAGG \\
M X1 & forward & GGACATCGCCACCACAGAGG \\
& reverse & TCCGCACCACATCCACAACC \\
$\beta$-actin & forward & TGGAGAAATCTGGCACCAC \\
& reverse & GAGGCGTACAGGGATAGCAC \\
\hline
\end{tabular}

\section{CPE test}

To determine the presence of infectious RV-1B particles, collected supernatant from infected A549 cells was diluted 2x in EMEM medium with $2 \%$ FCS, nonessential amino acids, L-glutamine $(2 \mathrm{mmol} / \mathrm{L})$ and sodium pyruvate $(1 \mathrm{mmol} / \mathrm{L})$ before addition to confluent M RC5 cells in 96-well plates. Per condition, $100 \mu \mathrm{l}$ of each dilution was added to the MRC5 cells (6-fold). After 3 days at $33^{\circ} \mathrm{C}$ and $5 \% \mathrm{CO}_{2}, \mathrm{CPE}$ was determined after staining and fixation with $0.13 \%$ crystal violet in $5 \%$ formaldehyde. Wells were indicated positive when CPE was present.

\section{IFNB detection}

An ELISA (PBL Biomedical Laboratories) was used to detect IFN $\beta$ levels on different time points in the supernatant of stimulated A549 cells.

\section{Statistical analysis}

Statistical analysis was carried out in SPSS 18.0. The Mann-Whitney $U$ test was used to analyse differences between groups. Values of $p \leq 0.05$ were considered statistically significant. Data are expressed as mean \pm SEM , unless stated otherwise. 


\section{Results}

Exposure to IFN $\beta$ has no toxic effects on A549 cells

To determine possible toxic effects of long-term exposure to IFN $\beta$, A549 cells were exposed to IFN $\beta$ for $138 \mathrm{~h}$, which will be the maximum time of exposure to IFN $\beta$ during the main experiments. No significant differences in the metabolic activity could be observed in IFN $\beta$-exposed A549 cells when compared to control A549 cells (figure 2), implicating that long-term exposure to IFN $\beta$ induces no toxic effects in A549 cells.

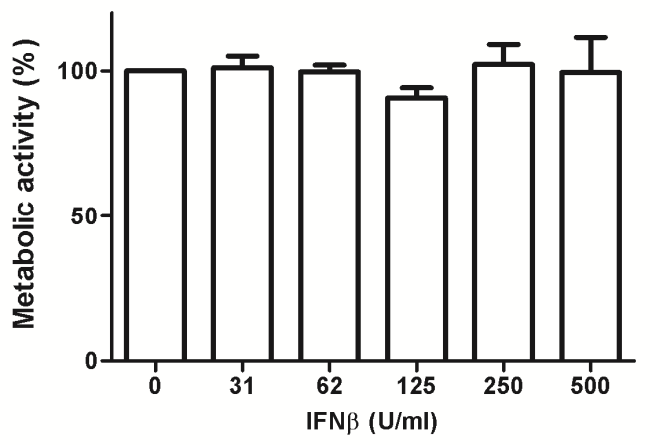

Figure 2. Toxicity of IFN $\beta$ in A549 cells. A549 cells were exposed to various concentrations of IFN $\beta$ for the maximum duration of the following experiments (138 h). Toxicity of IFN $\beta$ was determined by measuring metabolic activity of the cells by $\mathrm{MTT}$ assay. Data are represented as mean \pm SEM of three independent experiments. No toxic effects of IFN $\beta$ were observed.

IFN $\beta$ protects $A 549$ cells against RV-1B infection

We determined the antiviral effect of various concentrations of IFN $\beta$ against $a$ subsequent RV infection ( $t=0$ ). In addition, we analysed the antiviral effect of IFN $\beta$ when cells were only pre-treated compared to cells which were continuously exposed to IFN $\beta$ during the infection. As illustrated in figure $3 \mathrm{~A}$, both pre-treatment and continuous exposure to all concentrations of IFN $\beta$ resulted in a strong reduction of viral RNA compared to non-exposed A549 cells. Next, we also determined whether the production of infectious progeny was inhibited by IFN $\beta$. The supernatant of infected A549 cells was used to determine the presence of CPE in human fibroblasts (MRC5 cells). The continuous exposure to IFN $\beta$ showed a stronger antiviral effect than only pretreatment of the cells and this was dose-dependent. Nevertheless, also pre- 
treatment showed a significant reduction of infectious particles (figure 3B). In addition, not only the presence of CPE but also the amount of CPE per well after exposure to supernatant of non-stimulated A549 cells was in general more extensive then the limited CPE per well observed in fibroblasts exposed to supernatant of pre-treated cells, which is not illustrated in the figure but further emphasizes the protective effect of IFN $\beta$.

A

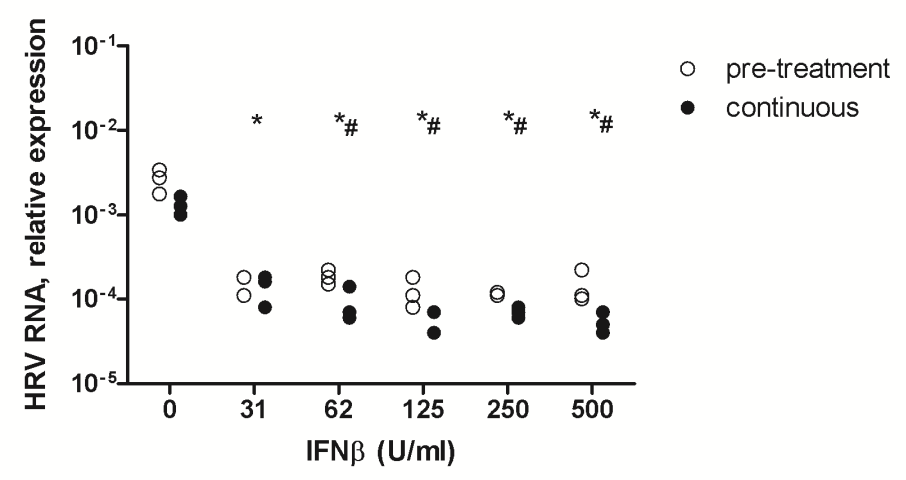

B

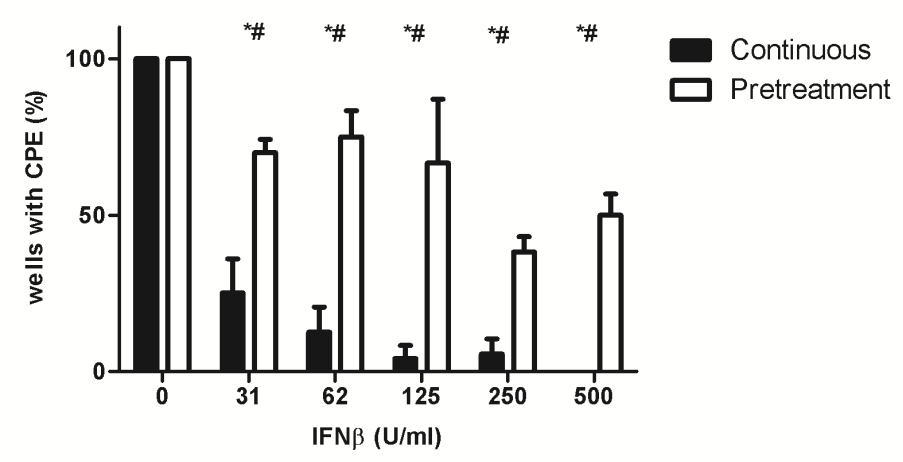

Figure 3. Antiviral effect of IFN $\beta$ in A549 cells during RV-infection. Cells were infected immediately after an $18 \mathrm{~h}$ period of exposure to IFN $\beta$. (A) RNA-levels were analysed at $48 \mathrm{~h} \mathrm{p.i.}$ by RT-qPCR. (B) Number of wells with MRC5 cells displaying CPE were analysed by a CPE test with a 2-fold dilution of the supernatant from RV-infected A549 cells. Data are represented as three independent experiments ( $\mathrm{A}$ ) or as mean \pm SEM of four independent experiments (B). * $=$ $\mathrm{P} \leq 0.05$ IFN $\beta$-exposed vs. non-exposed cells, $\#=\mathrm{P} \leq 0.05$ pre-treatment vs. continuous. 
IFN $\beta$ induces a long-lasting and dose-dependent antiviral condition in A549 cells

In the next step, we investigated how long the protective effect of IFN $\beta$ would last. Cells were now infected $72 \mathrm{~h}$ after the initial $18 \mathrm{~h}$ exposure to IFN $\beta$ ( $\mathrm{t}=72$ ). Again, under both conditions viral RNA levels were strongly reduced compared to non-exposed A549 cells (figure 4A) although continuous exposure was more effective than pre-treated only. This corresponds well with the reduction in production of infectious virus particles (figure 4B).

A

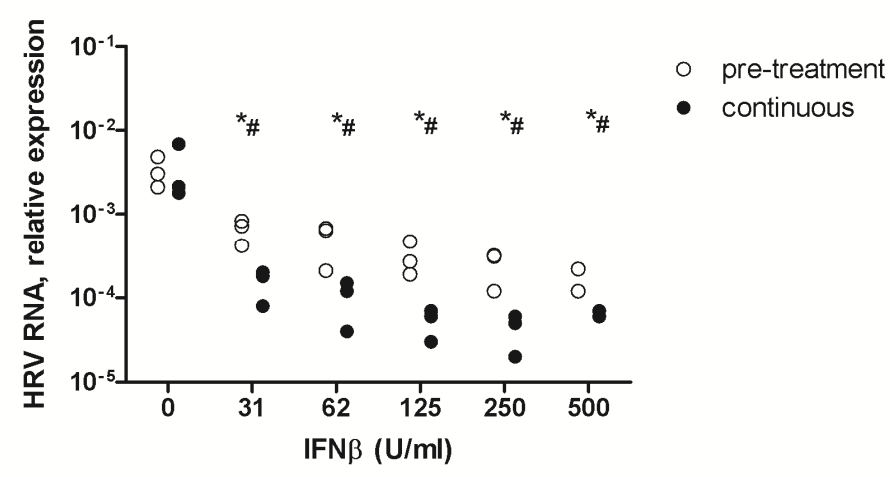

B

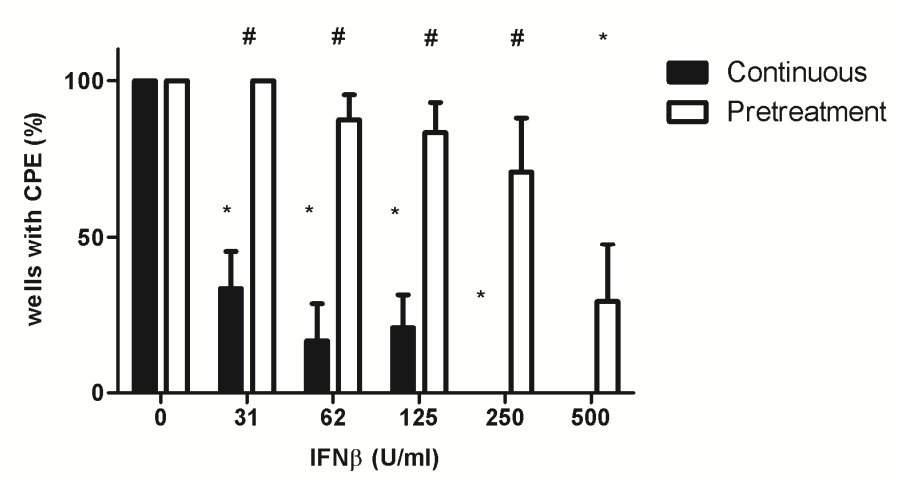

Figure 4. Long-term antiviral effect of IFN $\beta$ in A549 cells. Cells were infected $72 \mathrm{~h}$ after the initial $18 \mathrm{~h}$ exposure to IFN $\beta$. (A) RNA-levels were analysed $48 \mathrm{~h}$ p.i. by RT-qPCR. (B) Number of wells with MRC5 cells displaying CPE were analysed by a CPE test with a 2-fold dilution of the supernatant from RV-infected A549 cells. Data are represented as three independent experiments (A) or as mean \pm SEM of four independent experiments. ${ }^{*}=\mathrm{P} \leq 0.05$ IFN $\beta$-exposed vs. non-exposed cells, $\#=P \leq 0.05$ pre-treatment vs. continuous. 
IFN $\beta$ protects PBECs against RV-1B infection

To substantiate the relevance of our findings, we also investigated the antiviral effect of IFN $\beta$ in PBECs. Therefore, we repeated the experiments with PBECs and exposed them to the lowest IFN $\beta$ concentration $(31 \mathrm{U} / \mathrm{ml}$ ) or the highest IFN $\beta$ concentration $(500 \mathrm{U} / \mathrm{ml})$. Again, both pre-treatment and continuous exposure with low or high dose IFN $\beta$ resulted in a (strong) reduction of viral RNA compared to non-exposed PBECs (figure 5). In general, these data show that IFN $\beta$ shows a strong antiviral effect not only in A549 cells but also in PBECs which emphasizes the clinical relevance of our findings. Due to the similarity between the results in A549 and PBEC, we decided to use the A549 cells to further investigate the mechanisms involved in the antiviral effect of IFN $\beta$.

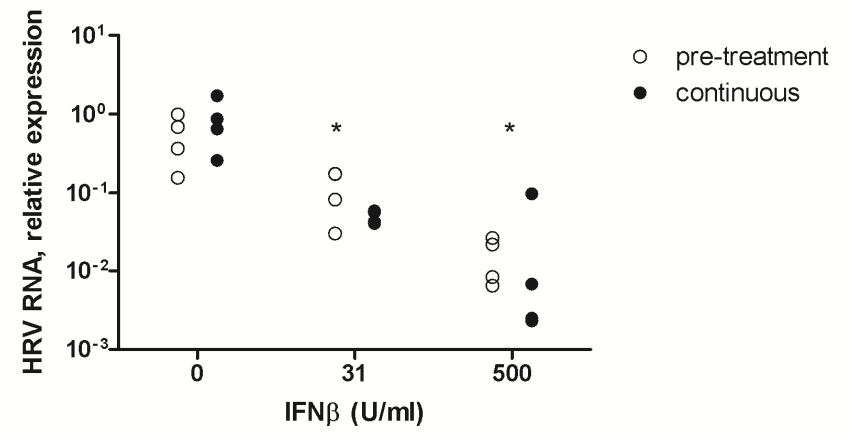

Figure 5. Antiviral effect of IFN $\beta$ in PBECs. Cells were infected immediately after the initial $18 \mathrm{~h}$ exposure to IFN $\beta$ and RNAlevels were analysed $48 \mathrm{~h}$ p.i. by RT-qPCR. Data are represented as four independent experiments. $*=P \leq 0.05$ IFN $\beta$-exposed vs. non-exposed cells.

Antiviral gene expression corresponds with the antiviral effect

To investigate which mechanisms are involved in the observed antiviral effect of IFN $\beta$, we measured the expression of various IFN-stimulated genes (ISGs), which have been shown to be involved in the IFN $\beta$-dependent antiviral system. First, ISG15 (IFN-stimulated protein of Mr15000) mRNA levels were dramatically enhanced in A549 cells $18 \mathrm{~h}$ after exposure to IFN $\beta$. Even the lowest IFN $\beta$ concentration resulted in high mRNA levels of ISG15 ( $>600$-fold; figure $6 \mathrm{~A}$ ), which further increased when $A 549$ cells were exposed to the highest IFN $\beta$ concentration (1200-fold; figure 6B). The exact changes in ISG mRNA are shown in table 2. Despite the reduction in ISG15 expression $72 \mathrm{~h}$ 
after removal of IFN $\beta$, ISG15 mRNA levels were still significantly elevated. When IFN $\beta$ was not removed from the cells, even higher levels of ISG15 mRNA were detected in the $A 549$ cells $72 \mathrm{~h}$ after the initial exposure to IFN $\beta$ (figure $6 \mathrm{~A}, \mathrm{~B}$ and table 2 )

In addition to ISG15 mRNA, Mx1 (Myxovirus resistance 1 ) mRNA in A549 also strongly increased $18 \mathrm{~h}$ after IFN $\beta$ exposure. The time- and dose-dependent expression of M X1-mRNA highly resembled the expression of ISG15 (figure 6C, $\mathrm{D}$ and table 2).

A

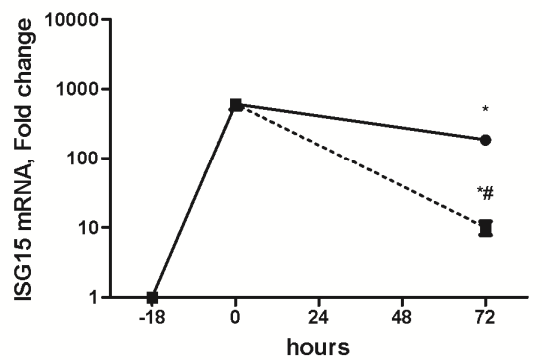

C

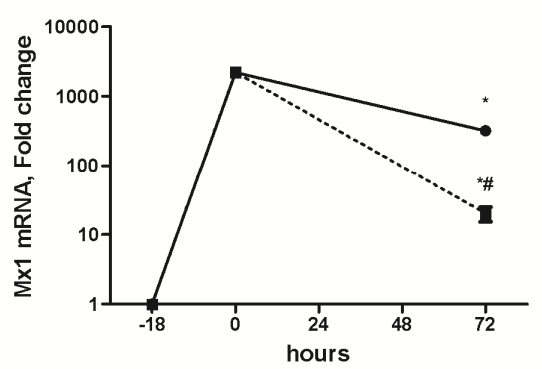

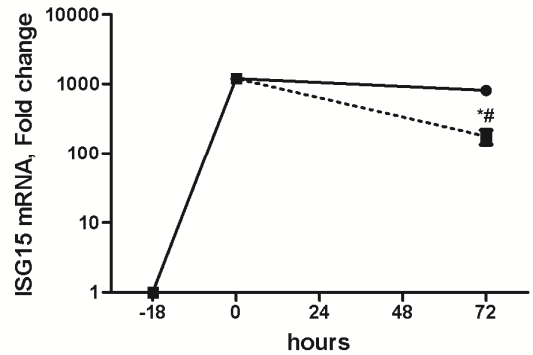

D

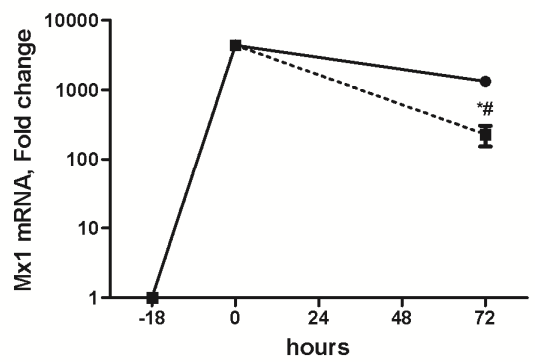

Figure 6. ISG expression in A549 cells after IFN $\beta$ exposure. mRNA expression of ISG15 (fig. 5A-B) and $M \times 1$ (fig. $5 C-D$ ) was measured at $t=0$ and $t=72$ after stimulation with low dose IFN $\beta(A, C)$ or high dose of IFN $\beta(B, D)$. Fold changes were calculated vs ISG mRNA levels in non-treated A549 cells. Dotted line, pre-treatment; solid line, continuous. Data are represented as mean \pm SEM of three independent experiments. ${ }^{*}=\mathrm{P} \leq 0.05 \mathrm{t}=72$ vs. $\mathrm{t}=0, \#=\mathrm{P} \leq 0.05$ pre-treatment vs. continuous. 
Table 2. Fold changes of ISG15 and Mx1 after IFN $\beta$ exposure

\begin{tabular}{|l|cc|cc|cc|}
\hline \multirow{2}{*}{ Time point } & \multicolumn{2}{|c|}{ T=0h } & \multicolumn{2}{c|}{$\begin{array}{c}\text { Pre-treatment } \\
\text { T=72h }\end{array}$} & \multicolumn{2}{c|}{$\begin{array}{c}\text { Continuous } \\
\text { T=72h }\end{array}$} \\
\hline IFN $\beta$ (IU/ml) & $\mathbf{3 1}$ & $\mathbf{5 0 0}$ & $\mathbf{3 1}$ & $\mathbf{5 0 0}$ & $\mathbf{3 1}$ & $\mathbf{5 0 0}$ \\
\hline ISG15 & 609 & 1194 & 10 & 176 & 185 & 811 \\
M X1 & 2208 & 4369 & 20 & 230 & 320 & 1323 \\
\hline
\end{tabular}

We also compared the IFN $\beta$-induced ISG expression with RV-induced ISG expression. Interestingly, the increase in ISG expression after RV-infection for $48 \mathrm{~h}$ was minor compared to ISG expression in IFN $\beta$-exposed A549 cells (figure $7 A$ and $B$ ), suggesting limited activation of the IFN response in these cells by RV-1B.

A

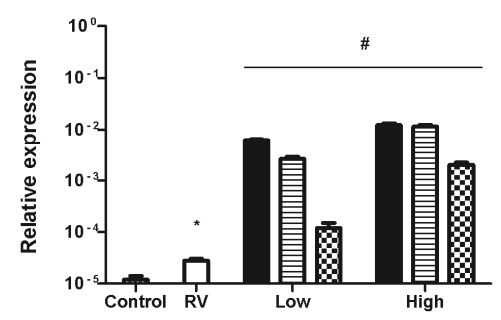

B

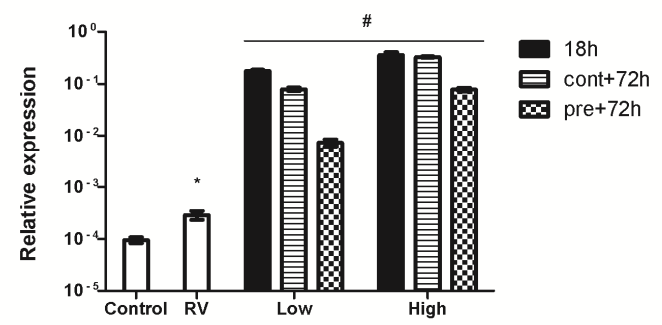

Figure 7. Relative ISG expression in A549 cells after RV infection or IFN $\beta$ exposure. The relative expression of ISG15 (A) or M X1 (B) in A549 cells after RV infection compared to the various low en high dose IFN $\beta$ exposure conditions. Cont = continuous; Pre = pre-treatment. Data are represented as mean \pm SEM of at least three independent experiments. $*=P \leq 0.05$ RV vs. control, \#= $\mathrm{P} \leq 0.05$ IFN $\beta$ vs. RV.

IFNB levels in the supernatant of stimulated $A 549$ cells decrease with time

As expected, IFN $\beta$ could easily be detected by ELISA in the culture supernatant after $18 \mathrm{~h}$ of pre- incubation with the highest dose $(500 \mathrm{U} / \mathrm{ml})$. Thereafter, levels rapidly declined and at $72 \mathrm{~h}$ only $\sim 25 \%$ of the initial amount of IFN $\beta$ could be detected (figure 8 ). In addition, removal of IFN $\beta$ resulted in undetectable levels of IFN $\beta$. The low dose of IFN $\beta$ (31 U/ml) could not be detected at any time-point. These data show that IFN $\beta$ levels correspond with the strength of the antiviral effect and the mRNA expression of the ISGs, but the antiviral effect is still present when levels of IFN $\beta$ are undetectable. 


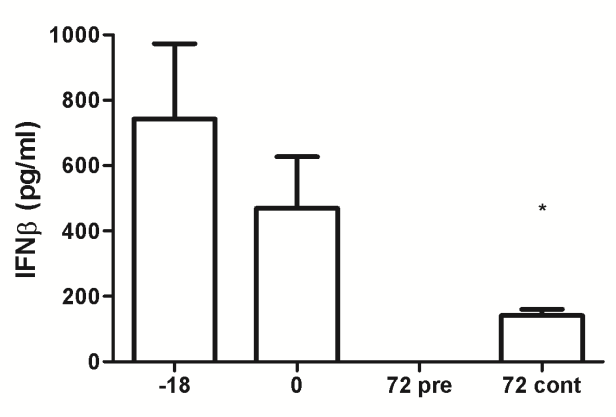

Figure 8. IFN $\beta$ levels in supernatant of IFN $\beta$-exposed A549 cells after high dose stimulation. IFN $\beta$ levels in the supernatant of A549 cells were detected by ELISA. Data are represented as mean \pm SEM of three independent experiments. $*=\mathrm{P} \leq 0.05$ continuous ( $t=72$ ) vs $t=-18$ and $t=0$.

\section{Discussion}

In this study we investigated the applicability of IFN $\beta$ as a prophylactic agent to protect human respiratory epithelial cells from rhinovirus infections. It has been shown that exogenous IFN $\beta$ protects cells against viral infections suggesting that IFN $\beta$ might have a therapeutic potential as a prophylactic drug 19. In particular, in susceptible patients like asthmatics or COPD patients, the prevention of viral infections might contribute significantly to reduce the incidence of acute exacerbations. However, its use as an antiviral drug in e.g. respiratory viral infections is still limited. Although earlier studies indeed revealed beneficial effects of recombinant type I IFN application during acute viral infection in asthmatics or healthy individuals ${ }^{16,23}$, clinicians are still hesitant about the use of IFNs because of earlier reported adverse reactions like flu-like symptoms ${ }^{16}$, dry pharynx and nasal erosion/bleeding ${ }^{23-26}$ in particular after frequent use. Therefore, a prerequisite for future clinical use will be a sustained antiviral state of the epithelial cells after a single application as frequent administrations may cause the aforementioned side effects. Here we demonstrated in an in vitro model that exogenous IFN $\beta$ indeed meets these criteria.

Recently, it has been shown by Cakebread et al. that epithelial cells pre-treated for $6 \mathrm{~h}$ with IFN $\beta$ are exceedingly protected against subsequent viral infections 19. Likewise, we also observed that even the lowest dose of IFN $\beta$ resulted in a remarkable protection of $\mathrm{A} 549$ cells against RV infection. The observed protection in our experiments is even more impressive since we used a viral dose approximately 10 -fold higher than the one used in the study by Cakebread and colleagues ${ }^{19}$. 
Next, we investigated whether the continuous presence of IFN $\beta$ was required for the observed antiviral effect. Interestingly, our data show that the continuous presence of IFN $\beta$ does not seem to be required since only pretreatment with IFN $\beta$, even at low concentrations, was also sufficient to significantly limit RV infection. More importantly, even an $18 \mathrm{~h}$ pre-treatment period with IFN $\beta$ was effective to protect $A 549$ cells against the infection when cells were exposed to RV at $72 \mathrm{~h}$ after removal of IFN $\beta$. This indicates that despite the absence of IFN $\beta$ for $72 h$, the cells are able to maintain their distinct antiviral condition, which is clearly sufficient to significantly inhibit viral infections. Furthermore, since CPE was determined only in a semi-quantitative way (wells were scored as positive if only a single CPE was observed; the actual amount of CPE was not determined) this may underestimate the genuine protective effect of IFN $\beta$ as CPE formation was in general more extensive in non-exposed A549 cells.

Although A549 cells are basically human alveolar epithelial cells, they were originally derived from an alveolar adenocarcinoma, and it can therefore not be excluded that they respond differently to external stimuli than primary cells. Therefore, to put our results with A549 cells into perspective, we repeated some of the experiments with PBECs. These experiments revealed that PBECs are susceptible to RV infection and, most importantly, IFN $\beta$ significantly limited the infection also in PBECs.

Then we aimed to unravel some of the mechanisms involved in the IFN $\beta$ induced antiviral effects in A549 cells. Because comparable results were obtained in both cell types, we decided to carry out further experiments in A549 cells. Previously, it has been demonstrated that the antiviral effect of IFN $\beta$ largely depends on the expression of ISGs. For example, ISG15 is an important immune modulator, while $M \times 1$ has more direct antiviral effects by targeting viral nucleocapsids ${ }^{27}$. The mRNA expression of these two ISGs was impressively increased after $18 \mathrm{~h}$ exposure to IFN $\beta$. Despite the significant reduction of both ISG mRNA levels at $72 \mathrm{~h}$ after removal of IFN $\beta$, these levels were still effective at $t=72$. Interestingly, the observed antiviral activity corresponded reasonably well with the mRNA levels of ISG15 and Mx1 suggesting that these antiviral proteins are indeed involved in the antiviral state induced by IFN $\beta$. 
We also investigated whether RV infection could induce ISG expression in A549 cells. However, the increase in both ISGs was limited compared to IFN $\beta$ exposed cells. Usually, viral infection of epithelial cells results in the production of type I IFNs and subsequent ISG expression ${ }^{28}$. However, RV has been shown to attenuate the antiviral response by interfering with IRF3 activation in A549 and HeLa cells ${ }^{29}, 30$. This will inhibit activation of the signalling cascades resulting in type I IFN production and ISG expression, a mechanism which is in line with the limited increase in ISG mRNA expression in our experiments.

Although it has been shown that binding of IFN $\beta$ to its receptor initiates an amplification loop resulting in increased IFN production, in our hands the IFN $\beta$ levels in the supernatant decreased with time and were even undetectable during low dose stimulation or after removal of IFN $\beta$. Nonetheless, the antiviral state remained effective even when IFN $\beta$ was undetectable. This suggests that very low levels of IFN $\beta$ are sufficient to maintain the antiviral state by continuously stimulating ISG expression, perhaps by autocrine signalling.

In conclusion, these data show that prophylactic treatment of human respiratory cells with IFN $\beta$ results in a long-lasting antiviral condition. Furthermore, even low concentrations of IFN $\beta$ were sufficient to limit RVinfection. This opens new opportunities to prevent e.g. virus-associated $A E$ in asthmatics or COPD patients, in which application of limited amounts of IFN $\beta$ (e.g. by nasal spray) might be sufficient to prevent AE without the danger for side effects as observed during therapeutic repetitive and/or systemic use.

\section{References}

1. Proud, D., and C. W. Chow. 2006. Role of viral infections in asthma and chronic obstructive pulmonary disease. Am J Respir Cell Mol Biol 35: 513-518.

2. Traves, S. L., and D. Proud. 2007. Viral-associated exacerbations of asthma and COPD. Curr Opin Pharmacol 7: 252-258.

3. Johnston, S. L. 2005. Overview of virus-induced airway disease. Proc Am Thorac Soc 2: 150-156.

4. Papi, A., C. M. Bellettato, F. Braccioni, et al. 2006. Infections and airway inflammation in chronic obstructive pulmonary disease severe exacerbations. Am J Respir Crit Care Med 173: 1114-1121. 
5. Corne, J. M., C. Marshall, S. Smith, et al. 2002. Frequency, severity, and duration of rhinovirus infections in asthmatic and non-asthmatic individuals: a longitudinal cohort study. Lancet 359: 831-834.

6. Seemungal, T., R. Harper-Owen, A. Bhowmik, et al. 2001. Respiratory viruses, symptoms, and inflammatory markers in acute exacerbations and stable chronic obstructive pulmonary disease. Am J Respir Crit Care M ed 164: 1618-1623.

7. Wedzicha, J. A. 2004. Role of viruses in exacerbations of chronic obstructive pulmonary disease. Proc Am Thorac Soc 1: 115-120.

8. Friedlander, S. L. and W. W. Busse. 2005. The role of rhinovirus in asthma exacerbations. J Allergy Clin Immunol 116: 267-273.

9. Mallia, P., and S. L. Johnston. 2006. How viral infections cause exacerbation of airway diseases. Chest 130: 1203-1210.

10. Rohde, G., A. Wiethege, I. Borg, et al. 2003. Respiratory viruses in exacerbations of chronic obstructive pulmonary disease requiring hospitalisation: a case-control study. Thorax 58: 37-42.

11. Seemungal, T. A., R. Harper-Owen, A. Bhowmik, et al. 2000. Detection of rhinovirus in induced sputum at exacerbation of chronic obstructive pulmonary disease. Eur Respir J 16: 677-683.

12. Khaitov, M. R., V. Laza-Stanca, M. R. Edwards, et al. 2009. Respiratory virus induction of alpha-, beta- and lambda-interferons in bronchial epithelial cells and peripheral blood mononuclear cells. Allergy 64: 375-386.

13. Contoli, M., S. D. Message, V. Laza-Stanca, et al. 2006. Role of deficient type III interferon-lambda production in asthma exacerbations. Nat Med 12: 1023-1026.

14. Wark, P. A., S. L. Johnston, F. Bucchieri, et al. 2005. Asthmatic bronchial epithelial cells have a deficient innate immune response to infection with rhinovirus. J Exp Med 201: 937-947.

15. Mallia, P., S. D. M essage, V. Gielen, et al. 2011. Experimental rhinovirus infection as a human model of chronic obstructive pulmonary disease exacerbation. Am J Respir Crit Care Med 183: 734-742.

16. Simon, H. U., H. Seelbach, R. Ehmann, et al. 2003. Clinical and immunological effects of low-dose IFN-alpha treatment in patients with corticosteroid-resistant asthma. Allergy 58: 1250-1255.

17. Fried, M. W. 2002. Side effects of therapy of hepatitis $C$ and their management. Hepatology 36: S237-244.

18. Herbeuval, J. P., and G. M. Shearer. 2007. HIV-1 immunopathogenesis: how good interferon turns bad. Clin Immunol 123: 121-128.

19. Cakebread, J. A., Y. Xu, C. Grainge, et al. 2011. Exogenous IFN-beta has antiviral and anti-inflammatory properties in primary bronchial epithelial cells from asthmatic subjects exposed to rhinovirus. J Allergy Clin Immunol 127: 1148-1154 e1149.

20. van Wetering, S., A. C. van der Linden, M. A. van Sterkenburg, et al. 2000. Regulation of SLPI and elafin release from bronchial epithelial cells by neutrophil defensins. Am J Physiol Lung Cell Mol Physiol 278: L51-58. 
21. Gaajetaan, G. R., T. H. Geelen, G. E. Grauls, et al. 2012. CpG and poly(I:C) stimulation of dendritic cells and fibroblasts limits herpes simplex virus type 1 infection in an IFNbeta-dependent and -independent way. Antiviral Res 93: 39-47.

22. Schmittgen, T. D., and K. J. Livak. 2008. Analyzing real-time PCR data by the comparative C(T) method. Nat Protoc 3: 1101-1108.

23. Gao, L., S. Yu, Q. Chen, et al. 2010. A randomized controlled trial of low-dose recombinant human interferons alpha-2b nasal spray to prevent acute viral respiratory infections in military recruits. Vaccine 28: 4445-4451.

24. Douglas, R. M., B. W. Moore, H. B. Miles, et al. 1986. Prophylactic efficacy of intranasal alpha 2-interferon against rhinovirus infections in the family setting. N Engl J M ed 314: 65-70.

25. Farr, B. M., J. M. Gwaltney, Jr., K. F. Adams, et al. 1984. Intranasal interferon-alpha 2 for prevention of natural rhinovirus colds. Antimicrob Agents Chemother 26: 31-34.

26. Hayden, F. G., D. L. Kaiser, and J. K. Albrecht. 1988. Intranasal recombinant alfa-2b interferon treatment of naturally occurring common colds. Antimicrob Agents Chemother 32: 224-230.

27. Sadler, A. J., and B. R. Williams. 2008. Interferon-inducible antiviral effectors. Nat Rev Immunol 8: 559-568.

28. Vareille, M., E. Kieninger, M. R. Edwards, et al. 2011. The airway epithelium: soldier in the fight against respiratory viruses. Clin Microbiol Rev 24: 210-229.

29. Drahos, J., and V. R. Racaniello. 2009. Cleavage of IPS-1 in cells infected with human rhinovirus. J Virol 83: 11581-11587.

30. Kotla, S., T. Peng, R. E. Bumgarner, et al. 2008. Attenuation of the type I interferon response in cells infected with human rhinovirus. Virology 374: 399-410. 



\section{Chapter}

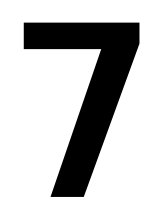

General discussion \& summary 
During the last centuries, pandemic outbreaks of viruses like smallpox, influenza and HIV claimed millions of lives. However, during the last decades, the high morbidity and mortality caused by viruses is impressively reduced in the Western world. The development of antiviral drugs and vaccination resulted in significant limitation of viral disease and dissemination. The success of antiviral drugs and vaccination can best be illustrated by the reduction in HIV-induced morbidity and mortality and the disappearance of the highly pathogenic smallpox virus.

Despite this success, viral infections are still common and cause major health problems. The overcrowded conditions and increasing travelling around the globe facilitate viral spread and the emergence of new or mutated viruses. This compromises not only the use of currently available vaccines but also antiviral drugs. Therefore, new therapies are urgently required.

Although the immune system is generally sufficient to protect us against or clear most viral infections, additional boosts of the immune system could be essential to limit viral disease and dissemination during insufficient immunity. For this, immunomodulating agents are now being investigated as prophylactic or even antiviral medication. In this thesis, we examined the antiviral potency and, when appropriate, underlying molecular mechanisms of some of these immunomodulating agents. We anticipate that the results of our studies are potentially relevant for future clinical applications of these agents, which is currently limited.

\section{Antiviral characteristics of different immunomodulating agents}

In this thesis we targeted different parts of the immune response. In general, the immune response towards viral infections is initiated through stimulation of pattern recognition receptors (PRRs), which are located both on the cell surface as in the intracellular compartment. When PRRs sense viruses, cells start producing type I interferons (IFNs), which then in an auto/paracrine way bind to the cell-surface located IFN $\alpha / \beta$ receptor (IFNAR). This results in the activation of interferon stimulated genes (ISGs) (figure 1), which execute many antiviral and immune-related functions. More importantly, IFN-stimulated cells 
acquire an antiviral state after ISG-activation, which is a collective term for limitation of viral replication, viral resistance of neighbouring cells and apoptosis of virally infected cells.

Although most cells can produce type I IFNs (IFN $\alpha / \beta$ ) after viral infection, dendritic cells (DCS) are the main producers of type I IFNs after engagement of their PRRs. Especially plasmacytoid DCs (pDCs), secrete large amounts of type I IFNs (figure 1) even in the absence of viral replication and are therefore indispensable in the response towards viral infection, as shown in our studies

\section{(chapter 3 and 4).}

Immunomodulating agents can initiate the antiviral response at the receptor level. For this, various ligands have been developed which can stimulate specific PRRs, including the Toll-like receptors (TLRs). In chapter 3, we extensively investigated which TLR ligands can protect against viral infection and how this is mediated. Also, probiotics can stimulate various PRRs (figure 1). These bacteria are mainly known for their health-promoting effects in the gastrointestinal tract, but also for their immunomodulating characteristics after stimulation of PRRs, including TLRs ${ }^{1-3}$. This prompted us to examine the antiviral potency of different probiotic strains (chapter 4). In addition, growth of probiotic strains in the gastrointestinal tract can be stimulated by the administration of oligosaccharides and the supplementation with specific prebiotic mixtures of oligosaccharides has been shown to result in activation of certain immune responses ${ }^{4-6}$. To test whether stimulation of beneficial bacteria with such mixtures may also result in augmented antiviral responses, we supplemented mice with a specific prebiotic diet, infected them with a murine herpes virus and evaluated viral loads in different organs (chapter 5). Another way to modulate antiviral immune responses is by direct targeting of the effector systems. For this, type I IFNs can be applied directly. For example, recombinant IFN $\alpha$ is currently used in the treatment of patients chronically infected with the hepatitis C virus (HCV) and IFN $\beta$ is used as an antiinflammatory component in multiple sclerosis (MS) patients ${ }^{7}$. Despite the potent antiviral effects in HCV-or HIV-infected patients, severe side effects are observed during the repetitive and systemic use of recombinant type I IFN in these patients ${ }^{8,9}$. This implicates that the clinical applicability of type I IFN against less life-threatening viral infections may be limited. Nevertheless, type I IFN therapy can be attractive when used non-repetitively, locally and in low 
doses. Therefore, we investigated not only the efficacy of different dosages of IFN $\beta$ but also the duration of protection against an infection in an in vitro model for a local viral infection (chapter 6).

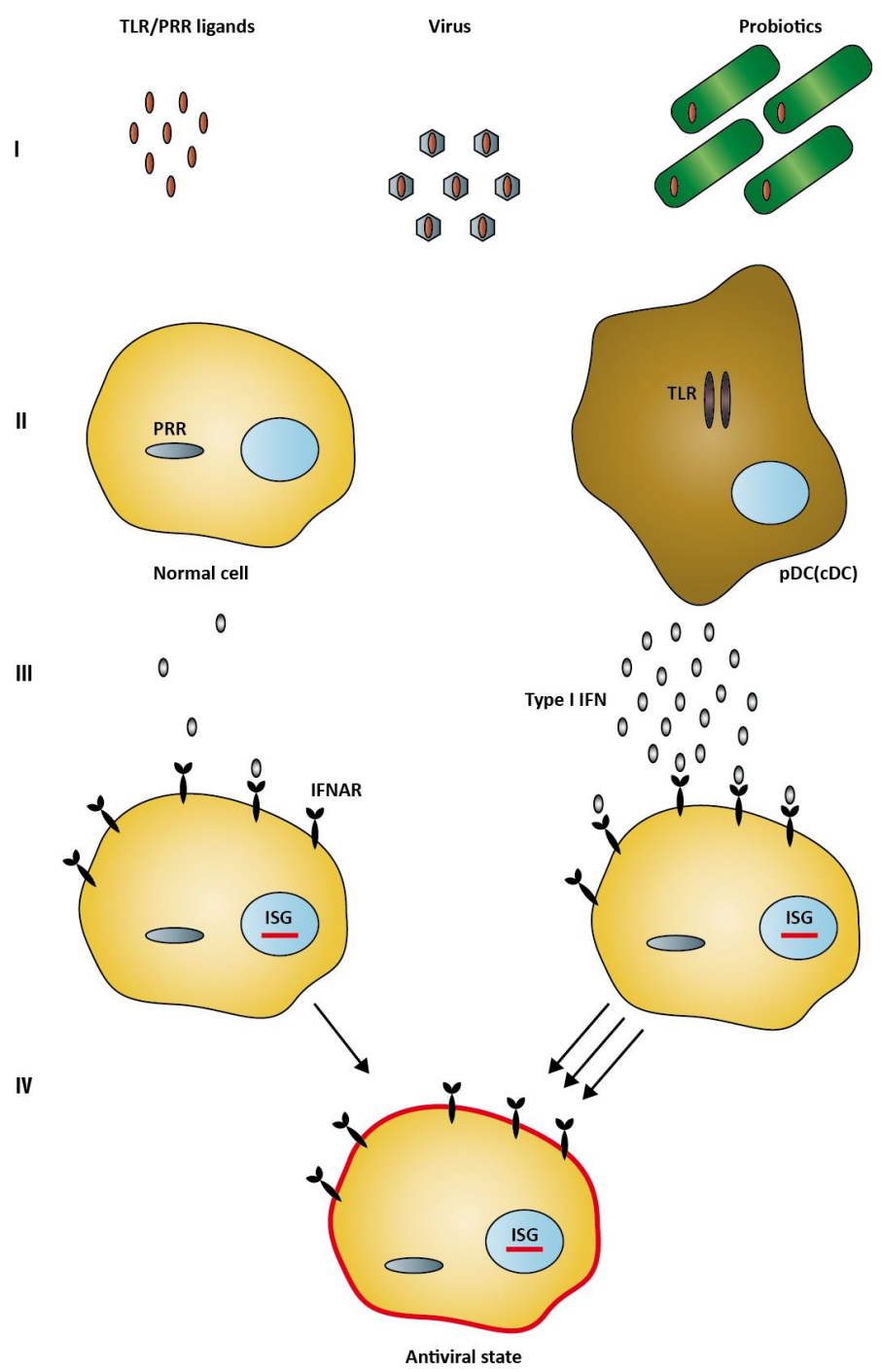

Figure 1. The type I IFN response in 4 phases. In phase I, TLR-ligands and probiotics can substitute the virus to stimulate specific (immune) cells. In phase II, cells are stimulated and can produce type I IFNs. In phase III, the produced type I IFNs bind to their IFNAR and activate ISG transcription. This will eventually lead to induction of the antiviral state in cells (phase IV). 


\section{Immunomodulating agents as antiviral drugs?}

Although TLR ligands are well recognized and extensively investigated as stimulators of the immune response ${ }^{10-13}$, few studies analysed whether the immunomodulating effect of TLR ligands can be used as protection against viral infections. To investigate which of several well-known TLR ligands have antiviral potential, we compared the antiviral effect of various TLR ligands in an in vitro model system (chapter 3). For this, we stimulated pDCs and CDCs, which have abundant but distinct expression of several TLRs, with different TLR ligands, collected the conditioned supernatant and tested whether these supernatants could protect fibroblasts against a subsequent HSV-1 infection.

The TLR ligands CpG ODNs, poly(l:C) and LPS all showed strong antiviral effects. Surprisingly, CpG ODN only induced an antiviral effect in mixed $\mathrm{pDC} / \mathrm{CDC}$ bone marrow-derived (BM)-DC cultures, but not in CDC monocultures (chapter 3). Previously, it has been suggested that stimulation of the TLR9 receptor on CDCs (or myeloid DCS) is mainly involved in IL-12-mediated immune responses towards fungal pathogens without CpG motifs ${ }^{14-16}$, which may explain the lack of antiviral effect in our hands. Thus, the presence of pDCs seems required to initiate strong antiviral responses after CPG ODN stimulation.

Exposure to poly $(\mathrm{l}: \mathrm{C})$ also resulted in an impressive antiviral effect, but this required neither pDCs nor $c D C s$. Although poly $(I: C)$ is recognized by TLR3, this ligand is also sensed by the cytoplasmic receptor MDA5 ${ }^{17,18}$. MDA5 is present in almost all cells and therefore poly $(\mathrm{l}: \mathrm{C})$ can stimulate also non-immune cells, as observed in fibroblasts. This non-specific and general stimulation by poly $(\mathrm{l}: \mathrm{C})$ can, however, result in overstimulation of immunity and/or production of unwanted inflammatory components ${ }^{19-21}$. This compromises the systemic use of poly(l:C) as an antiviral agent, despite its impressive antiviral effects.

Also the gram-negative bacterial component LPS was able to reduce viral infection independently of pDCs, but required only cDCs, as shown by others ${ }^{13}$, 22. However, LPS is also a well-known pro-inflammatory component which strongly narrows down its clinical applicability ${ }^{23,24}$. Surprisingly, the stimulation of the TLR7 receptor by R848, which normally results in a pronounced release of type I IFNs ${ }^{13,25,26}$, was not sufficient to protect against 
viral infection. However, in line with our results, Kim et al showed that TLR7 stimulation by R848 does not result in a potent antiviral response in pDCs of mice ${ }^{27}$. Additional experiments with human cells are therefore warranted to determine the antiviral potency of TRL7 ligands like R-848.

Thus, although various TLR ligands showed strong antiviral effects, clinical applicability seems hindered due to possible systemic activation of immunity and inflammatory responses. For this, we considered other immunomodulating agents with a non-pathogenic nature. As CpG ODNs, which showed a pronounced antiviral effect in our first experiments, are normally also present in bacteria, we evaluated if certain bacteria may also stimulate antiviral responses. As such, beneficial bacteria or probiotics may protect the host against viral invaders. More importantly, these probiotics are nonpathogenic and therefore induce no or only limited side effects in the host ${ }^{28}$. To determine the antiviral potency of probiotics, we tested three well-known bacterial strains for their antiviral effects in the same in vitro infection model. Remarkably, stimulation of BM-DC cultures containing pDCs with L. rhamnosus and $L$. casei resulted in strong antiviral effects, while B. breve stimulation did not induce antiviral effects (chapter 4). This is in line with previous reports which have similarly shown protective effect of lactobacilli, but not bifidobacteria, against various viral infections ${ }^{29-33}$. Probably, lactobacilli and bifidobacteria stimulate different cells ${ }^{34}$ and/or different PRRs ${ }^{1}$, which results in different immune responses.

Previous studies have shown that a specific prebiotic mixture of oligosaccharides induced the growth of beneficial bacteria like lactobacilli and bifidobacteria ${ }^{4-6,35,36}$. In view of the observed antiviral effect of lactobacilli in particular, we hypothesize that such a prebiotic mixture may augment the proportion of probiotics with antiviral characteristics in the host, and as such enhance the efficacy of the antiviral response. However, when mice were supplemented with a prebiotic mixture, which has previously been shown to be able to modulate the immune system ${ }^{5,6}$, no effect on the efficacy of the antiviral response against a systemic cytomegalovirus infection was observed (chapter 5). As prebiotics normally stimulate the growth of beneficial bacteria in the gut, perhaps these oligosaccharides are only effective during infections of the gastrointestinal tract, or have to be applied locally. Moreover, we did 130 
not evaluate the composition of bacteria in the gastrointestinal tract after feeding the mice the prebiotic mixture. Therefore we cannot exclude the possibility that the absence of antiviral effects is due to insufficient growth of beneficial bacteria to observe antiviral effects. Nevertheless, combinations of beneficial bacteria (probiotics) and prebiotics could be a better option than only prebiotic stimulation to limit (local) viral infections.

\section{Local protection against viral invaders: Protection of the respiratory tract}

Systemic administration of immunomodulating agents can induce severe side effects. For example, HCV-infected patients, who are repetitively treated systemically with high dosages of recombinant type I IFN, frequently show chronic signs of flu-like symptoms, sleeping disorders and even severe depressions. Alternatively, these side effects may be limited when type I IFNs can be applied locally, non-frequently and in low dosages. As such, the use of type I IFNs for the prevention or limitation of respiratory viral infections might therefore be an attractive option, as type I IFNs in these cases could be applied locally (e.g. intranasally). By recalling our data presented in chapter 3 and 4, all antiviral effects we observed after stimulation with $\mathrm{CpG} O D N$, poly $(\mathrm{l}: \mathrm{C})$ or lactobacilli were predominantly IFN $\beta$-mediated. Thus, we examined if the direct administration of IFN $\beta$ may have potential as a (prophylactic) antiviral strategy against respiratory infections.

In chapter 6, we investigated the antiviral potency of IFN $\beta$ in an in vitro model for respiratory viral infections. In this model we exposed respiratory epithelial cells to different concentrations of IFN $\beta$ and examined whether this resulted in protection against an infection with a human rhinovirus (RV). Moreover, since frequent administrations may cause side effects, we evaluated how long a single dose is protective. This can be of interest to chronic obstructive pulmonary disease (COPD) and asthmatic patients, which have deficient type I IFN production and are prone to virally-induced acute exacerbations (AE). Administrations of exogenous IFN $\beta$ may be useful in these patients as it may protect them against viral infections and subsequent sequelae. As previously 
reported by Cakebread et al ${ }^{37}$, also in our hands IFN $\beta$ was a powerful antiviral agent and respiratory epithelial cells were efficiently protected against a RV infection. More importantly, we demonstrated that even low amounts of IFN $\beta$ administered $72 \mathrm{~h}$ before RV infection protected the respiratory cells impressively. The protective effect corresponded with the increased mRNA expression of ISGs, which are involved in the acquisition of an antiviral state.

These data suggest that local application of type I IFN e.g. by nasal spray should be considered as a future strategy to protect vulnerable patients against respiratory viruses. Another crucial finding is that even small amounts of IFN $\beta$ induced a long-lasting antiviral state in the respiratory epithelium, which suggests that a single low dose application of IFN $\beta$ may protect the host against viral respiratory infections for days.

Although our in vitro results with IFN $\beta$ are promising (chapter 6), in vivo studies are essential to confirm our data and to further explore the possibilities of intranasal administration of IFNs. Furthermore, the recently discovered IFN $\lambda$, a type III IFN, should also be considered as a potential candidate for intranasal application. This IFN is strongly antiviral and is produced by pDCs and more importantly by epithelial cells of the respiratory tract ${ }^{10,38-40}$. The role of this cytokine is still poorly understood but its important role in the respiratory tract suggests that IFN $\lambda$ is perhaps even more attractive for use in nasal sprays to prevent viral infection of the respiratory tract.

In addition to IFNs, the intranasal application of TLR ligands also deserves further attention. TLR ligands induce also other cytokines than only IFN $\beta$, which are important for shaping adaptive immunity ${ }^{41}$. This mimics the natural response very accurate and stimulation with TLR ligands could therefore be more efficient than the administration of only IFN $\beta$. It has already been shown that the local application of TLR ligands (CPG ODNs) exerts a protective effect against a local viral infection, in contrast to the systemic application ${ }^{42}$. This suggests that TLR ligands could be efficient antiviral agents when applied intranasally. For this purpose, also poly $(\mathrm{l}: \mathrm{C})$ might be an attractive antiviral agent as it can limit viral infection independently of DCs. To further improve its clinical application, the duration of protection induced by various concentrations of poly $(\mathrm{l}: \mathrm{C})$ should be investigated. 
Our in vitro data suggest that lactobacilli may also be useful to limit viral infections. Currently, probiotic strains like lactobacilli are mainly used to improve the intestinal microbial balance. Their antiviral effects, however, have not been studied in great detail so far. Nonetheless, recent studies in mice have shown that intranasal administration of various probiotics resulted in significant protection against respiratory infections ${ }^{29,31}$. And although some of these protective effects might be due to dampening of the "cytokine storm" following viral infection ${ }^{29,34}$, here we show that also the stimulation of a mixed dendritic cells population by Lactobacilli spp. may contribute to the antiviral effects of probiotics. In particular pDCs seem required for this antiviral effect, as stimulation of a CDC cell population with lactobacilli had no significant antiviral effect. Since pDCs are usually present in low amounts in the lung under basal conditions, but are recruited in larger amounts during infections, prophylactic or even therapeutic administration of specific probiotics may become a future clinical option against respiratory viral infections. Nevertheless, because of safety issues when administering live Lactobacilli spp., additional studies are mandatory to investigate whether inactivated lactobacilli are as efficacious as live bacteria, or to identify the bacterial components responsible for the observed antiviral effects. Moreover, illustrated by our data as well as data by others ${ }^{43}$, the choice of the probiotic species used may be of crucial importance and deserves great attention.

\section{Therapy versus prophylaxis}

Since type I IFNs are strong antiviral mediators, they are attractive agents to limit viral infection and dissemination. For example, recombinant IFN $\alpha$ is currently used as an antiviral agent for the treatment of HCV-infected patients. However, although this treatment with IFN $\alpha$ is effective, it is well known that the required systemic and repetitive administration of high doses of IFN $\alpha$ is accompanied by severe side effects. This limits the clinical application of these type I IFNs significantly. Nevertheless, under certain circumstances, like acute life-threatening (respiratory) infections the application of high amounts of type I IFNs might be justified despite severe side effects. In this context, the use of IFNs has been advocated in case of (re-)emergence of SARS ${ }^{44}$ but may also be 
applicable during influenza pandemics. Furthermore, the severity of these viral infections is mainly a result of their efficient inhibition of the natural type I IFN response ${ }^{45-49}$ (chapter 2). Thus, IFN administration can be essential to overcome the viral inhibition of the hosts natural type I IFN production. That this approach is promising, is already been shown in studies which investigated IFN-therapy during SARS infection ${ }^{50,51 .}$

Although local and non-repetitive IFN-therapy is an attractive way to limit or control acute viral infections, in chapter 6 we showed that prophylactic (and local) exposure to type I IFN (IFN $\beta$ ) might also be promising as a future clinical application. The prophylactic application of type I IFNs is perhaps even more attractive as this results in an antiviral state of the host cells before the virus can inhibit the effect of the IFNs, as has been shown to be a characteristic of several viruses ${ }^{52,53}$. Moreover, as the antiviral state is very efficient after prophylactic exposure, lower amounts of type I IFNs can be used, which could limit the side effects. Furthermore, we demonstrated that even these low dosages of IFN $\beta$ protect the respiratory epithelium for days against RV infection. This, when shown also to be effective in the clinical situation, will significantly lower the risk for unwanted side effects.

Summarizing, these data open opportunities for future clinical application of (intranasal) IFN $\beta$ prophylaxis to limit or even prevent viral (respiratory) infections. Alternatively, also type III IFNs, which have recently been shown to be intimately involved in the respiratory antiviral response, deserve further attention in future studies.

\section{Concluding remarks and future perspectives}

Our in vitro data show that prophylactic stimulation of cells with immunomodulating agents induces strong antiviral effects. Modulation of the type I IFN response resulted in the successful inhibition of viral replication and infection through stimulation at the receptor level (CpG, poly(I:C) and lactobacilli), the cell level (mainly pDCs) and the effector level (IFN $\beta$ ). However, to investigate their potential for future clinical application, in vivo experiments are indispensable to examine the (antiviral) effects of these immunomodulating agents when used locally. The prevention or limitation of 
viral respiratory tract infections by these immunomodulating agents is interesting as these viral infections are common and highly contagious and more importantly, adequate therapy is lacking. Nevertheless, to improve the protective effect of immunomodulation, it is essential to further elucidate the molecular and cellular pathways involved in the immune response towards viral (respiratory) infections.

\section{References}

1. Plantinga, T. S., W. W. van Maren, J. van Bergenhenegouwen, et al. 2011. Differential Toll-like receptor recognition and induction of cytokine profile by Bifidobacterium breve and Lactobacillus strains of probiotics. Clin Vaccine Immunol 18: 621-628.

2. Zeuthen, L. H., L. N. Fink, and H. Frokiaer. 2008. Toll-like receptor 2 and nucleotidebinding oligomerization domain-2 play divergent roles in the recognition of gutderived lactobacilli and bifidobacteria in dendritic cells. Immunology 124: 489-502.

3. Weiss, G., S. Rasmussen, L. H. Zeuthen, et al. 2010. Lactobacillus acidophilus induces virus immune defence genes in murine dendritic cells by a Toll-like receptor-2dependent mechanism. Immunology 131: 268-281.

4. Gori, A., G. Rizzardini, B. Van't Land, et al. 2011. Specific prebiotics modulate gut microbiota and immune activation in HAART-naive HIV-infected adults: results of the "COPA" pilot randomized trial. Mucosal Immunol 4: 554-563.

5. Vos, A. P., M. Haarman, A. Buco, et al. 2006. A specific prebiotic oligosaccharide mixture stimulates delayed-type hypersensitivity in a murine influenza vaccination model. Int Immunopharmacol 6: 1277-1286.

6. Vos, A. P., M. Haarman, J. W. van Ginkel, et al. 2007. Dietary supplementation of neutral and acidic oligosaccharides enhances Th1-dependent vaccination responses in mice. Pediatr Allergy Immunol 18: 304-312.

7. Kieseier, B. C. 2011. The mechanism of action of interferon-beta in relapsing multiple sclerosis. CNS Drugs 25: 491-502.

8. Fried, M. W. 2002. Side effects of therapy of hepatitis $C$ and their management. Hepatology 36: S237-244.

9. Herbeuval, J. P., and G. M. Shearer. 2007. HIV-1 immunopathogenesis: how good interferon turns bad. Clin Immunol 123: 121-128.

10. Coccia, E. M., M. Severa, E. Giacomini, et al. 2004. Viral infection and Toll-like receptor agonists induce a differential expression of type I and lambda interferons in human plasmacytoid and monocyte-derived dendritic cells. Eur J Immunol 34: 796-805.

11. Hedayat, M., K. Takeda, and N. Rezaei. 2010. Prophylactic and therapeutic implications of toll-like receptor ligands. M ed Res Rev.

12. Kanzler, H., F. J. Barrat, E. M. Hessel, et al. 2007. Therapeutic targeting of innate immunity with Toll-like receptor agonists and antagonists. Nat M ed 13: 552-559. 
13. Lore, K., M. R. Betts, J. M. Brenchley, et al. 2003. Toll-like receptor ligands modulate dendritic cells to augment cytomegalovirus- and HIV-1-specific T cell responses. J Immunol 171: 4320-4328.

14. Miyazato, A., K. Nakamura, N. Yamamoto, et al. 2009. Toll-like receptor 9-dependent activation of myeloid dendritic cells by Deoxynucleic acids from Candida albicans. Infect Immun 77: 3056-3064.

15. Tanaka, M., K. Ishii, Y. Nakamura, et al. 2012. Toll-Like Receptor 9-Dependent Activation of Bone Marrow-Derived Dendritic Cells by URA5 DNA from Cryptococcus neoformans. Infect Immun 80: 778-786.

16. Xiao, G., A. Miyazato, Y. Abe, et al. 2010. Activation of myeloid dendritic cells by deoxynucleic acids from Cordyceps sinensis via a Toll-like receptor 9-dependent pathway. Cell Immunol 263: 241-250.

17. Gitlin, L., W. Barchet, S. Gilfillan, et al. 2006. Essential role of mda-5 in type I IFN responses to polyriboinosinic:polyribocytidylic acid and encephalomyocarditis picornavirus. Proc Natl Acad Sci U SA 103: 8459-8464.

18. Kato, H., O. Takeuchi, S. Sato, et al. 2006. Differential roles of MDA5 and RIG-I helicases in the recognition of RNA viruses. Nature 441: 101-105.

19. Johnson, A. C., X. Li, and E. Pearlman. 2008. M yD88 functions as a negative regulator of TLR3/TRIF-induced corneal inflammation by inhibiting activation of c-Jun N-terminal kinase. J Biol Chem 283: 3988-3996.

20. Lam, K. P., Y. T. Chu, C. H. Kuo, et al. 2011. Suppressive effects of procaterol on expression of IP-10/CXCL 10 and RANTES/CCL 5 by bronchial epithelial cells. Inflammation 34: 238-246.

21. Sugiura, H., T. Ichikawa, A. Koarai, et al. 2009. Activation of Toll-like receptor 3 augments myofibroblast differentiation. Am J Respir Cell Mol Biol 40: 654-662.

22. Boonstra, A., C. Asselin-Paturel, M. Gilliet, et al. 2003. Flexibility of mouse classical and plasmacytoid-derived dendritic cells in directing $T$ helper type 1 and 2 cell development: dependency on antigen dose and differential toll-like receptor ligation. J Exp Med 197: 101-109.

23. Daubeuf, B., J. Mathison, S. Spiller, et al. 2007. TLR4/MD-2 monoclonal antibody therapy affords protection in experimental models of septic shock. J Immunol 179: 6107-6114.

24. Mitsuzawa, H., C. Nishitani, N. Hyakushima, et al. 2006. Recombinant soluble forms of extracellular TLR4 domain and MD-2 inhibit lipopolysaccharide binding on cell surface and dampen lipopolysaccharide-induced pulmonary inflammation in mice. J Immunol 177: 8133-8139.

25. Gibson, S. J., J. M. Lindh, T. R. Riter, et al. 2002. Plasmacytoid dendritic cells produce cytokines and mature in response to the TLR7 agonists, imiquimod and resiquimod. Cell Immunol 218: 74-86.

26. Hemmi, H., T. Kaisho, O. Takeuchi, et al. 2002. Small anti-viral compounds activate immune cells via the TLR7 M yD88-dependent signaling pathway. Nat Immunol 3: 196200.

27. Kim, T. W., K. Staschke, K. Bulek, et al. 2007. A critical role for IRAK4 kinase activity in Toll-like receptor-mediated innate immunity. J Exp M ed 204: 1025-1036. 
28. Borchers, A. T., C. Selmi, F. J. Meyers, et al. 2009. Probiotics and immunity. J Gastroenterol 44: 26-46.

29. Gabryszewski, S. J., O. Bachar, K. D. Dyer, et al. 2011. Lactobacillus-mediated priming of the respiratory mucosa protects against lethal pneumovirus infection. J Immunol 186: 1151-1161.

30. Maragkoudakis, P. A., W. Chingwaru, L. Gradisnik, et al. 2010. Lactic acid bacteria efficiently protect human and animal intestinal epithelial and immune cells from enteric virus infection. Int J Food Microbiol 141 Suppl 1: S91-97.

31. Youn, H. N., D. H. Lee, Y. N. Lee, et al. 2012. Intranasal administration of live Lactobacillus species facilitates protection against influenza virus infection in mice. Antiviral Res 93: 138-143.

32. Hori, T., J. Kiyoshima, K. Shida, et al. 2002. Augmentation of cellular immunity and reduction of influenza virus titer in aged mice fed Lactobacillus casei strain Shirota. Clin Diagn Lab Immunol 9: 105-108.

33. Maeda, N., R. Nakamura, Y. Hirose, et al. 2009. Oral administration of heat-killed Lactobacillus plantarum L-137 enhances protection against influenza virus infection by stimulation of type I interferon production in mice. Int Immunopharmacol 9: 11221125.

34. Ivec, M., T. Botic, S. Koren, et al. 2007. Interactions of macrophages with probiotic bacteria lead to increased antiviral response against vesicular stomatitis virus. Antiviral Res 75: 266-274.

35. Buddington, K. K., J. B. Donahoo, and R. K. Buddington. 2002. Dietary oligofructose and inulin protect mice from enteric and systemic pathogens and tumor inducers. J Nutr 132: $472-477$.

36. Roller, M., G. Rechkemmer, and B. Watzl. 2004. Prebiotic inulin enriched with oligofructose in combination with the probiotics Lactobacillus rhamnosus and Bifidobacterium lactis modulates intestinal immune functions in rats. J Nutr 134: 153156.

37. Cakebread, J. A., Y. Xu, C. Grainge, et al. 2011. Exogenous IFN-beta has antiviral and anti-inflammatory properties in primary bronchial epithelial cells from asthmatic subjects exposed to rhinovirus. J Allergy Clin Immunol 127: 1148-1154 e1149.

38. Khaitov, M. R., V. Laza-Stanca, M. R. Edwards, et al. 2009. Respiratory virus induction of alpha-, beta- and lambda-interferons in bronchial epithelial cells and peripheral blood mononuclear cells. Allergy 64: 375-386.

39. Wang, J., R. Oberley-Deegan, S. Wang, et al. 2009. Differentiated human alveolar type II cells secrete antiviral IL-29 (IFN-lambda 1) in response to influenza A infection. J Immunol 182: 1296-1304.

40. Vareille, M., E. Kieninger, M. R. Edwards, et al. 2011. The airway epithelium: soldier in the fight against respiratory viruses. Clin Microbiol Rev 24: 210-229.

41. Kawai, T., and S. Akira. 2010. The role of pattern-recognition receptors in innate immunity: update on Toll-like receptors. Nat Immunol 11: 373-384.

42. Ashkar, A. A., S. Bauer, W. J. Mitchell, et al. 2003. Local delivery of CpG oligodeoxynucleotides induces rapid changes in the genital mucosa and inhibits replication, but not entry, of herpes simplex virus type 2. J Virol 77: 8948-8956. 
43. Weiss, G., H. R. Christensen, L. H. Zeuthen, et al. 2011. Lactobacilli and bifidobacteria induce differential interferon-beta profiles in dendritic cells. Cytokine 56: 520-530.

44. Haagmans, B. L. and A. D. Osterhaus. 2006. Coronaviruses and their therapy. Antiviral Res 71: 397-403.

45. Cameron, M. J., J. F. Bermejo-Martin, A. Danesh, et al. 2008. Human immunopathogenesis of severe acute respiratory syndrome (SARS). Virus Res 133: 1319.

46. Geiss, G. K., M. Salvatore, T. M. Tumpey, et al. 2002. Cellular transcriptional profiling in influenza A virus-infected lung epithelial cells: the role of the nonstructural NS1 protein in the evasion of the host innate defense and its potential contribution to pandemic influenza. Proc Natl Acad Sci U SA 99: 10736-10741.

47. Imai, H., K. Shinya, R. Takano, et al. 2010. The HA and NS genes of human H5N1 influenza A virus contribute to high virulence in ferrets. PLoS Pathog 6: e1001106.

48. Meunier, I., and V. von Messling. 2011. NS1-mediated delay of type I interferon induction contributes to influenza A virulence in ferrets. J Gen Virol 92: 1635-1644.

49. Smits, S. L., A. de Lang, J. M. van den Brand, et al. 2010. Exacerbated innate host response to SARS-CoV in aged non-human primates. PLoS Pathog 6: e1000756.

50. Loutfy, M. R., L. M. Blatt, K. A. Siminovitch, et al. 2003. Interferon alfacon-1 plus corticosteroids in severe acute respiratory syndrome: a preliminary study. JAMA 290: 3222-3228.

51. Haagmans, B. L., T. Kuiken, B. E. Martina, et al. 2004. Pegylated interferon-alpha protects type 1 pneumocytes against SARS coronavirus infection in macaques. Nat Med 10: 290-293.

52. Peng, T., S. Kotla, R. E. Bumgarner, et al. 2006. Human rhinovirus attenuates the type I interferon response by disrupting activation of interferon regulatory factor 3. J Virol 80: 5021-5031.

53. Spiegel, M., A. Pichlmair, L. M artinez-Sobrido, et al. 2005. Inhibition of Beta interferon induction by severe acute respiratory syndrome coronavirus suggests a two-step model for activation of interferon regulatory factor 3. J Virol 79: 2079-2086. 
Samenvatting 
Gedurende de laatste eeuwen hebben wereldwijde uitbraken van virussen zoals pokken, influenza en HIV vele levens gekost. Echter, vooral in de westerse wereld zijn de hoge sterftecijfers en ziektegevallen, die veroorzaakt worden door virussen, de laatste decennia sterk afgenomen als gevolg van de ontwikkeling van antivirale medicijnen en vaccins. Het succes van antivirale medicijnen en vaccins kan het beste worden geillustreerd door de daling van het aantal aidspatiënten en het verdwijnen van het pokkenvirus.

Ondanks deze successen komen virussen nog steeds veel voor en veroorzaken ze regelmatig ernstige gezondheidsproblemen. Door de overbevolking en de toegenomen mobiliteit in de wereld kunnen virussen zich gemakkelijker verspreiden. Ook worden we regelmatig geconfronteerd met nieuwe en/of gemuteerde virussen waarvoor geen vaccins beschikbaar zijn en waar antivirale medicijnen minder effectief tegen zijn. Daarom zijn nieuwe therapieën dringend noodzakelijk.

Normaal gezien is de werking van het immuunsysteem voldoende om ons te beschermen tegen de meeste virale infecties. Echter, extra stimulatie van het immuunsysteem kan essentieel zijn om virale ziekte en verspreiding tegen te gaan wanneer er sprake is van onvoldoende afweer. Daarom worden op dit moment middelen onderzocht die in staat zijn om het immuunsysteem te beïnvloeden, zodanig dat ze als bescherming kunnen worden ingezet tegen virale infecties. In deze thesis hebben we de antivirale eigenschappen en, waar mogelijk, de onderliggende moleculaire mechanismen onderzocht van deze zogenaamde immuunmodulerende middelen. Wij verwachten dat de resultaten van onze studies mogelijk belangrijk kunnen zijn voor de toekomstige toepassing van deze middelen.

\section{Immuunreactie tegen virussen}

In deze thesis hebben we onderzocht of we verschillende delen van het immuunsysteem kunnen beïnvloeden om zo de reactie tegen een virus te versterken. De immuunreactie tegen virale infecties wordt normaal geïnitieerd door de stimulatie van zogenaamde herkenningsreceptoren, welke aanwezig zijn zowel op het oppervlak van een cel als binnenin een cel. Tot de familie van 
de herkenningsreceptoren behoren onder andere de Toll-like receptoren (TLR's). Als deze receptoren virussen herkennen zetten ze de cel aan om diverse antivirale stoffen te produceren, de zogenaamde type I interferonen (IFN's). Deze IFN's binden vervolgens aan de interferon receptor (IFNAR), die aanwezig is op het oppervlak van de cel, wat resulteert in de activatie van vele verschillende genen ("ISG's"), die antivirale en immuun-gerelateerde functies hebben. Na deze activatie kunnen cellen een antivirale staat aannemen. In deze staat wordt het vermenigvuldigen van het virus in de cel onderdrukt. Daarnaast worden in de buurt gelegen cellen gewaarschuwd en gaan geïnfecteerde cellen vervolgens in apoptose (geprogrammeerde celdood) om verdere verspreiding van het virus te voorkomen.

Alhoewel de meeste cellen type I IFN (IFN $\alpha / \beta$ ) kunnen produceren na een virale infectie, bezit het immuunsysteem speciale cellen, de dendritische cellen (DC's), die in staat zijn om extreem grote hoeveelheden type I IFN te produceren na stimulatie van hun receptoren. Daarom zijn deze DC's onontbeerlijk in de reactie tegen virale infecties, iets wat ook uit onze studies blijkt (hoofdstuk 3 en 4).

\section{Antivirale eigenschappen van immuunmodulerende middelen}

Immuunmodulerende middelen kunnen de antivirale reactie nabootsen o.a. door het stimuleren van receptoren. Om dit te bewerkstelligen zijn er verschillende stoffen ontwikkeld die de eerder genoemde Toll-like receptoren specifiek kunnen stimuleren (TLR liganden). In hoofdstuk 3 hebben we uitvoerig onderzocht welke van deze TLR liganden bescherming kunnen bieden tegen een virale infectie en hoe dit wordt gereguleerd. Daarvoor hebben we een bepaald soort immuuncellen gebruikt (de DC's), die een hoge expressie van diverse TLR's hebben, en deze gestimuleerd met de verschillende TLR liganden. Vervolgens hebben we onderzocht of de stoffen geproduceerd door de immuuncellen na TLR stimulatie in staat waren cellen te beschermen tegen een virale infectie. Uit de resultaten bleek dat sommige TLR liganden sterke antivirale effecten hadden. Echter, de manier waarop deze antivirale effecten werden verkregen was verschillend tussen de TLR liganden. 
Vanwege het feit dat stimulatie met bepaalde TLR liganden kan leiden tot ontstekingsreacties en andere bijwerkingen, hebben we ook andere immuunmodulerende middelen getest. Probiotica - bacteriën die vooral bekend zijn om hun gezondheids-bevorderende effect in de darmen - zijn namelijk ook in staat om immuuncellen te stimuleren. Op basis hiervan hebben wij in hoofdstuk 4 bekeken of deze probiotica mogelijk ook antivirale eigenschappen hebben. Om de antivirale sterkte van deze probiotica te bepalen hebben we drie bekende bacterie stammen getest op hun antivirale effecten met behulp van hetzelfde celkweek systeem als in hoofdstuk 3 . Opmerkelijk was dat deze sterke antivirale effecten alleen werden gezien bij stimulatie met 2 gelijkaardige stammen (de lactobacillen), maar niet bij de afwijkende $3^{\mathrm{e}}$ stam (bifidobacterium). De manier waarop de antivirale effecten van lactobacillen werden verkregen leek sterk op de werking van één specifieke TLR ligand uit hoofdstuk 3.

Eerdere studies hebben aangetoond dat de groei van probiotica in de darmen gestimuleerd wordt door de toediening van bepaalde koolhydraten, genaamd oligosachariden. Onderzoek heeft ook uitgewezen dat de toediening van een specifieke mix van oligosachariden tot bepaalde immuunreacties kan leiden. Gebaseerd op de geobserveerde antivirale effecten van de twee probiotica stammen in hoofdstuk 4, hebben wij onderzocht of zo'n mix het aandeel probiotica met antivirale karakteristieken kan versterken om zo een meer efficiënte antivirale respons te verkrijgen. Daarom hebben we muizen op een oligosacharidenrijk dieet gezet waarvan eerder was aangetoond dat het immuunmodulerende effecten heeft (hoofdstuk 5). Vervolgens zijn deze muizen geïnfecteerd met een herpesvirus en hebben we de hoeveelheid virus geëvalueerd in verschillende organen. Echter, het oligosacharidenrijk dieet bleek geen waarneembaar effect te hebben op de antivirale respons tegen een herpesvirus infectie. Het is mogelijk dat de oligosachariden alleen effectief zijn gedurende infecties van de darmen of dat ze lokaal moeten worden toegediend. Ook hebben we de samenstelling van de bacteriën in de darmen van de dieet-gevoede muizen niet bepaald. Daarom kunnen we de mogelijkheid niet uitsluiten dat de afwezigheid van antivirale effecten een gevolg is van de beperkte groei van probiotica.

Een andere mogelijkheid om de antivirale respons te beïnvloeden is om de productie van antivirale stoffen, zoals de ISG's, te stimuleren. Om dit te 142 
verwezenlijken kan type I IFN (IFN $\alpha$ of IFN $\beta$ ) direct worden toegediend. IFN $\alpha$ wordt bijvoorbeeld al gebruikt voor de behandeling van patiënten die chronisch geïnfecteerd zijn met het hepatitis C virus (HCV) en IFN $\beta$ wordt toegepast als ontstekingsremmend middel in multiple sclerose (MS) patiënten. Echter, naast de sterke antivirale effecten in HCV- of HIV-geïnfecteerde patiënten, ervaren deze patiënten vaak ernstige bijwerkingen wanneer type I IFN herhaaldelijk wordt geïnjecteerd. Dit impliceert dat de klinische toepasbaarheid van dit type IFN tegen virale infecties beperkt is. Desalniettemin kan type I IFN therapie aantrekkelijk zijn wanneer blijkt dat IFN ook werkzaam is wanneer het niet frequent hoeft te worden gebruikt, op de plaats van een mogelijke infectie kan worden toegediend én werkzaam is in lage concentraties. Dit is mogelijk belangrijk voor COPD en astma patiënten, die een gebrekkige productie van type I IFN hebben en daarom gevoelig zijn voor virale luchtweginfecties, welke vaak verantwoordelijk zijn voor acute verslechteringen van hun gezondheidstoestand. Daarom hebben we in een celkweek systeem onderzocht of IFN $\beta$ de epitheelcellen afkomstig uit de luchtwegen kan beschermen tegen een infectie met het verkoudheidsvirus, ook wel rhinovirus (RV) genoemd (hoofdstuk 6). In deze studie hebben we niet alleen verschillende concentraties van IFN $\beta$ getest, maar hebben we ook gekeken hoe lang een enkele dosis beschermend werkte tegen een infectie. Uit onze experimenten bleek dat IFN $\beta$ goed in staat was om de epitheelcellen te beschermen tegen een RV infectie. Belangrijker echter was de bevinding dat zelfs lage IFN $\beta$ concentraties de epitheelcellen beschermden tegen een RVinfectie, die pas 72 uur na de behandeling plaatsvond. Deze experimenten lieten dus zien dat IFN $\beta$ nog steeds effectief kan zijn tegen RV-infecties ondanks minder frequent gebruik van IFN $\beta$.

\section{Conclusie en toekomstperspectief}

Onze celkweek data laten zien dat stimulatie van cellen met immuunmodulerende middelen leidt tot sterke antivirale effecten. Het beïnvloeden van de antivirale reactie resulteerde in beperking van virale vermenigvuldiging en infectie door stimulatie op receptor niveau (TLR liganden en probiotica), cel niveau (de DC's) en effector niveau (IFN $\beta$ ). Echter, om hun 
potentieel verder te onderzoeken in het kader van toekomstige klinische toepassingen zijn dierexperimenten onontbeerlijk. Het voorkomen of beperken van virale luchtweg infecties door middel van deze middelen is interessant omdat deze virale infecties veel voorkomen en erg besmettelijk zijn en nog belangrijker, een adequate therapie ontbreekt momenteel. Verder is het belangrijk om de moleculaire en cellulaire mechanismen, die betrokken zijn bij de afweerreactie tegen virale (luchtweg-) infecties, beter te begrijpen, zodat we op den duur in staat zullen zijn om effectieve immuunmodulerende middelen te ontwikkelen en daarmee infecties uiteindelijk succesvol te voorkomen of te behandelen. 


\section{Dankwoord}


Hèhè...eindelijk. Na 5 jaar kan het. Het dankwoord. Het deel van mijn boekje wat waarschijnlijk door velen als enigste wordt gelezen (en begrepen ;-)) en dus ook het deel waar ik nog even goed voor ga zitten. Het moge duidelijke zijn dat ik dit deel niet eens kon schrijven zonder de hulp en steun van velen die ik dan ook allen graag wil bedanken. Omdat het er zoveel zijn, hoop ik dat het mij vergeven wordt dat ik niet iedereen persoonlijk kan bedanken.

Ten eerste wil ik mijn co-promotor bedanken. Frank, jij hebt me 5 jaar van dag tot dag kunnen volgen. Ik weet nog dat je in het begin zei: ' Hij moet nog veel leren'. Als ik daar nu op terug kijk kan ik je alleen maar gelijk geven. Maar het doel is bereikt. Ik heb in die 5 jaar ontzettend veel van je geleerd en daarom ben ik nu iets minder groen. Je hebt me laten kennis maken met de wetenschap en het onderzoek. Ondanks alle tegenslagen en frustraties had ik dit voor geen goud willen missen. Het was fijn dat ik altijd kon binnenlopen (tot vervelends toe ;-)) om discussies over experimenten te voeren en tevens mijn frustraties te uiten. En last but not least, jij hebt me de kans gegeven om dit toch pittige project gestalte te geven en we mogen dan ook trots zijn op het resultaat.

Cathrien, mijn promotor, ik wil u bedanken voor de interesse die u toonde in mijn onderzoek en presentaties. Dankzij u kon ik ook een uitstapje naar Boston verwezenlijken en dat heeft een positieve wending gegeven aan mijn onderzoek.

M ijn paranimfen. Wendy, jij zat 3,5 jaar met mij opgescheept. En dat heb je met vlag en wimpel doorstaan. Je (sorry ge) bent niet voor niets mijn paranimf. Ons wederzijds gezever heeft veel leuke quotes en buitenlandse taalkennis opgeleverd wat ten goede kwam/komt van eventuele verfilmingen. Daarnaast was je altijd buitengewoon geïnteresseerd in mijn privéleven (en ook mijn frustraties op het werk). Maar ik heb vooral veel met je kunnen lachen en ik had lang niet zo'n leuke jaren gehad als jij er niet was geweest.

Ray, dude, beste kerel, wat heb ik aan jou moeten wennen in het begin. Ook al hadden we werk-technisch gezien weinig met elkaar te maken, ik had toch al snel in de gaten dat je een fijne vent was. Ook jij was altijd geïnteresseerd in de ontwikkelingen op het werk en in mijn privésfeer. Maar vooral jou relaxte 
houding en je (speciale) humor zijn een geweldige mix om alles te relativeren en om een geweldige paranimf te zijn.

Dan mijn andere collega's. Hier moet ik echt veel mensen gaan bedanken. Ik kan maar 2 paranimfen kiezen maar er was voor mij keuze in overvloed.

Ten eerste de "AIO" groep, Amita, Tanja, Ellen, Wendy, Marijke, Judith, Christel, Fahad, Sander, Casper, M ichelle, Ruud, Laura en Ray(mond), het was altijd ontzettend gezellig met jullie en ik hoop dat we elkaar in de toekomst nog vaak mogen tegenkomen. Ik kan tig pagina's over jullie schrijven, maar de boodschap is dat vele van jullie meer dan collega's voor mij zijn geweest.

Gert \& Erik, het onmisbare duo. Wat was er van het labwerk terecht gekomen zonder jullie. Dankzij jullie kennis, ervaring en interesse is het nog goed gekomen met mij. En M argriet, je was een fijne kamergenoot en met jou kon ik ook lekker over sport praten.

Ik wil uiteraard ook het secretariaat bedanken en in het bijzonder José. Jij wist werkelijk alles te regelen voor mijn promotie en dankzij jouw organisatorisch vermogen is alles snel gegaan.

De collega's van baclab, moldiag, AIOS en de spoelkeuken. Ook hier wil ik een aantal mensen in het bijzonder bedanken. Mayk, jouw talent heeft mij de gewenste kaft bezorgd en dat is toch wat iedereen het eerste voor zijn neus krijgt. Laat de whisky smaken! John, jouw statistische kennis en vooral de manier van uitleggen heeft mij zelfs statistiek leren begrijpen. Resi, jij had altijd tijd voor mijn frustraties op werk en sollicitatiegebied. Ans, jouw behulpzaamheid en altijd-in-voor-een-praatje mentaliteit maakte mijn werk gemakkelijker. Je bent een onmisbare kracht! En Guy... wat kun jij praten zeg. Jij zou het zeker goed doen in de politiek ;-).

Dan hebben we nog een aantal mensen die een link hebben met de M MB. Kris, bedankt voor al die leuke gesprekken, ik heb veel met je kunnen lachen.

Het kwartet dat ik heb gevormd met Laura, Dionne en Kevin. We zijn samen in 2006 bij de M M B begonnen en met jullie heb ik altijd veel lol gehad, vooral 'de vriedag veur carnaval'. Kevin man, ik stikte soms bijna in mijn lach. Het "nanodrop trio" van de weefseltypering: Mathijs, Talia en Kevin (alweer). Het duurde altijd wel even voordat ik weer weg was. 
Ook de mensen van Danone research ben ik dankbaar. Bea en Jeroen, dankzij jullie expertise en input heb ik weer 2 hoofdstukken voor mijn boekje.

En dan zijn er nog mijn nieuwe collega's van PathoFinder/PathoNostics in $M$ aastricht. Nu ik dit schrijf ben ik nog niet bij jullie begonnen, maar ik kan er toch al iets over kwijt. Gijs en Guus, ik heb zowat in het hele land (en daarbuiten) gesolliciteerd maar dankzij jullie kan ik 1 oktober in mijn geboortestad aan een nieuwe uitdaging beginnen. Ik heb er zin in! Bedankt voor jullie vertrouwen.

M ijn vrienden (mien vrun). Jullie hebben gezorgd voor mijn portie ontspanning die ik nodig had om af en toe mijn werk even te vergeten. De vele stapavonden, etentjes, vakanties en andere activiteiten met jullie hebben geleid tot onvergetelijke momenten en hopelijk mogen er nog vele komen. Ik hoop jullie allemaal op mijn feest te mogen verwelkomen, Hoi jong $(\mathrm{HJ})$ ! Toch wil ik een paar van jullie persoonlijk noemen. Yannick, we hebben elkaar leren kennen in het $1^{\mathrm{e}}$ jaar van MLW en na een decennium zijn we nog steeds goede vrienden. Door jou ben ik in contact gekomen met jouw vrienden die nog steeds deel uit maken van onze "beruchte" groep. Daarnaast zijn we ook huisgenoten geweest op Charles Vos cour (CVC) samen met Roelf 'Ali Kerim Bey' (AKB) en Gilles. En dat was een geweldige tijd. Gilles, ook jou ken ik nu bijna 10 jaar en daarnaast waren we nog 3,5 jaar huisgenoten. Jij hebt alles tijdens mijn promotietraject van dichtbij meegemaakt en jij weet als geen ander hoeveel voeten dit in de aarde heeft gehad. Bedankt voor je luisterend oor en het zijn van een goede vriend. Bas(sie), de wereld verandert voortdurend maar jij was altijd aanwezig en hetzelfde in 25 jaar tijd: de relaxedheid zelve en mijn oudste vriend. En dat wil ik graag zou houden. Daarnaast is jullie steun, interesse en advies tijdens mijn Koos Werkloos periode heel belangrijk voor mij geweest.

Uiteraard wil ik ook mijn familie betrekken in mijn dankwoord. Tant Net, Noonk Grignion, Tant Hélène en Anita die er altijd zijn voor mij als neef zijnde. En recentelijk heb ik mijn kleine familie aangevuld met een gigantische schoonfamilie. Nu gaan we dus even van Limburg naar Brabant. Het was fijn voor mij dat jullie deze Limburger (vlaaienbakker) hebben opgenomen als 148 
eigen familie en ik voel me dan ook net zo thuis in Brabant als in Limburg. Het is gewoon Limburg maar dan zonder de heuvels en met Bavaria. Rien en Jeannette, ik ben maar al te blij met jullie als schoonouders. Jullie gastvrijheid, interesse en steun betekent veel voor mij.

Nu komen we uit bij het feit dat ik schoonouders heb. Christel (Chris), het heeft even geduurd maar de kamerwisseling heeft ons geen windeieren gelegd. Als je iets zoekt, is het vaak dichterbij dan je denkt. Onze relatie ging als vanzelf (in tegenstelling tot mijn promotietraject) en dat was voor mij de laatste zet die ik nodig had om nu mijn dankwoord te kunnen schrijven. We delen onze liefde voor de microbiologie en voor elkaar. Jouw steun in mijn onderzoek, mijn Koos Werkloos periode en nog een hele reeks zal ik nooit vergeten. En ik denk, nee ik weet dat er nog heel veel mooie jaren voor ons samen in het verschiet liggen...

Tot slot een woordje voor degene die mij op aarde hebben gezet ( $\mathrm{e}^{\mathrm{e}}$ bedankje). Pap en mam, het klinkt misschien cliché, maar zonder jullie was ik nooit zover gekomen. Jullie hebben mij altijd de gelegenheid en steun gegeven om me te ontwikkelen tot de persoon die ik nu ben ( $2^{\mathrm{e}}$ bedankje). Dit proefschrift is dan ook voor en van jullie, ook al zullen jullie (net als iedereen) waarschijnlijk niet het hele boekje lezen. Het dankwoord is voldoende ;-). Als zoon kan ik me werkelijk geen betere ouders bedenken als jullie. Het is dan ook niet alleen dat jullie trots op mij zijn, maar ik vooral op jullie. Pap, jij hebt mij besmet met het motorvirus en recentelijk ook met het whiskyvirus ( $3^{e}$ bedankje). Schotland was dan ook de ideale bestemming voor onze motortripjes. Ook al heb ik steeds minder tijd, motorrijden is een belangrijk onderdeel van mijn leven en ik hoop nog vele uitstapjes met jou te kunnen maken (misschien op een Triumph?). Mam, jij bedankt dat je je enigste kind laat motorrijden ;-) (4 bedankje). En vooral voor de vele gesprekken en opbeurende woorden die mij nu bij het einde van dit hoofdstuk hebben gebracht en mij naar een nieuw brengen ( $5^{\mathrm{e}}$ bedankje).

Bedaank veur alles! 

Curriculum vitae \&

List of publications 


\section{Curriculum vitae}

Giel Gaajetaan werd geboren te Maastricht (Mestreech) op 15 april 1984. In 2002 behaalde hij het VWO diploma aan het toenmalige Jeanne d'Arc college te $M$ aastricht. In hetzelfde jaar begon hij aan de universiteit van Maastricht met de nieuwe opleiding moleculaire levenswetenschappen (nu biomedische wetenschappen). Hij behaalde zijn bachelor diploma in 2005 en startte toen met de master clinical molecular science. Na zijn afstudeerstage 'Toll-like receptor 7-mediated prevention of cytomegalovirus reactivation' bij de vakgroep medische microbiologie van de universiteit van Maastricht behaalde hij zijn master diploma om vervolgens daar in dienst in dienst treden als promovendus onder leiding van $d r$. Frank Stassen en Prof. dr. Cathrien Bruggeman. De resultaten van zijn promotieonderzoek zijn te lezen in dit proefschrift. Per 1 oktober 2012 is hij werkzaam als onderzoeker bij PathoNostics B.V. in Maastricht. Hier participeert hij in de ontwikkeling van nieuwe moleculaire diagnostische testen voor de identificatie van pathogene micro-organismen. 


\section{List of publications}

Giel R Gaajetaan, Cathrien A Bruggeman, Frank R Stassen. The type I IFN response during viral infections: a "SWOT" analysis. Reviews in M edical Virology 2012 22(2): 122-137

Giel R Gaajetaan, Tanja H Geelen, Gert E Grauls, Cathrien A Bruggeman, Frank R Stassen. $\mathrm{CpG}$ and poly(l:C) stimulation of dendritic cells and fibroblasts limits herpes simplex virus type 1 infection in an IFN $\beta$-dependent and -independent way. Antiviral Research 2012 93(1): 39-47

Giel R Gaajetaan, Tanja H Geelen, Juanita H Vernooy, Mieke A Dentener, Niki Reynaert, Gernot G Rohde, Erik V Beuken, Gert E Grauls, Cathrien A Bruggeman, Frank R Stassen. Interferon- $\beta$ induces a long-lasting antiviral state in human respiratory epithelial cells. Submitted for publication.

Giel R Gaajetaan, Tanja H Geelen, Johan Garssen, Belinda van 't Land, Gert E Grauls, Cathrien A Bruggeman, Frank R Stassen. Lactobacilli limit herpes simplex virus type 1 infection through stimulation of a dendritic cell-dependent antiviral mechanism. In preparation.

Giel R Gaajetaan, Belinda van 't Land, Arjan P Vos, Gert E Grauls, Johan Garssen, Cathrien A Bruggeman, Frank R Stassen. The effects of a specific mixture of oligosaccharides on a systemic infection with cytomegalovirus in mice. In preparation. 

The best-laid schemes o'mice an 'men, gang aft agley.

Robert Burns (1785)

'Do you expect me to talk?'

'No Mr. Bond, I expect you to die!'

Goldfinger (1964) 



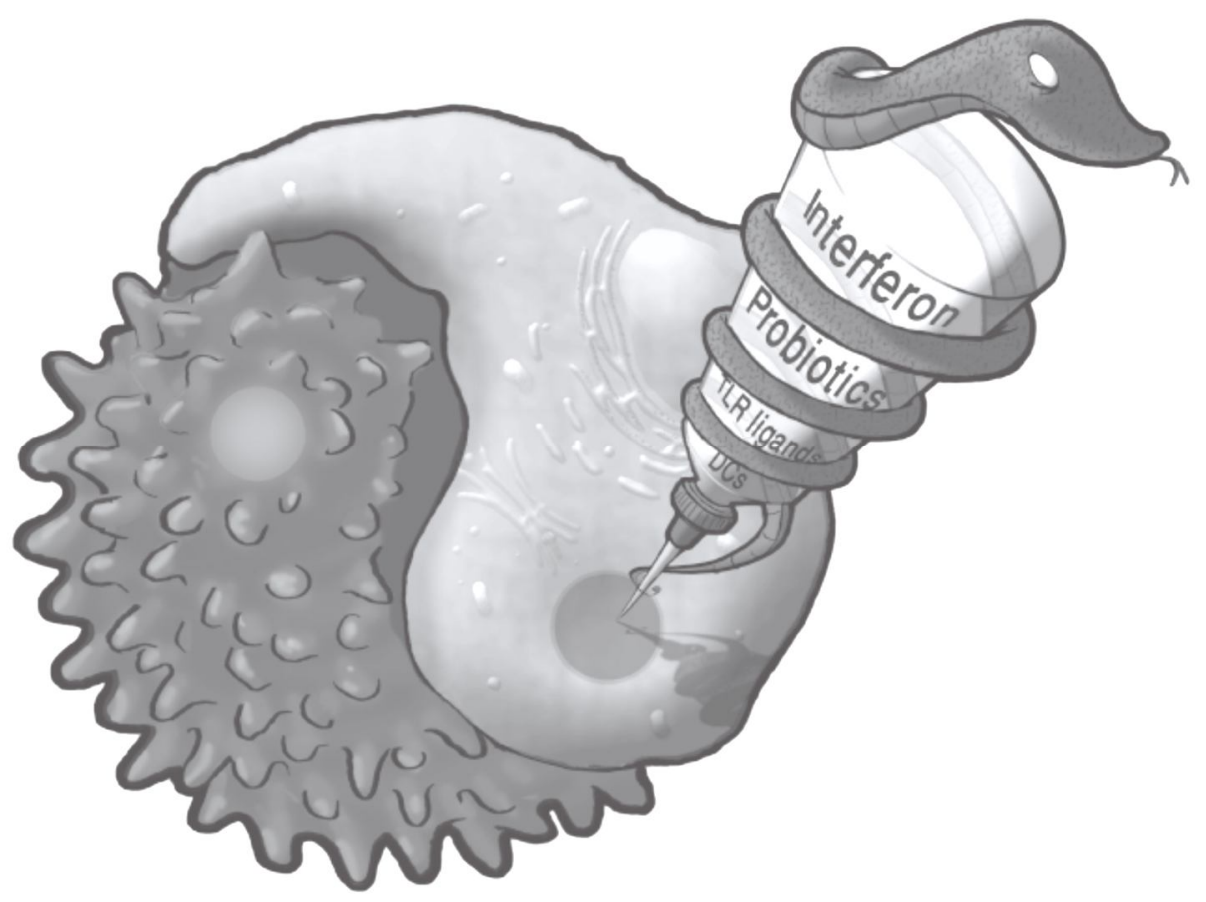


